\title{
1991 Pacific Northwest Loads and Resources Study
}
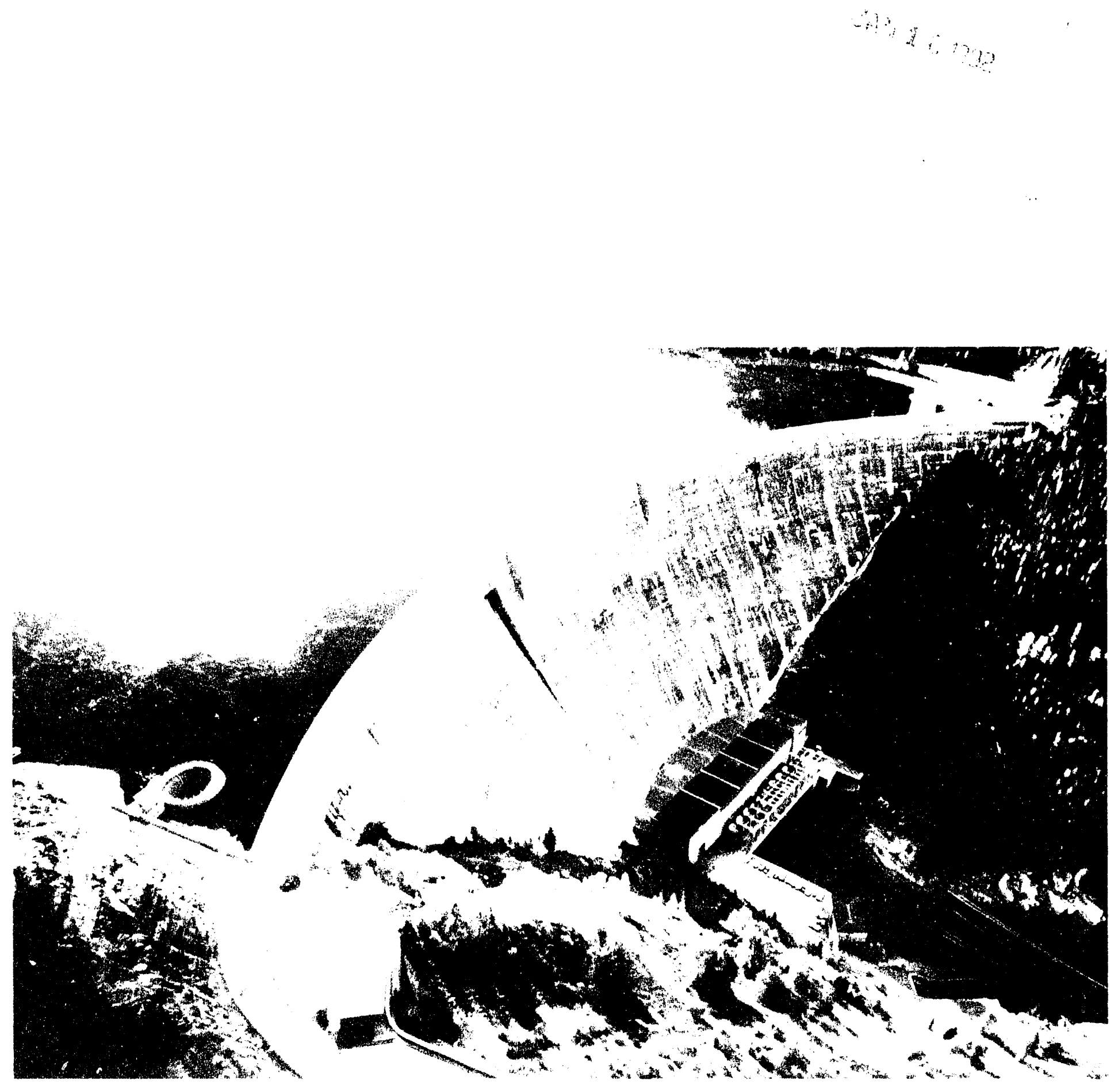

\section{Bonneville}


$\mathrm{DOE} / \mathrm{BP}--1738$

DE92 005341

\section{PACIFIC NORTHIISTT LOADS ADD RESOURCES STODY}

BONNEVILLE POWER ADMINISTRATION

DECEMBER 1991 
Cover: Hungry Horse Dam

Owned and operated by the U.S. Bureau of Reclamation; Pacific Northfiwest BPA photo 


\section{ACKOWLEDGXENTS}

Preparation of the annual Pacific Northwest loads and resources study is a complex, multidisciplinary effort. The managers of BPA's Power Forecasting Branch wish to acknowledge the team--BPA staff and others--whose diligence and dedication result in a reliable, high quality document.

Power Forecasting Branch Loads and Resources Section Customer Loads Section Long-Term Forecasting Section Economic Forecasting Section

BPA's Power Systems Branch Completion of the hydro system regulation and data collection

Pacific Northwest Utilities Conference Committee Load and resource data collection 


\section{Energy Resources Development and Implementation Process}

This document presents the compilation and analys is of information developed during several distinct activities which are part of BPA's Energy Resources Program.

The flow chart below illustrates how the Energy Resources Program works. Broadly speaking, the program has two primary functions--resource planning, and resource management. The first three blocks in the chart cover most of the planning tasks.

\section{What Are the Needs of Our Customers?}

To define the overal1 situation, BPA first assesses what the energy needs of customer utilities are likely to be over a 20-year planning horizon. Projections are developed and published joint: " with the Northwest Power Planning Council. Also part of this initial stup are forecasts of how much energy is available from existing Federal resources. BPA then compares demand and supply estimates in a Loads and Resources Study (this document), a1so known as the Whitebook.

\section{What Choices Do We Have to Meet Those Needs?}

The second step is to identify all the available alternatives for meeting customer needs. BPA develops resource supply forecasts for both generation and conservation resources. These studies also consider such factors as environmental and regulatory constraints, new technologies, and public opinion. Other efforts include examining opportunities for coordinating hydro system operations with Canada and arranging power purchases and transfers with Canadian and Southwest utilities.

Define

Picture/

Situation
Identify

Alternatives

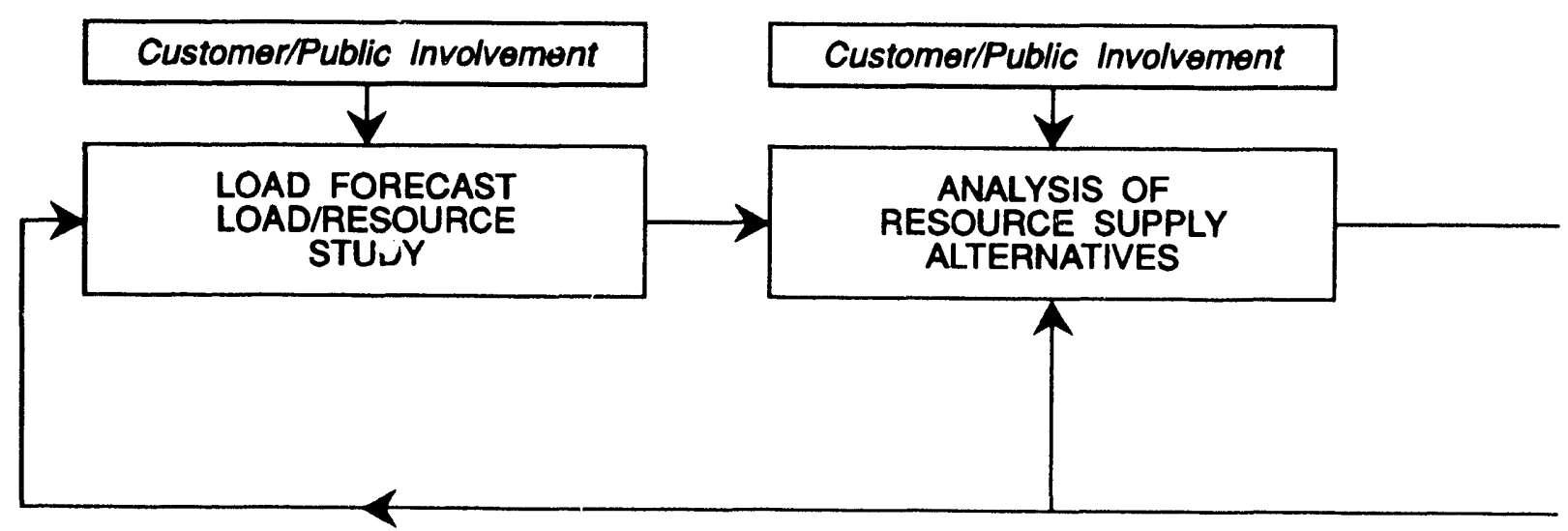




\section{How Can We Best Meet Those Needs?}

Step three involves weighing the available alternatives and their consequences to arrive at the most appropriate and cost-effective resource mix for the short-term. Developing the Resource Program is a public review process in which BPA's customer utilities and other interested parties have an opportunity to influence resource decisions. The process focuses on a specific multi-year planning period, i.e., the 1990 Resource Program focuses on Fiscal Years (FY) 1992 and 1993, and the 1992 Resource Program, currently in draft form, focuses on FY 1994 through 2003. Preliminary results of this process are included as planned acquisitions in this document.

\section{What Are We Doing to Meet Customer Needs?}

From planning and strategy, BPA then moves to step four--meeting customer power needs. Based upon the policies and directives in the Resource Program, managers draw up an overall plan to capture the conservation available in the region's homes, factories, and offices. This results in many programs and projects, ranging from about 25 to 40 in any year. In the past, BPA teams have designed and managed most conservation programs. Now, utilities and other power producers are sponsoring their own programs with BPA support.

Bonneville is responsible for planning and acquiring generating resources--both conventional and renewable. Another part of step four is BPA's oversight function--seeing that BPA gets value from contracts for generated power.

\section{How Well Did We Meet Those Needs?}

Finally, in step five, BPA looks at how well it is doing its job. It is agency policy to evaluate all programs. Evaluation provides a means of comparing initial objectives with actual results. It is essential for verifying the energy savings from conservation programs and understanding the quality of our actions to acquire the energy.

Select

Strategies
Implement Strategies
Evaluate Performance

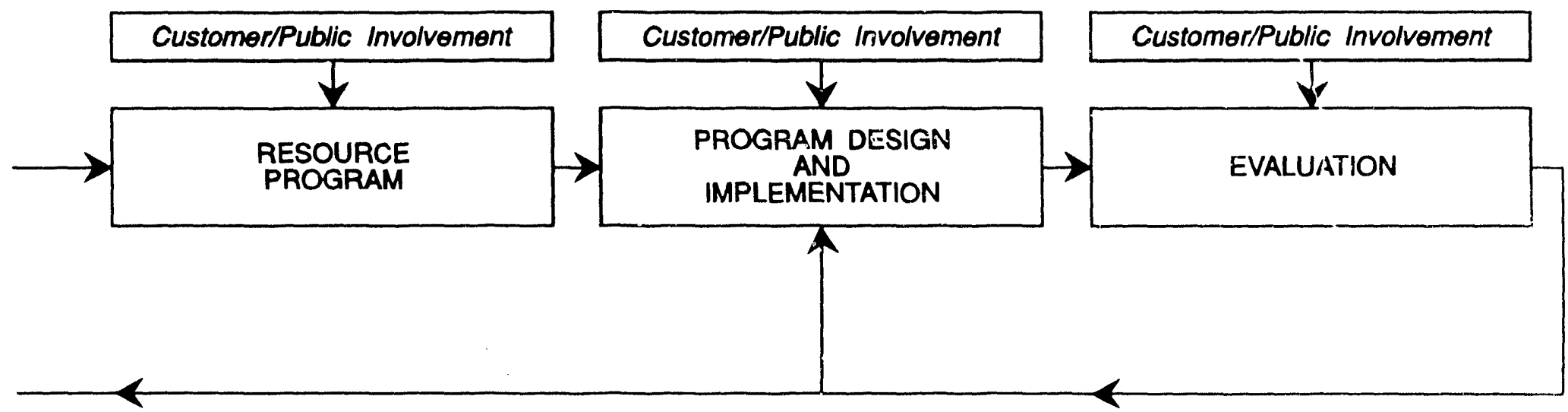




\section{TABLE OF CONTENTS}

Section I: Introduction ..................... 1

Section 11: Background

Pacific Northwest Planning Area . . . . . . . . . . . . 3

Regional Firm Resources . . . . . . . . . . . . . . . . . . . . . 5

Analys is of Regional Firm Loads and Resources . . . . . . . . . . . 5

Analys is of Federal syserce Planning to Resource . . . . . . . . . . 6

BPA's Approach to Resource Planning . . . . . . . . . . . . . 6

Nonfirm Resources ...................... 7

Major Sources of Uncertainty . . . . . . . . . . . . . 9

Section 111: Changes in the 1991 Pacific Northwest

Loads and Resources Study

New Federal System Firm Resources . . . . . . . . . . . . . 11

Trojan Nuclear Power Plant . . . . . . . . . . . . . . . 11

Hydro Regulation Study. . . . . . . . . . . . . . . . . . . . 11

Federal System Long-Term Firm Surplus Energy Deficit. . . . . . 12

Section IV: Federal System Analysis

Federa1 System Firm Energy Loads . . . . . . . . . . . . . 13

Federal System Firm Peak Loads . . . . . . . . . . . . . . 17

New Federal System Firm Resources... . . . . . . . . . . 18

Existing Federal System Firm Resources . . . . . . . . . . . 18

Federal System Nonfirm Resources . . . . . . . . . . . . . 21

Federal System Firm Energy Surpluses/Deficits . . . . . . . . . 21

Planned Federal System Resource Acquisitions . . . . . . . . . 26

Federal System Resource Options . . . . . . . . . . . . . 28

Contractual Resource Options. . . . . . . . . . . . . . 28

Non-Treaty Storage. . . . . . . . . . . . . . . . 30

Planning To Meet Forecasted Deficits.............. . 32

Federal System Firm Capacity Surpluses/Deficits . . . . . . . . 34

Federal System Marketable Capacity . . . . . . . . . . . . 37

Federal System Loads and Resources Comparison . . . . . . . . 39

Section V: Regional Analysis

Regional Firm Energy Loads . . . . . . . . . . . . . 42

Regional Firm Peak Loads .. . . . . . . . . . . . . . 44

Regional Firm Resources... . . . . . . . . . . . . . 45

Regional Nonfirm Resources . . . . . . . . . . . . . . . 46

Regional Firm Energy Surpluses/Deficits . . . . . . . . . . . 47

Regional Firm Capacity Surpluses/Deficits . . . . . . . . . 50 


\section{Section VI: Federal System Exhibits}

Federal Firm Energy Surpluses/Deficits Under Various Load Forecasts For 20 Operating Years:

Exhibit 1. Medium Loads .. . . . . . . . . . . . . 54

Exhibit 2. High Loads . . . . . . . . . . . . . . . . 58

Exhibit 3. Medium-High Loads . . . . . . . . . . . . 62

Exhibit 4. Medium-Low Loads . . . . . . . . . . . . . 66

Exhibit 5. Low Loads . . . . . . . . . . . . . . 70

Footnotes For Exhibits 1 through 5.............. 74

Federal Firm Capacity Surpluses/Deficits Under Various Load Forecasts Monthly For 20 Operating Years:

Exhibit 6. Medium Loads .. . . . . . . . . . . . . . 77

Exhibit 7. High Loads... . . . . . . . . . . . . . 78

Exhibit 8. Medium-High Loads .. . . . . . . . . . . 79

Exhibit 9. Medium-Low Loads . . . . . . . . . . . . . 80

Exhibit 10. Low Loads . . . . . . . . . . . . . . 81

\section{Section VII: Regional Exhibits}

Regional Firm Energy Surpluses/Deficits Under Medium Load Forecast For 20 Operating Years:

Exhibit 1.1. Medium Loads . . . . . . . . . . . . . . . 84

Exhibit 12. High Loads ................... . 86

Exhibit 13. Medium-High Loads . . . . . . . . . . . . 88

Exhibit 14. Medium-Low Loads . . . . . . . . . . . . . 90

Exhibit 15. Low Loads.................. . . 92

Footnotes For Exhibits 11 through 16 . . . . . . . . . . 94

Regional Firm Capacity Surpluses/Deficits Under Medium Load Forecast

Monthly For 20 Operating Years:

Exhibit 16. Medium Loads . . . . . . . . . . . . . 97

Exhibit 17. High Loads ....................... . 98

Exhibit 18. Medium-High Loads . . . . . . . . . . . . . 99

Exhibit 19. Medium-Low Loads . . . . . . . . . . . . 100

Exhibit 20. Low Loads . . . . . . . . . . . . . . 101

Section VIII: Glossary . . . . . . . . . . . . . . 103 


\section{FIGURES}

Figure 1. Federal System Firm Loads for OY 1992-93 • • • • • • • 14

Figure 2. Federal Firm Energy Loads • • • • • • • • • • • • • $・ 15$

Figure 3. Federal Firm Peak Loads Under Medium BPA Forecast • .17

Figure 4. Federal Firm Energy Loads and Resources. . . . . . . " 23

Figure 5. Federal Firm Energy Surpluses/Deficits . . . . . . . . . 25 20-Year Projection

Figure 6. Planning to Meet Forecasted Deficits . . . . . . . . 33

Federal Firm Capacity Surpluses/Deficits for:

Figure 7. OY 1992-93 . . . . . . . . . . . . . . . . . . . 35

Figure 8. OY 1997-98. . . . . . . . . . . . . . . . . . . . 35

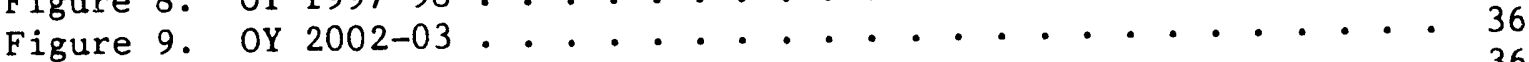

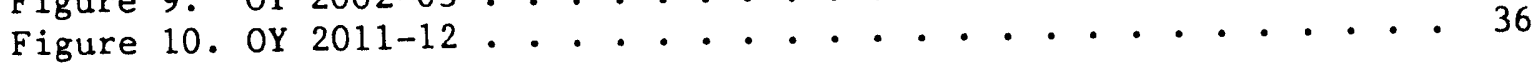

Figure 11. Regional Firm Energy Loads . . . . . . . . . . . . . . 43

Figure 12. Regional Firm Peak Loads Under Medium BPA Forecast $• \quad 45$

For OY 1992-93, 1997-98, 2002-03, and 2011-12

Figure 13. Regional Firm Energy Loads and Resources • • . • • • • 47 For OY 1992-93, 2002-03, and 2011-12

Figure 14. Regional Firm Energy Surpluses/Deficits • • • • • • . 49 20-Year Projection

Regional Firm Capacity Surpluses/Deficits for:

Figure 15. OY 1992-93 •. . . . . . . . . . . . . . . . . 51

Figure 16. OY 1997-98 . . . . . . . . . . . . . . . . . . . . 51

Figure 17. OY 2002-03 . . . . . . . . . . . . . . . . . 52

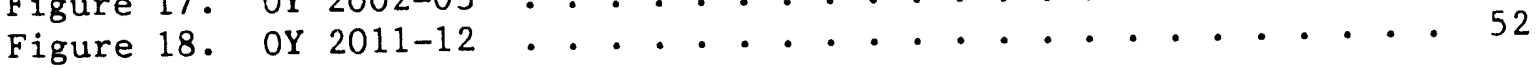

\section{TABLES}

Table 1. Federal System Firm Loads . . . . . . . . . . . . . . $~ . ~ 16$

Table 2. New Non-Federally Owned BPA Resources . • • . . . . ..$~ \cdot 18$

Table 3. Federal System Hydroelectric Projects . . . . • • • • . 19

Table 4. Non-Federally Owned BPA Resources and Contracts . • • $~ 20$

Table 5. Federal System Firm Energy Resources. • . . . . . . . . . 21

Table 6. Federal System Firm Energy Surpluses/Deficits . • • • • 24

Table 7. Planned Federal System Resource Acquisitions . • • • . $\quad 27$

Table 8. Federal System Resource Options . . . . . . . . • . . • . 31

Table 9. Changes in Federal System Firm Surplus/Deficit . • • • 41

Table 10. Regional Firm Loads . . . . . . . . . . . . . . . . . 44

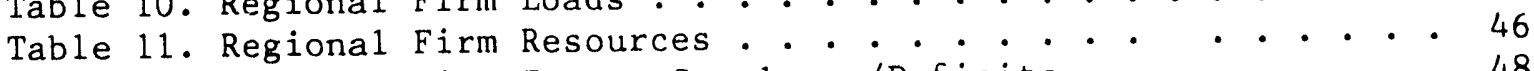

Table 12. Regional Firm Energy Surpluses/Deficits . • . . . . . • . 48 


\section{PACIFIC NORTHWEST LOADS AND RESOURCES STUDY}

\section{INTRODUCTION}

The 1991 Pacific Northwest Loads and Resources Study establishes the Bonneville Power Administration's (BPA) planning bas is for supplying electricity to BPA customers. The Loads and Resources Study is presented in three documents: 1) this summary of Federal system and Pacific Northwest region loads and resources; 2) a technical appendix detailing forecasted Pacific Northwest economic trends and loads, and 3) a technical appendix detailing the loads and resources for each major Pacific Northwest generating utility. This analysis updates the 1990 Pacific Northwest Loads and Resources Study, pub1ished in December 1990.

BPA's long-range planning incorporates resource availability with a range of forecasted electrical consumption. The forecasted future electrical demands--firm loads--are subtracted from the projected capability of existing resources to determine whether $B P A$ and the region will be surplus or deficit. If resources are greater than loads in any particular year or month, there is a surplus of energy and/or capacity, which BPA can sell to increase revenues. Conversely, if firm loads exceed available resources, there is a deficit of energy and/or capacity, then additional conservation, contract purchases, or generating resources will be needed to meet load growth.

The Pacific Northwest Loads and Resources Study analyzes the Pacific Northwest's projected loads and available generating resources in two parts: 1) the loads and resources of the Federal system, for which BPA is the marketing agency; and 2) the larger Pacific Northrest regional profile, which includes loads and resources in addition to the Federal system.

The loads and resources analysis in this study emulates the operation of the power system under the Pacific Northwest Coordination Agreement (PNCA) produced by the Pacific Northwest Coordinating Group. I/

1/ The PNCA operating year is being shanged from July 1 through June 30 to August 1 through July 31. This new operating year will be incorporated into the 1992 Pacific Northwest Loads and Resources Study. Using the new operating year will have negligible impacts on future studies. 
This study presents the Federal system and regional analyses for five load forecasts: high, medium-high, medium, medium-low, and low. This analysis projects the yearly average energy consumption and resource availability for Operating Years (OY) 1992-93 through 2011-12.1/ The study shows the Federal system's and the region's monthly estimated maximum electrical demand and monthly maximum generating capability--capacity--for OY 1992-93, 1997-98, 2002-03 and 2011-12. The Federal system and regional monthly capacity surpluses/deficits are summarized for 20 operating years.

With the 1990 loads and resources study, BPA initiated the concent of using resource options to cover firm energy deficits in the near term. This method of accounting for resources continues with this study and is discussed in BPA's Approach to Resource Planning on page 6.

The Federal system analysis is presented in Section IV, beginning on page 13. The analysis for the Pacific Northwest region is presented in section $V$, page 42 .

A glossary of terms is included in Section VIII, page 103.

Additional copies of this summary, along with copies of the documents listed below, can be obtained from BPA's Public Involvement office, toll-free, 1-800-624-9495, or in Oregon, 1-800-841-5867:

1991 Pacific Northwest Economic and Electricity Use Forecast Technical Appendix: Volume 1 (available January 1992).

1991 Pacific Northwest Loads and Resources Study Technical Appendix: Volume 2 (available January 1992).

Fiscal Year Loads and Resources Summary for Major Utility Groups in the Pacific Northwest (Load and resource tables for the Pacific Northwest, the Federal System, public agencies, and private utilities in BPA fiscal year format).

Non-Utility Generation Summary. BPA's Loads and Resources Section maintains a non-utility generation database. This database contains regional non-utility generation (NUG), which consists of all PURPA and independent power producers' (IPP) firm resources included in the loads and resources study. These resources are reported by 1) type of resource, i.e., hydro, cogeneration, etc., and 2) all NUGs for each utility in the region. Last year's study lumped all these resources under the PURPA category.

1/ Operating Year (OY) is the 12-month period July 1 to June 30 . For example, OY 1992-93 is July 1, 1992 through June 30, 1993. 


\section{BACKROOND}

Following is general background information on resources and an explanation of the load forecasting techniques used in preparing this study.

\section{Pacif ic Northwest Planning Area}

The Pacific Northwest regional planning area is defined by the Pacific Northwest Electric Power Planning and Conservation Act (Northwest Power Act), enacted December 5, 1980. It includes Oregon, Washington, Idaho, Montana west of the Continental Divide, and portions of Nevada, Utah, and Wyoming that lie within the Columbia River drainage basin. The Pacific Northwest region also includes any rural electric cooperative customers not in the geographic area described above that were served by BPA on the effective date of the Northwest Power Act.

\section{Regional Firm Resources}

The Pacific Northwest regional resources are comprised of generating resources operated or being built by Federal entities, public agencies, investor-owned utilities (IOUs), and independent power producers (IPPs). This study contains BPA's current projection of generation from existing resources and those future reso'srces with signed utility contracts.

BPA long-range planning is based on the firm energy capability of the hydro system. The firm hydro energy capability is the amount of power produced by these regional hydro resources in the worst low-water period--called the critical period--recorded for the Columbia River Basin. The energy produced by the region's hydro projects during the critical period is calculated using the generation average for the period September 1928 through February 1932, excluding the months of May. This creates a 39-month critical period. May is excluded from the average to avoid overstating the Federal firm hydro energy generation resulting from implementing water budget flows to assist $\mathrm{f}$ ish migration. The regional hydro system generates approximately 12,400 average megawatts of firm energy under critical water conditions.

Pacific Northwest hydro projects have many uses besides power generation. The projects may provide flood control, supply irrigation for farming, assist in river navigation and recreation, and contribute to municipal water supplies. Additional constraints are also in place to protect and enhance anadromous fish populations. These nonpower uses place operating constraints on the reservoirs and limit hydroelectric power production. BPA's resource planning takes into account all presently known hydro constraints in assessing regional hydro system capability.

The hydro analysis for this year's study used all operating constraints currently adopted by the hydroelectric project owners. Many of these constraints were added to the system in support of the Pacific Northwest Power Planning Council's fish flow program. Constraints placed on the hydro system over the past 10 years to enhance $f$ ish flows have decreased the firm energy by approximately 400 average megawats. 
The Pacific Northwest Power Planning Council, BPA, and other Pacific Northwest entities are currently evaluating new ways to enhance fisheries and wildlife. These include amendments to the Council's fish and wildlife program, completion of the System Operation Review, and implementation of additional programs in support of the Endangered Species Act. The Council recently presented an amendment to their Columbia River Basin Fish and Wildlife Program that would reduce regional hydro firm energy by 73 average megawatts. The impacts of future proposals are unknown; they could, however, reduce the generating capability by as little as 50 or as much as several thousand average megawatts. BFA does not expect the potential impacts to approach the high end of the range of estimates. These proposals, however, will most likely increase constraints on the hydro system and reduce operating flexibility, change the monthly shape of streamflows, and change the availability of sustained Fer' ral capacity. Future studies will evaluate these impacts.

The monthly instantaneous capacity of hydro projects is defined as the full-gate-flow maximum available generation at each project, based on the average monthly elevation, resulting from 1929-30 water levels. BPA assumes 1929-30 water levels to estimate the cegional hydro capacity because that year approximates a peaking capability that is consistent with the reliability criteria set forth in the Pacific Northwest Coordination Agreement. Additional information on water-year selection is contained in the 1991 Pacific Northwest Loads and Resources Study Technical Appendix: Volume 2 .

The monthly instantaneous capacity is also limited to 10 times the project's average monthly energy production because, at low or minimum water discharge, a plant may not be allowed to release enough water to achieve maximum capacity. The region's hydro projects have constraints and storage limitations within any water condition.

BPA's planning projections reduce the estimaced instantaneous hydro capacity to reflect a Federal sustained peaking level of 50 hours per week. This provides firm hydro capacity estimates that can be maintained each day and continued for weeks at a time. This definition of firm capacity provides a better measure of resource capability. The hydro generation is also adjusted to allow for scheduled hydro maintenance, spinning reserves, and forced outage reserves. Sections VI and VII contain tables showing the amount of surplus capacity as defined above. These capacity tables should not be used to determine the amount of capacity to support non-firm sales. Additional information regarding the determination of the region's firm hydro capacity is contained in the loads and resources technical appendix.

Capacity surplus values do not reflect potential nighttime return problems on the system. If peaking replacement energy from capacity sales is returned at night, the output of the hydro system and other regional resources could be greater than the region's nighttime load. Nighttime overgeneration is due to low loads, nonpower hydro constraints that require minimum streamflows, and the inability of thermal resources to cycle from day to night. These constraints restrict the ability to accept nighttime return energy, even thrigh there is surplus generating capability during the daytime. These constraints are common in summer and fall, when the Northwest nighttime loads are low and will greatly reduce sustained capacity surplus availability. 
The expected output of regional thermal resources is based on the energy and capacity capabilities submitted to BPA by the project owners. The output of all thermal plants is reduced to allow for scheduled maintenance, spinning reserves, and forced outage reserves. This study does not include Washington Public Power Supply System (WPPSS) nuclear plants 1 and 3 (WNP-1, WNP-3) as planned resources, though the plants have been retained in a state of preservation.

\section{Analysis of Regional Firm Loads and Resources}

The Pacific Northwest regional analysis contains the Federal system loads and resources, plus non-Federal regional loads, contractual obligations, and generating resources. The region has three load groups: Federal system, public agencies, and IOUs. The regional hydro resources are owned and operated by various Federal entities, public agencies, and IOUs. The regional thermal generating resources are owned and operated by regional entities; they are fueled by biomass, coal, natural gas, oil, and nuclear power.

The regional analysis is presented in Section $V$, beginning on page 42 .

\section{Analysis of Federal System Firm Loads and Resources}

BPA is a power marketing agency, responsible for acquiring and delivering sufficient power to serve the needs of its customers. BPA does not own generating resources. BPA's customer loads and contractual obligations, combined with the resources from which BPA acquires the power it sells, are collectively referred to as the Federal system. BPA owns and operates the primary transmission grid--more than 14,700 circuit miles of powe 1 ines--in the Pacific Northwest.

The Federal system loads are made up of BPA's sales to other Federal agencies, the region's pub1ic agencies, several Direct Service Industrial (DSI) customers, and other contractual obligations to deliver power. Sales to public agencies and DSIs comprised over 80 percent of the Federal system loads in OY 1990-91.

The hydro resources of the Federal system include 31 dams owned and operated by the United States Bureau of Reclamation (USBR) and the United States Army Corps of Engineers (COE), plus hydroelectric projects owned by the city of Idaho Falls, WPPSS and Lewis County PUD. BPA has the exclusive right to sell power generated by USBR and COE hydroelectric projects. BPA also markets the thermal generation from WNP-2, operated by WPPSS, 30 percent of the output of Portland General Electric's (PGE) Trojan nuclear power plant and a short-term seasona 1 purchase of about 8 percent of the Boardman coal plant acquired from the Pacific Northwest Generating Company (PNGC).

The Federal system aralysis is shown in Section IV, beginning on page 13 . 


\section{BPA's Approach to Resource Planning}

This study treats Federal planned resource acquisitions consistent with BPA's resource planning described in the 1990 Rescurce Program. This treatment of planned acquisitions started with the 1990 Pacific Northwest Loads and Resources Study. The Resource Program plans for the cost-effective development of an aggressive, steadily increasing conservation program, coupled with the acquisition of a diverse mix of generation resources to meet the power requirements of BPA's customers. BPA has a long-term commitment to acquire cost-effective conservation and generating resources and retain maximum flexibility in its acquisition program.

For the short-term, BPA issued a Request For Proposals (RFP) in 1991 to acquire some of the resources identified in the Resource Program through FY 1992-93. These proposals of fer a combination of both conservation and generating resources. BPA is now evaluating these proposals and selecting resources $B P A$ will negotiate to acquire. In the future, the resources to be acquired become even less defined. Because these planned resource acquisitions are not actually on-1ine or contracted for, they are excluded as firm resources in the loads and resources study. These resources will be counted as firm resources when BPA signs contracts to acquire them. The categories of planned resource acquisitions are included in Table 7, page 27.

To offset possible short-term firm energy deficits, and to meet operational uncertainties such as load overruns or poor thermal performance, BPA has and will continue to acquire firm energy resource options. Some of these resource options guarantee BPA rights to terminale surplus firm power sales or purchase $\mathrm{f}$ irm power as needed. The generation resource options, if exercised, will have value as cost-effective firm resource additions. These resource options are, however, viewed primarily as insurance against extreme conditions. The value of these options diminishes if they are treated as firm resources in long-range planning. Since these options may or may not be exercised, they are excluded as firm resources in the loads and resources study.

Currently, most of BPA's firm resource options are long-term surplus firm power sales and capacity/energy exchange agreements with Pacific Southwest utilities. These contracts contain provisions by which BPA may completely or partially terminate the power sales and convert the contracts to capacity/ energy exchanges. BPA's resource options also include 115 average megawatts of available non-treaty storage in Canada.

BPA's 1992 Resource Program will address how these resource options and planned resource acquisitions should be combined to meet future needs in the most cost-effective manner.

\section{Nonf i rm Resources}

BPA resource planning uses critical water flows to compute the region's and the Federal system's firm hydro energy. The regional hydro system, however, has historically experienced precipitation levels which produce greater than critical period flows. This excess water is used to produce nonfirm energy. 
BPA planning does not include nonfirm energy in the loads and resources balance. Nonfirm energy increases regional resources by about 3,800 average megawatts annually when averaged over 50 years of historical water flows. The Federal share of this nonfirm energy is about 2,400 average megawatts based on 50 years of data. Nonfirm energy is even larger for both systems when based on 102 years of historical water flows. Capacity is generally available to support nonfirm energy sales.

\section{Load Forecasting}

The five load forecasts presented in this study were prepared jointly by BPA and the Northwest Power Planning Council (Council) in the spring and summer of 1991. Key factors considered in developing the forecasts are the prices of electricity and fossil fuels; the effects of increasing employment, population, and number of households; future changes in energy-using technologies; and planned conservation actions. Numerous secondary determinants are also considered.

To prepare these five load forecasts, ranges of employment, population, households, and fossil fuel price forecasts are developed. They are based on national economic forecasts and historical relationships between the Pacific Northwest and national economies. These major determinants are introduced into a series of electricity demand and pricing models. This modeling system projects future electricity loads and prices based on price/demand relationships. The cost of acquiring new resources to meet increased demand for power--and the resulting increase in electricity prices--are factored into the analysis. The result is a range of public agency and IOU load forecasts: high, medium-high, medium, medium-10w and low. In a similar manner, five DSI load forecasts are produced, with the primary determining factors being aluminum prices, electricity costs, and other DSI production costs.

The medium load forecast falls roughly at the center of the distribution of the load projections. The most likely range of loads is between the medium-high and medium-low forecasts. There is a 50 percent probability that loads will be in this range. The probability of loads being between the medium-high and high or between the medium-10w and low cases is 20 percent each. The high and low forecasts are unlikely to occur, with probabilities of load being higher than the high case or lower than the low case of 5 percent each.

The Council's Regional Power Plan and BPA's Resource Program are built upon the full range of forecasts, without strong weighting toward the medium case. However, BPA's power sales contract administration and operational and financial planning focus on the medium forecast. In response to these different needs, BPA staff took primary responsibility for developing the medium forecast for this year's study, while the Council staff took the lead in developing the other forecasts making up the range. 
The high, medium-high, medium-low, and low forecasts were prepared jointly with the Council in the spring of 1991, using the Council's pricing model, as part of the development of their Power Plan. The medium forecast was prepared at the same time, using BPA's Supply Pricing Model. The BPA pricing model allows the medium forecast to better reflect the detailed near-term assumptions regarding resource costs and loads. An updated medium forecast was prepared in August 1991, incorporating more recent economic trends and load tracking data. This updated forecast did not differ materially from the medium forecast prepared for the final Council Plan, and BPA elected to use the final Plan forecast for this year's study.

The medium forecast used in this study incorporates a merging of BPA's mid-term public agencies econometric load forecast (prepared in March 1991), with the 1991 Joint Long-Term Forecast. The mid-term and joint long-term load projections were combined to take advantage of the strengths of both near-term and long-term forecasting methods. BPA's mid-term forecast of public agency loads incorporates seasonal and cyclical variations in employment and near-term economic projections without breakdown by consumer sector. The mid-L.irm forecasting method was used to produce the public agency forecast through December 1994; the long-term method was used beginning January 1995 and continuing through the remainder of the study period.

Only the public agency medium forecast was merged in this manner. The high, medium-high, medium-low, and low forecasts were produced solely from the long-term forecasting models and are virtually identical to the public agency forecasts presented in the Council's Power Plan. The IOU load forecasts were generated from the long-term forecasting models and were not merged.

All forecasts assume that energy consumers will change their consumption in response to changes in electricity prices, but that utilities and state or local governments will not implement new or additional demand-side load reduction initiatives such as conservation programs, adoption of model conservation standards (MCS), or cost-effective cogeneration beyond currently budgeted programs. These long-term "price-effects" forecasts include:

- Price-induced conservation;

- Future impacts of all current building codes and appliance standards in effect at the time the forecasts were produced. These impacts include Federal appliance standards effective January 1990 and January 1993, the 1990 Washington State Energy Codes (MCS), which became effective July 1991, and the 1992 Oregon Building Code (MCS), which becomes effective January 1993;

- Conservation savings that have already been achieved, such as weatherization of existing dwellings, construction of Super Good Cents houses, and savings from conservation programs budgeted for 
Fiscal Years (FY) 1991-92, 1992-93, and 1993-94.1/ These conservation programs were included as reductions in loads, as shown in Table 7 , page 27 , which presents a reconciliation of the treatment of conservation acquisitions.

- Anticipated savings from aluminum DSIs' contracted-for conservation and modernization measures through July 1991; and

- The levels of electricity prices to consumers if the region pursues the least-cost mix of conservation, demand-side load reductions, and new generating resources.

For more information about the joint forecast and load forecasting methods, see the 1991 Pacific Northwest Economic and Electricity Use Forecast Technical Appendix, and chapters 5 and 6 of the Northwest Power Planning Council's Northwest Conservation and Electric Power Plan, Volume 2.

\section{Major Sources of Uncertainty}

\section{Loads and Resources Uncertainty}

Future Federal system and regional firm surpluses/deficits are subject co a number of uncertainties over the 20 -year study period. These uncertainties include:

- Differences in the rate of forecasted load growth;

- Changes in conservation program levels, including MCS implementation;

- Failure of generating resources to operate at anticipated times and levels;

- Changes in hydro system operation in response to programs developed to address the Endangered Species Act or other environmental considerations; and

- Possible Loss of Trojan Nuclear Plant -- During the 1991 maintenance outage, operators of Portland General Electric Company's Trojan nuclear plant discovered unexpected corrosion of the mechanisms in the steam generators. PGE is undertaking a study to determine the future of the project, and is contemplating replacing the steam generators during 1995 or 1996 . An extended or permanent shutdown

1/ Fiscal Year (FY) is the 12-month period October 1 to September 30 . For example, FY 1992-93 is October 1, 1992 through September 30, 1993. 
of Trojan would cause a loss of 1,104 megawatts of capacity and 717 average megawatts of firm energy in the region. (PGE would lose 745 megawatts of capacity and 483 averaze megawatts of energy; the Federal system would lose 331 megawatts of capacity and 215 average megawatts of energy; and Pacific Power \& Light Company would lose 28 megawatts of capacity and 18 average megawatts of energy.)

These uncertainties could affect both the size of projected surpluses or deficits and the times at wich they occur.

\section{Contractual Uncertainty}

BPA's contractual obligation to serve future regional load growth is uncertain because there is no precise way to predict the amount of load growth regional utilities will place on BPA in coming years. This study assumes that the following contracts, though they are subject to change as noted, will extend throughout the 20-year study period. What occurs when these contracts expire, which will be at varying times during the 20-year study period, may affect the Federal system and regional loads and resources balances:

- BPA's power sales contracts with its DSI, public agency, and IOU customers expire June 30,2001 . Renegotiaticn of these contracts may result in new or different Federal obligations during the last 11 years of the study period.

- The Pacific Northwest Coordination Agreement will expire June 30,2003 . BPA expects this agreement, which coordinates operation of the Pacific Northwest power system and that of Canada, will be replaced with a new agreement. The provisions of a new agreement may be different from the existing agreement. Any changes will affect the later years of this analysis. 


\section{Changes in the 1991 Pacific Northwest Loads and Resourres Study}

This section describes the major changes in the structure and assumptions of the 1991 Pacific Northwest Loads and Resources Study compared to the 1990 study. Other changes are reflected in the data for each utility contained in the 1991 Pacific Northwest Loads and Resources Study Technical Appendix.

\section{New Federal System Firm Resources}

On January 28, 1991, BPA contracted for the output of the Cowlitz Falls hydro project. Cowlitz Falls has a rated capability of 70 megawatts and an annual generation of 22 average megawatts. The project is scheduled to begin operating in April 1994.

BPA acquired the output of PNGC's share of the Boardman coal plant for October through April of OY 1991-92, and September through April for OY 1992-93 through 1994-95. BPA purchased 50 megawatts of capacity and 28 average megawatts of energy.

\section{Trojan Nuclear Power Plant}

Recent events at PGE's Trojan nuclear plant have resulted in an adjustment of the capacity factor from 70 percent to 65 percent for this study. This results in a 62-average-megawatt loss to the plant's participants. Trojan operators, during the 1991 maintenance outage, discovered unexpected corrosion of mechanisms in the steam generators. PGE is contemplating replacing the steam generators during 1995 or 1996. The interim period will be marked by uncharacteristic operation and refueling schedules, with extended outages to facilitate steam generator inspection and repairs. This is the same capacity factor assumed for WNP-2, the region's other operating nuclear plant.

\section{Hydro Regulation Study}

The hydro regulation study for this year's loads and resources study was designed to simulate the operational hydro study completed for PNCA planning. The changes include the following:

- The adoption of the PNCA maximum shift philosophy in the first two years of the 4-year critical period. This increases loads and hydro resources in the first two years of the critical period and shapes the return of that energy into the last two years of the 4-year critical period, and

- The Corps and Bureau increased the minimum amount of reservoir storage in Libby, Hungry Horse, and Dworshak hydro projects. These new hydro constraints increase the probability that these reservoirs refill each year by limiting the availability of water which may be used from these projects to meet loads. 
These changes altered the shape of the monthly energy and sustained capacity of the hydro system from prior studies. PNCA planning resulted in heavier drafting of the hydro system, which increased streamflows and firm energy in the first two years of the critical period study. In this same timeframe, higher reservoir elevations at Hungry Horse, Dworshak, and Libby forced heavier drafts, reducing reservoir elevations at Grand Coulee. Winter elevations at Grand Coulee dropped significantly--to the 1,260-foot range in February (full reservoir occurs at 1,290 feet)--causing substantial sustained capacity losses. This reduced the Federal sustained capacity surplus in the winter and increased the capacity surplus in the summer and fall.

Future hydro regulation studies may contain additional project constraints that could further impact monthly energy and capacity capabilities.

\section{Federal System Long-Term Firm Surplus Energy Deficit}

BPA has discontinued its long-term firm energy marketing program. The Federal system firm surpluses which might occur in a given year have declined to such a point that there is no longer any firm energy surplus from a long-term planning perspective, and any potential short-term surplus will be marketed only under existing contracts or short-term contracts. 


\section{FEDERAL SYSTEM ANALYSIS}

The Federal system loads and resources analysis is based on the following as sumptions:

- The Pacific Northwest Coordination Agreement, which expires June 30,2003 , is replaced with a like agreement;

- BPA's power sales contracts with Pacific Northwest Federal and public agencies, IOUs, and DSIs, which expire June 30, 2001, are renewed with like agreements;

- Al1 existing Federal contractual arrangements not included under Pacific Northwest power sales contracts expire and are not renewed;

- Federal surplus firm power sales with the cities of Burbank, Glendale and Pasadena, and the Southern California Edison Company (SCE), are shown as power sales through their expiration; the Federal surplus firm power sale with the M-S-R Public Power Agency, whose members include Modesto Irrigation District, and the cities of Santa Clara and Redding, California, is shown as a power sale through October 31 , 2009, then converts to a capacity/energy exchange until it expires;

- The IOUs do not make long-term BPA purchases under their power sales contracts; and

- Federal resource acquisitions include the long-term purchase of the Cowlitz Falls hydro project, and the seasonal purchase of PNGC's share of the Boardman coal piant through April 1995.

\section{Federal System Firm Energy Loads}

The Federal system firm loads include BPA's firm DSI load, sales to Federal agencies, current obligations to regional public agencies and IOUs under their power sales contracts, and other inter- and intra-regional contractual obligations. Figure 1, page 14, shows the components of the Federal system firm load for oY $1992-93$.

The economic projections of the 1991 Joint Forecast used for this analysis are generally higher than the 1990 Joint Forecast projections used in last year's study. The 1991 forecast contains more optimistic projections of regional employment, slightly lower retail electricity prices, and relatively unchanged fossil fuel price projections. The exception is in the high case, where a slightly lower DSI forecast, coupled with savings attributable to Federal Appliance Standards and the adoption of the Model Conservation Standards (MCS) in Oregon and Washington, result in a slightly lower high case forecast through OY 1999-2000. 


\section{Figure 1 \\ Federal System Firm Load \\ OY 1992-93 Medium Load Forecast Energy in Average Megawatts}

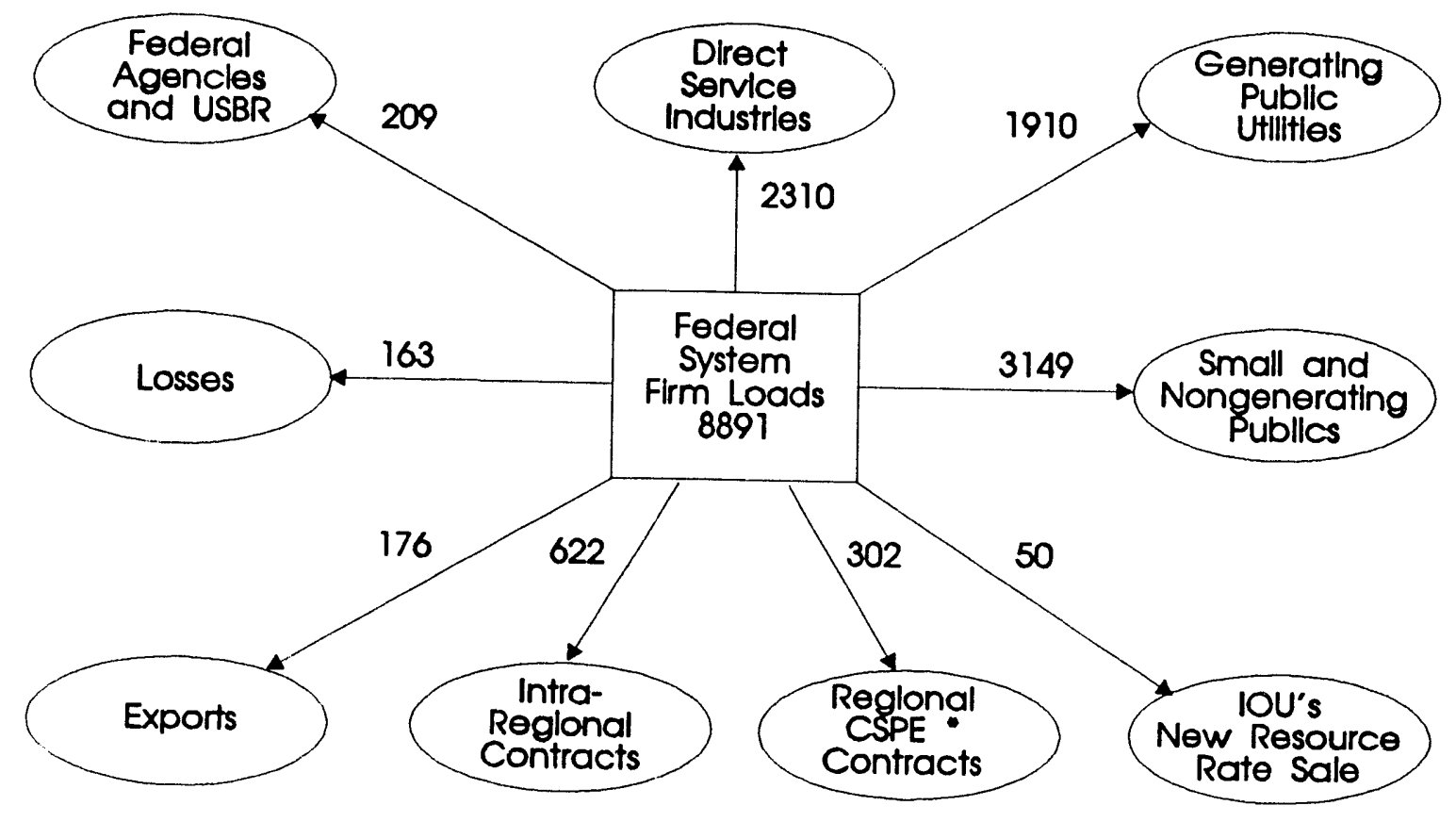

- Columbla Storage Power Exchange

RPCE: $11 / 91$

1) Operating Year (OY) is the 12-month period July 1 to June 30.
For example, OY 1992 is July 1, 1992 through June 30, 1993.

The Federal system firm energy loads under the high, medium-high, medium, medium-1ow, and low load forecasts for OY 1992-93 through 2011-12 are shown in Figure 2, page 15. The loads are based on the long-term 1991 Joint Forecast prepared by BPA and the Council. This study assumes that BPA serves all of the public agencies' net firm load requirements not served by their own resources. Additionally, the Federal loads assume no long-term IOU power sales contract purchases from BPA. This is due to the uncertainty of the IOUs' intentions concerning whether to make long-term BPA purchases under their power sales contracts. BPA believes this decision is reasonable because: 1) The IOUs have not informed BPA to the contrary; and 2) the IOU power sales contracts contain a 7 -year notice requirement that provides BPA adequate time to secure resources to meet increased IOU obligations. Currently, only one IOU, Puget Sound Power and Light Company (Puget), is purchasing energy from BPA under their power sales contract. Puget has extended this BPA energy purchase through June 30, 1998. Previously, they were to purchase power through June $30,1993$. 


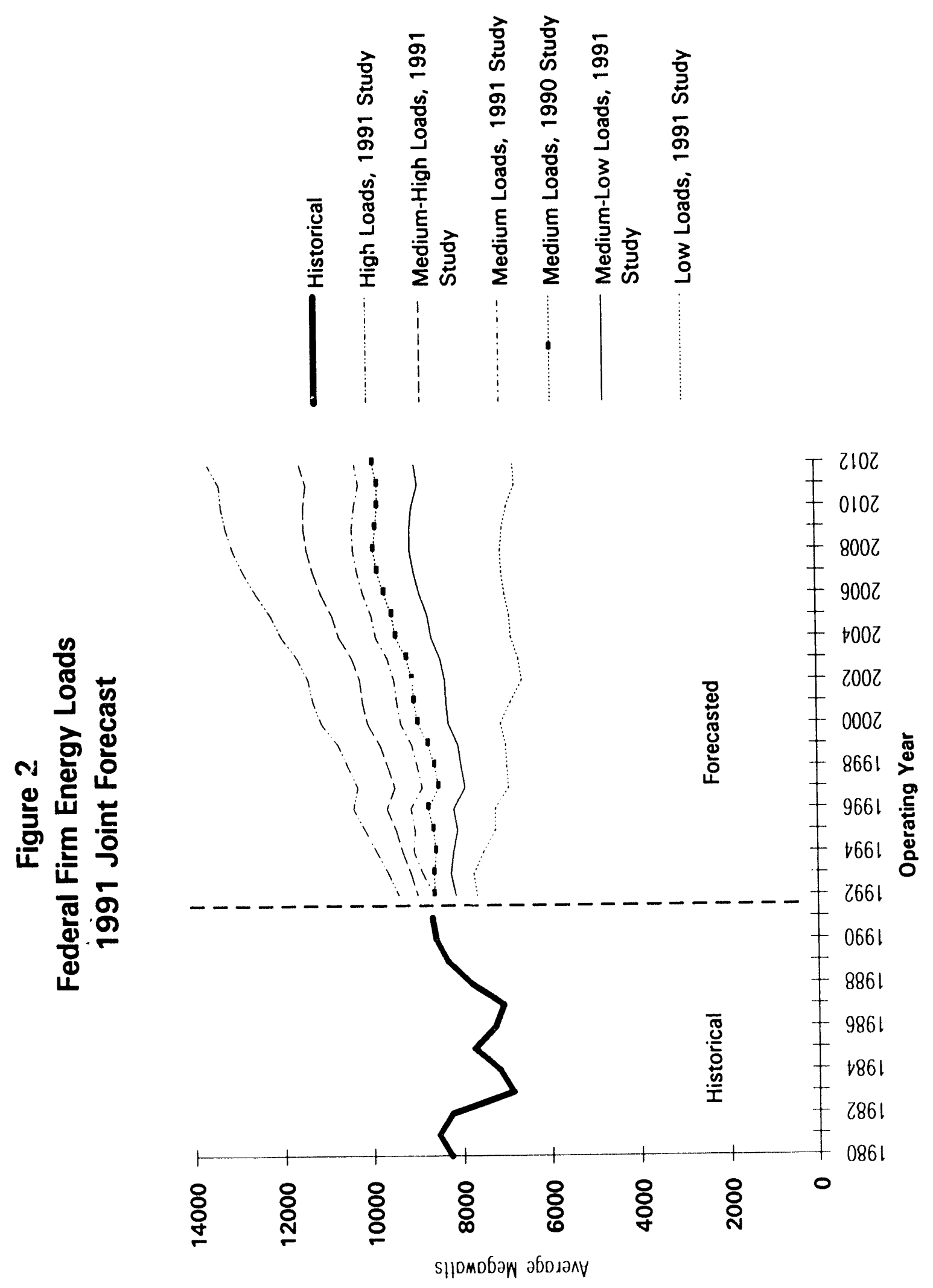


The Federal loads include all intra-regional contracts made within the Pacific Northwest, called contracts out, and inter-regional contracts or exports to Southwest utilities. Below, Table 1 summarizes the Federal system firm energy loads and percentage of load growth under the $f$ ive load forecasts through the 20-year study period. The Federal firm energy loads under the medium forecast are presented in Exhibit 1, 1 ine 15, pages 54 through 57 . The Federal firm energy loads under the high, medium-high, medium-low, and low forecasts are shown on 1 ine 15 of Exhibits 2 through 5, pages 58 through 73.

\section{Table 1}

Federal System Firm Loads $\underline{1}$ ' Includes Contractual obligations

Energy in Average Megawatts

\begin{tabular}{|c|c|c|c|c|}
\hline \multirow{2}{*}{$\begin{array}{c}\text { Load } \\
\text { Forecast }\end{array}$} & \multicolumn{2}{|c|}{ Operating Year } & \multirow{2}{*}{$\begin{array}{c}\text { Load } \\
\text { Growth }\end{array}$} & \multirow{2}{*}{$\begin{array}{l}\text { Load Growth } \\
\text { (Avg. \%/yr) }\end{array}$} \\
\hline & 1992-93 & 2011-12 & & \\
\hline High & 9,632 & 13,625 & 3,993 & 1.8 \\
\hline Medium-High & 9,147 & 11,570 & 2,423 & 1.2 \\
\hline Medium & 8,891 & 10,333 & 1,442 & 0.8 \\
\hline Medium-Low & 8,243 & 9,004 & 761 & 0.5 \\
\hline Low & 7,724 & 6,767 & -957 & -0.7 \\
\hline
\end{tabular}

1/ Federal System load growth may not parallel load growth for the Pacific Northwest. Federal system loads consist of many contracts and obligations that may increase or decrease through the study period due to customer rights under these contracts.

2/ Operating Year (OY) is the 12 -month period July 1 to June 30 . For example, OY 1993 is July 1, 1992 through June 30, 1993. 


\section{Federal System Firm Peak Loads}

Figure 3, below, shows the Federal firm peak loads under the medium load forecast for OY 1992-93, 1997-98, 2002-03, and 2011-12, based on the 1991 Joint Forecist. The peak loads project the expected 1-hour maximum demand for each month. There is a 50 percent probability that the actual load will be either higher or lower at some time during that month. The peak load projections are reduced by a diversity component to address the fact that all peak electrical demands do not occur simultaneously throughout the region. The loads also include BPA's inter- and intra-regional contractual on-peak commitments. This study assumes that public agencies will purchase capacity from BPA under their power sales contracts to meet peak loads not served by their own resources.

Figure 3

Federal Firm Peak Loads Medium Loads

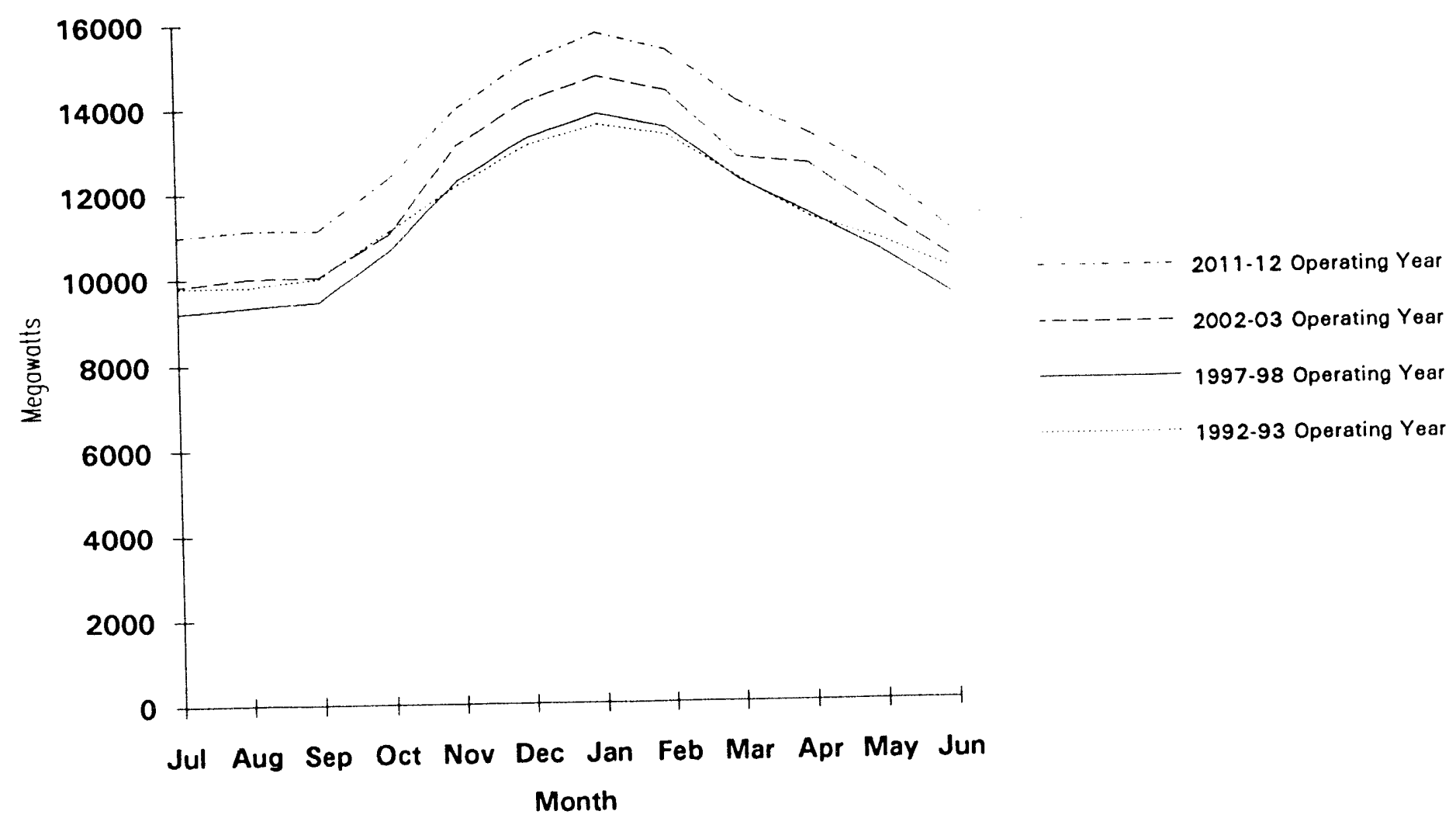

RPCE:11/91 


\section{New Federal System Firm Resources}

\section{Cowlitz Falls Hydro Project}

Since last year's study, BPA, on January 28, 1991, contracted for the output of the Cowlitz Falls hydro project. Cowlitz Falls has a rated capability of 70 megawatts and an annual generation of 22 average megawatts. The project is scheduled to begin operating in April 1994.

\section{Seasonal Purchase of Boardman Share}

BPA seasona11y acquired PNGC' .are of the Boardman coal plant for October through Apri1, OY 1991-92, and September throligh April, OY 1992-93 through 1994-95. This purchase increases BPA's available firm resources by 50 megawatts of capacity and 28 average megawatts of annual energy through April 1995.

\section{Table 2}

New Non-Federally Owned BPA Resources (Included as Federal System Firm Resources)

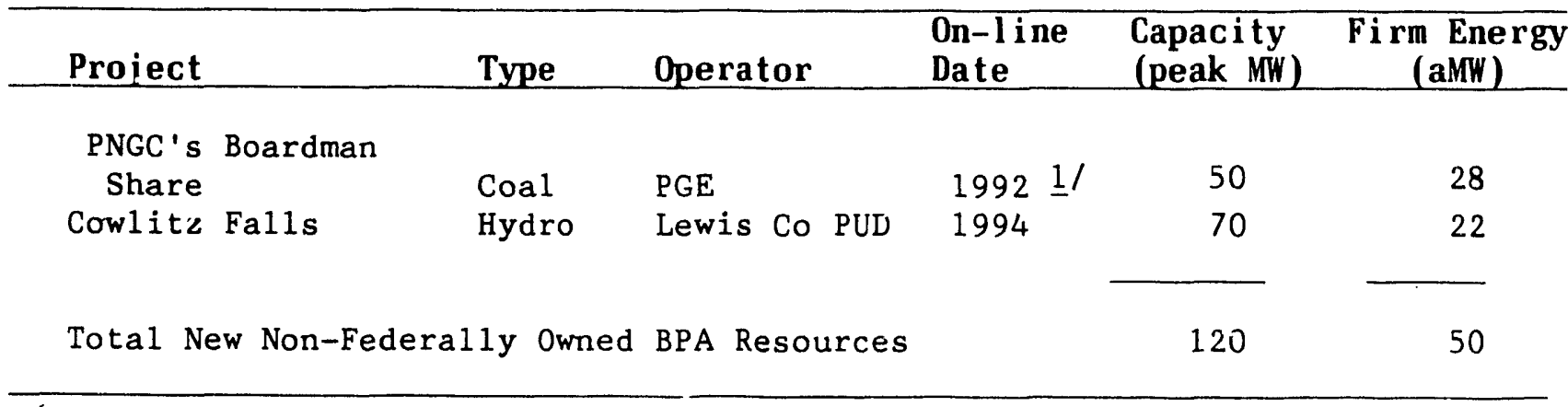

\section{1/ Seasonally acquired by BPA through April 1995}

\section{Existing Federal System Firm Resources}

The Federal system hydro resources from which BPA markets power are shown in Table 3, page 19. In addition, BPA markets power purchased from non-Federa11y owned resources. BPA's capacity/energy exchange contracts provide energy to $B P A$ as payment for the capacity BPA delivers. The non-Federally owned resources, return energy associated with BPA's existing capacity/energy exchanges, and other BPA hydro-related contracts are shown in Table 4, page 20. The combination of these resources represent BPA's available firm resources. 
Table 3

Federal System Hydroelectric Projects

September 30, 1991

\begin{tabular}{|c|c|c|c|c|}
\hline Project & $\begin{array}{l}\text { ial Year } \\
\text { Service }\end{array}$ & $\begin{array}{l}\text { Number } \\
\text { of Units }\end{array}$ & $\begin{array}{l}\text { Generat ing } \\
\text { Capacity } \\
\text { (peak MW) }\end{array}$ & $\begin{array}{c}\text { Firm } \\
\text { En:rgy } \\
\text { (aMW) }\end{array}$ \\
\hline \multicolumn{5}{|c|}{ U.S. Bureau of Reclamation Hydroelectric Projects } \\
\hline Grand Coulee & 1941 & 30 & 6,984 & 1,820 \\
\hline Hungry Horse & 1952 & 4 & 430 & 100 \\
\hline Palisades & 1957 & 4 & 131 & 61 \\
\hline Anderson Ranch & 1950 & 2 & 40 & 11 \\
\hline Minidoka & 1909 & 7 & 16 & 9 \\
\hline Roza & 1958 & 1 & 13 & 4 \\
\hline Chandler & 1956 & 2 & 13 & 7 \\
\hline B1ack Canyon & 1925 & 2 & 10 & 7 \\
\hline Boise River Diversion & 1912 & 3 & 2 & 0 \\
\hline Total Bureau of Reclamation Projects & & $\overline{55}$ & $\overline{7,639}$ & $\overline{2,019}$ \\
\hline \multicolumn{5}{|c|}{ U.S. Army Corps of Engineers Hydroelectric Projects } \\
\hline Chief Joseph & 1955 & 27 & 2,614 & 1,112 \\
\hline John Day & 1968 & 16 & 2,484 & 891 \\
\hline The Dalles & 1957 & 22 & 2,074 & 707 \\
\hline Bonneville & 1938 & 18 & 1,147 & 565 \\
\hline McNary & 1953 & 14 & 1,127 & 623 \\
\hline Lower Granite & 1975 & 6 & 930 & 191 \\
\hline Lower Monumental & 1969 & 6 & 930 & 195 \\
\hline Little Goose & 1970 & 6 & 930 & 191 \\
\hline Ice Harbor & 1961 & 6 & 693 & 194 \\
\hline Libby & 1975 & 5 & 620 & 185 \\
\hline Dworshak & 1974 & 3 & 460 & 155 \\
\hline Lookout Point & 1954 & 3 & 138 & 21 \\
\hline Detroit & 1953 & 2 & 115 & 28 \\
\hline Green Peter & 1967 & 2 & 92 & 19 \\
\hline Lost Creek & 1975 & 2 & 56 & 23 \\
\hline Albeni Falls & 1955 & 3 & 49 & 28 \\
\hline Hills Creek & 1962 & 2 & 35 & 12 \\
\hline Cougar & 1964 & 2 & 29 & 11 \\
\hline Foster & 1968 & 2 & 23 & 8 \\
\hline Big Cliff & 1954 & 1 & 21 & 9 \\
\hline Dexter & 1955 & 1 & 17 & 7 \\
\hline \multicolumn{2}{|l|}{ Total Corps of Engineers Projects } & 149 & 14,584 & 5,175 \\
\hline \multicolumn{2}{|l|}{$\begin{array}{l}\text { Total Bureau of Reclamation and Corps } \\
\text { of Engineers Projects }\end{array}$} & 204 & 22,223 & 7,194 \\
\hline
\end{tabular}


Table 4

Non-Federally Owned BPA Resources and Contracts

\begin{tabular}{|c|c|c|c|c|c|}
\hline Project & Type & Operator & $\begin{array}{l}\text { Date in } \\
\text { Service }\end{array}$ & $\begin{array}{r}\text { Capacity } \\
\text { (peak MW) }\end{array}$ & $\begin{array}{l}\text { OY 1992-93 } \\
\text { Fi rm Energy } \\
\text { (aMW) }\end{array}$ \\
\hline
\end{tabular}

Existing Non-Federally Owned BPA Resources

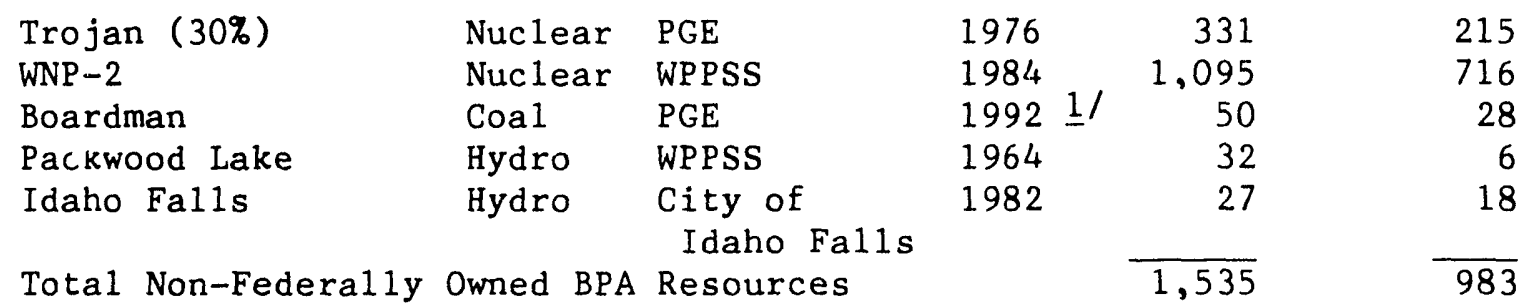

\section{Firm Contracts}

Canadian Entitlement

Restoration, Columbia River Treaty w/Canada

$\begin{array}{rrr}-- & 209 & 67 \\ -- & 0 & -23 \\ -- & 0 & 6 \\ -- & 0 & 29 \\ -- & 185 & 93 \\ -- & 0 & 114 \\ & & \\ & 394 & 286\end{array}$

Total BPA Firm Contracted Resources

Future Non-Federally Owned Resources

Cowlitz Falls Hydro Lewis Co PUD $1994 \quad 70 \underline{2} / 22$ I

1/ Seasonally acquired by BPA from PNGC, October through April, OY 1991-92 and September through Apri1, OY 1992-93 through 1994-95

2/ Acquired by BPA on January 28,1991 and will become operational Apri1 1, 1994.

Table 5, page 21, summarizes the Federal system firm energy resources and contracts available to meet Federal firm loads for oY 1992-93. Hydroelectric power comprises 86 percent of the Federal system firm energy resources. Of the remaining firm energy resources, 11 percent comes from two nuclear plants, 3 percent is derived from BPA's firm contracts, and less than 1 percent comes from one coal plant. 
Table 5

Federal System Firm Energy, Resources

\begin{tabular}{lcccc}
\hline $\begin{array}{c}\text { Project } \\
\text { Type }\end{array}$ & $\begin{array}{c}\text { Generating } \\
\text { Peak Capacity } \\
\text { (MW) }\end{array}$ & $\begin{array}{c}\text { Generating } \\
\text { Peak Capacity } \\
\text { \% of Total }\end{array}$ & $\begin{array}{c}\text { Firm Energy } \\
\text { (aMW) }\end{array}$ & $\begin{array}{c}\text { Firm Energy } \\
\text { \% of Total }\end{array}$ \\
\hline & & & & \\
Hydro Resources & 20,670 & 92 & 7,219 & 86 \\
Nuclear Plants & 1,426 & 6 & 931 & 11 \\
Coal Plants & 50 & 0 & 28 & 3 \\
Firm Contracts & 394 & -100 & 286 & 100 \\
Total. Federa1 & 22,540 & 100 & & \\
Resources & & & & \\
\end{tabular}

1/ Operating Year (OY) is the 12-month period July 1 to June 30 . For example, OY 1992 is July 1, 1992 through June 30, 1993.

\section{Federal System Nonfirm Resources}

BPA planning does not include nonfirm energy in its Federal system loads and resources balance; however, it is an important component of BPA's marketing programs and revenue forecasts. Regional nonfirm energy can vary from zero in the worst water year, to as much as 8,300 average megawatts in the best water year. Federal system nonfirm energy comprises approximately 60 percent of the region's nonfirm energy. Federal nonfirm energy averaged over 50 years of historical water flows would increase the Federal system resources by about 2,400 average megawatts. Federal nonfirm energy is even larger when based on historical water flows of the past 102 years.

\section{Federal System Firm Energy Surpluses/Deficits}

The hydro analysis for this year's study used all operating constraints currently adopted by the hydroelectric project owners. Many of these constraints were added to the system in support of the Pacific Northwest Power Planning Council's fish flow program. Constraints placed on the hydro system over the past 10 years to enhance fish flows have decreased the firm energy by approximately 400 average megawatts.

The Pacific Northwest Power Planning Council, BPA, and other Pacific Northwest entities are currently evaluating new ways to enhance fisheries and wildlife. These include amendments to the Council's fish and wildlife program, completion of the System Operation Review, and implementation of additional programs in support of the Endangered Species Act. The Council recently presented an amendment to their Columbia River Basin Fish and Wildlife Program that would reduce regional hydro firm energy by 73 average megawatts. The impacts of future proposals are unknown; they could, however, reduce the generating capability by as 1 ittle as 50 or as much as several thousand average megawatts. These proposals will most likely increase constraints on 
the hydro system and reduce operating flexibility, change the monthly shape of streamflows, and change the monthly availability of Federal energy and sustained capacity. However, BPA does not expect the potential impacts to approach the high end of the range of estimates. When specific constraints have been adopted, they will be incorporated in future studies.

Figure 4, page 23, illustrates the variability of the Federal firm energy loads and available Federal resources under the high, medium-high, medium, medium-low, and low load forecasts. Federal resources change over time due to yearly scheduled maintenance and the expiration of inter- and intra-regional contracts.

The Federal firm energy surpluses/deficits under the various load forecasts for OY 1992-93 through 2011-12 are presented in Table 6, page 24, and graphically shown in Figure 5, page 25. The Federal system would be energy deficit throughout the 20-year study period under the medium, medium-high, or high load forecast, and would become deficit in OY 2003-04 under the medium-low load case. The Federal system would remain firm energy surplus throughout the 20-year study period under the low load forecast. Although utility loads continue to grow through the 1990s, the Federal system deficit, under medium loads, does not increase significantly due to the following changes:

- DSI loads, 26 percent of the Federal load, are forecasted to decline slightly through OY 1996-97, then remain constant through the balance of the planning period; and

- The WNP-1 exchange contract obligation expires June 30, 1996, returning 340 average megawatts of firm energy to the Federal system.

The components of the Federal energy loads and resources balances under the five load scenarios are presented in Exhibits 1 through 5, pages 54 through 73. The Federal system firm energy surpluses/deficits, based on medium loads, are presented in Exhibit 1, 1 ine 41, pages 54 through 57. The 20-year Federal system firm energy surpluses/deficits under the high, medium-high, medium-1ow, and low load forecasts are shown on 1 ine 41 of Exhibits 2 through 5, pages 58 through 73. 
Figure 4

Federal Firm Energy Loads and Resources Includes Inter- and Intra-Regional Contracts

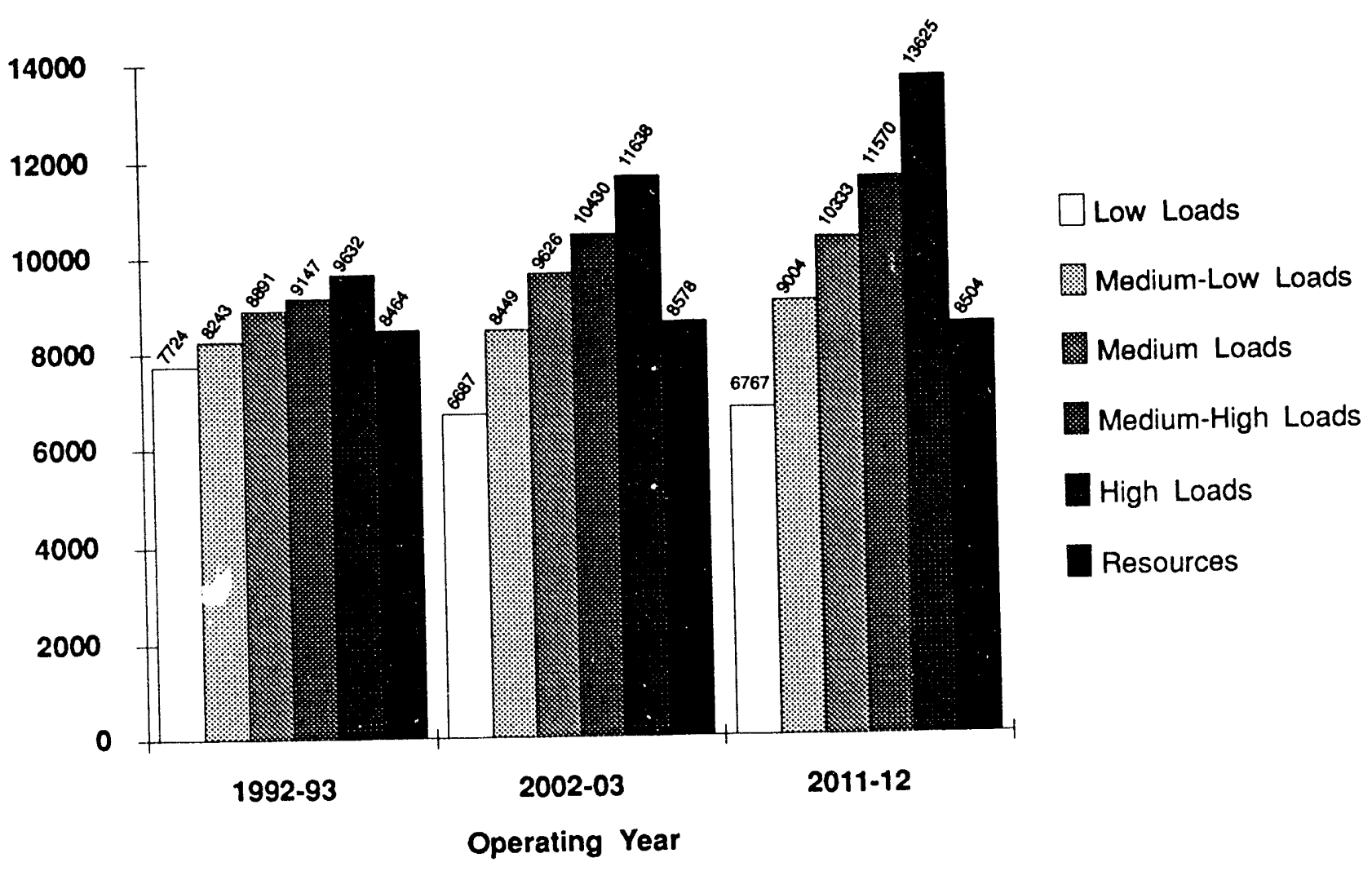

RPCE:11/91 
Table 6

Federal System Firm Energy Surpluses/Deficits

Assuming Existing Loads, Resources, and Contracts ${ }^{\prime}$

Energy In Average Megawat s

\begin{tabular}{lrrrrrrrrrr}
\hline OPERATING YEAR 2/ & 1993 & $\mathbf{1 9 9 4}$ & $\mathbf{1 9 9 5}$ & $\mathbf{1 9 9 6}$ & $\mathbf{1 9 9 7}$ & $\mathbf{1 9 9 8}$ & $\mathbf{1 9 9 9}$ & $\mathbf{2 0 0 0}$ & $\mathbf{2 0 0 1}$ & $\mathbf{2 0 0 2}$ \\
\hline & & & & & & & & & & \\
High Loads & -1169 & -1425 & -1669 & -1912 & -1810 & -2030 & -2232 & -2553 & -2745 & -2818 \\
Medium-High Loads & -684 & -860 & -988 & -1155 & -979 & -1126 & -1269 & -1515 & -1635 & -1676 \\
Medium Loads & -427 & -613 & -581 & -630 & -386 & -485 & -585 & -796 & -877 & -915 \\
Medium-Low Loads & 220 & 285 & 385 & 342 & 592 & 520 & 456 & 282 & 233 & 227 \\
Low Loads & 739 & 943 & 1219 & 1261 & 1568 & 1545 & 1533 & 1449 & 1680 & 1945 \\
\hline
\end{tabular}

\begin{tabular}{|c|c|c|c|c|c|c|c|c|c|c|}
\hline OPERATING YEAR 2/ & 2003 & 2004 & 2005 & 2006 & 2007 & 2008 & 2009 & 2010 & 2011 & 2012 \\
\hline High Loads & -3059 & -3400 & -3636 & -3961 & -4238 & -4470 & -4685 & -4789 & -4864 & -5119 \\
\hline Medium-High Loads & -1852 & -2115 & -2257 & -2488 & -2672 & -2805 & -2925 & -2933 & -2908 & -3064 \\
\hline Medium Loads & -1048 & -1261 & -1362 & -1549 & -1691 & -1784 & -1858 & -1809 & -1732 & -1829 \\
\hline Medium-Low Loads & 129 & -60 & -144 & -309 & -434 & -513 & -572 & -518 & -426 & -499 \\
\hline Low Loads & 1891 & 1750 & 1719 & 1605 & 1535 & 1514 & 1507 & 1615 & 1756 & 1737 \\
\hline
\end{tabular}

1/ The load forecasts on which this study is based were reduced by budgeted conservation acquisitions for FY 1990-91 through 1993-94.

$2 /$ Operating Year (OY) is the 12 -month period July 1 to June 30 . For example, OY 1993 is July 1, 1992 through June 30, 1993. 


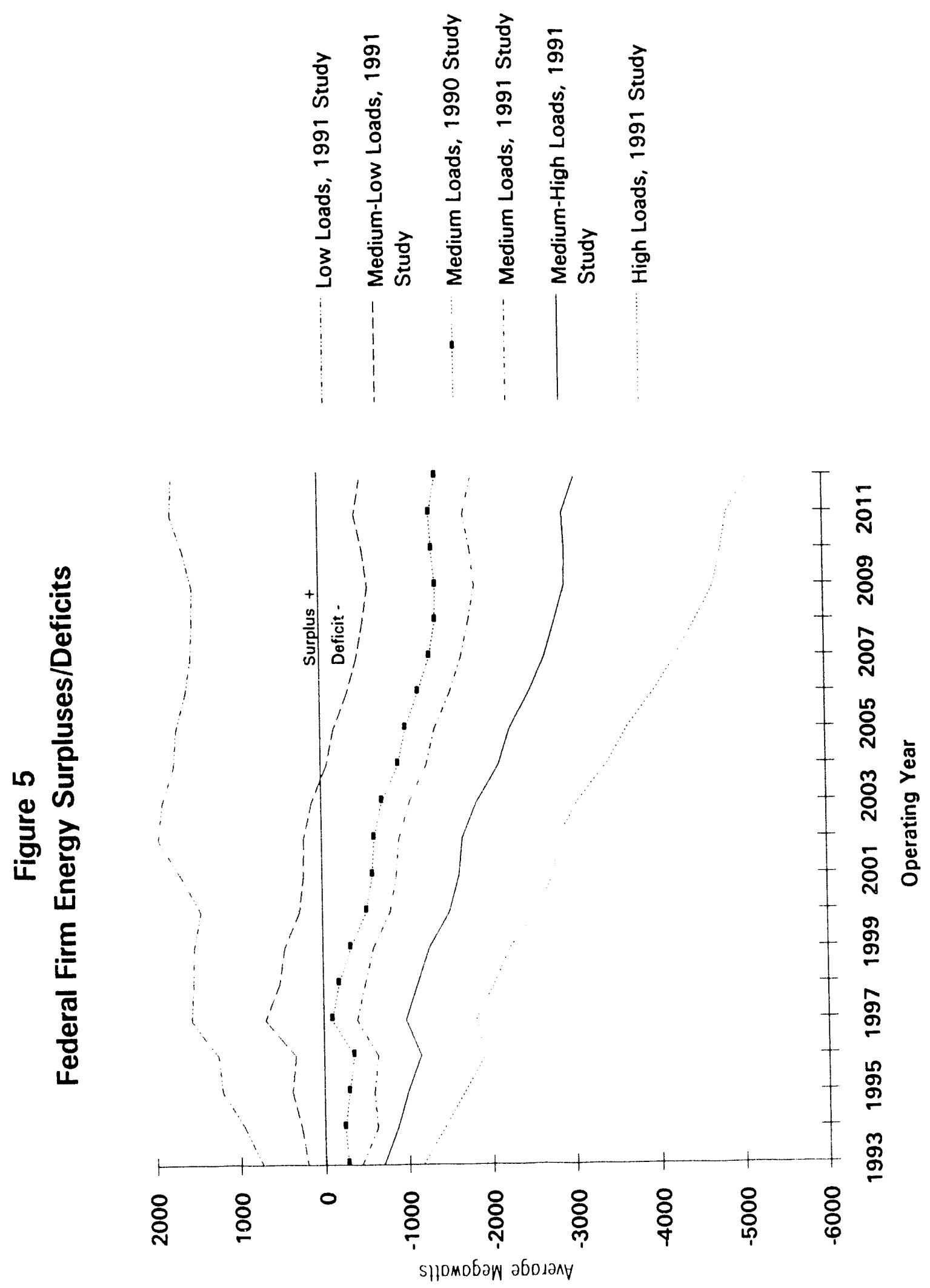




\section{Planned Federal System Resource Acquisitions}

BPA plans to acquire resources during the 1990 s to of fset projected energy deficits. These planned Federal resource acquisitions include those generation and conservation resources being budgeted or planned through FY 1996-97, as discussed in BPA's 1990 Resource Program. Table 7, page 27, shows Resource Program conservation and planned generation resource acquisitions, plus other planned resources. It also details that portion of the planned Federal conservation acquisitions included as a load reduction in the load forecasts used in this year's study; the remainder is available now if needed to meet future deficits. Since FY 1996-97 extends 3 months into OY 1997-98, a portion of these acquisitions is shown in OY 1997-98.

BPA issued two requests for proposals (RFPs) to provide some of these resources. BPA is now in the process of evaluating these proposals and selecting the resources BPA will negotiate to acquire. This acquisition process, including negotiating contracts, awarding bids, and evaluating possible environmental impacts, requires considerable time. Consequently, a11 planned acquisitions scheduled for OY 1992, and most of the OY 1992-93 acquisitions, were delayed and are included in OY 1993-94.

These resources are not yet actually on-line or contracted for; therefore, they are not included as firm resources in this study. Federal planned resource acquisitions will become firm resources only after BPA signs contracts to acquire them.

BPA is in the process of developing the Draft 1992 Resource Program. This draft program will be completed and issued for public review by the end of 1991. BPA's proposed course of action is to acquire an accelerated level of conservation above that identified in the 1990 Resource Program. This proposed "accelerated pathway" was outlined in the Draft Conservation Implementation Plan issued by the Office of Energy Resources on September 16, 1991. To avoid double-counting, the proposed program levels from this plan are reduced by the conservation program levels contained in BPA's 1990 Resource Program. The resulting net conservation level is included as a planned acquisition in Table 7.

The strategy of acquiring 250 average megawatts of additional generation resources by 1998 , plus another 250 average megawatts of resource options, is included in this study, and is one of four strategies detailed in the Draft 1992 Resource Program. WPPSS is in the process of signing contracts to increase the operating efficiency of the WNP-2 nuclear project. This efficiency improvement is included in the 1992 Resource Program. 


\section{Table 7}

Planned Federal System Resource Acquisitions 1/

Energy in Average Megawatts

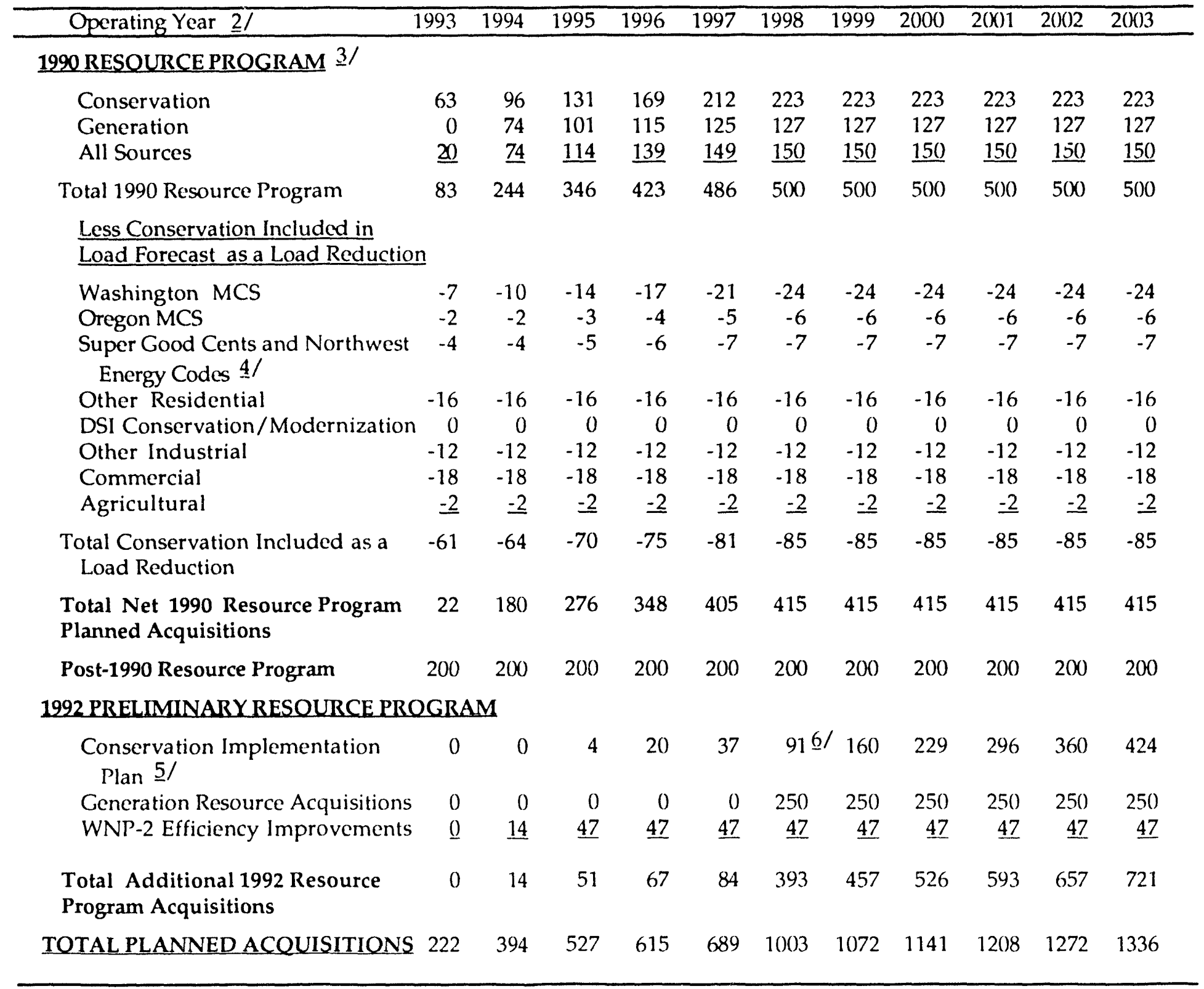

1/ The resources shown for each year are cumulative, not incremental, additions in that year. Resources in any given year differ from those in the 1990 Resource Program due to the difference between Fiscal Year and Operating Year calculations.

2/ Operating Year (OY) is the 12-month period July 1 to June 30. For example, OY 1993 is July 1, 1992 to June 30, 1993.

3/ The 1990 Resource Program conservation and generation for OYs 1990 through 1991 are not included in this table. Programs for OY 1992 and most of OY 1993 were delayed and are included in OY 1994.

4/ Incentive payments end January 1994.

5/ Additional conservation beyond 1990 Resource Program planned acquisitions.

6/ The 1990 Resource Program estimated conservation acquisitions through FY 1997. When converted to operatirg year, a portion of FY 1997 is shown in OY 1998. Similarly, the Draft Conservation Implementation Plan targets acquisitions through FY 2003. Converting conservation acquisitions to OY makes values in OYs 1998 through 2003 increase slightly from FY conservation program estimates. 


\section{Federal System Resource Options}

To offset possible short-term firm energy deficits, load overruns, or poor resource performance, $B P A$ has and will continue to acquire firm energy resource options. Some of these resource options guarantee BPA rights to terminate surplus firm power sales or purchase firm power as needed. These generating resource options, with low capital costs and high operating costs, have value as cost-effective firm resources in long-range planning. Since these options may or may not be exercised in a given operating year, they are excluded as firm resources in the loads and resources study.

Currently, most of BPA's firm resource options are long-term surplus firm power sales and capacity/energy exchange agreements with Pacific Southwest utilities. These contracts contain provisions by which BPA may completely or partially terminate the power sales and convert the contracts to capacity/ energy exchanges. BPA's resource options also include 115 average megawatts of available non-treaty storage.

\section{Contractual Resource Options}

BPA has long-term surplus firm power sale and capacity/energy exchange contracts with five Southwest utilities--Southern California Edison (SCE), the M-S-R Public Power Agency (M-S-R) whose members include the Modesto Irrigation District, and the cities of Santa Clara and Redding, California, and the cities of Burbank, Glendale, and Pasadena, California. $B P A$ also has a long-term surplus $f$ irm power sale and seasonal exchange contract with one Northwest utility--Puget Sound Power and Light.

The above contracts contain provisions, throughout their duration, for complete or partial termination of energy deliveries if that energy is needed to serve BPA's firm requirements. However, the M-S-R contract contains provisions for complete or partial termination of energy deliveries through October 31,2009 , then converts to a capacity/energy exchange until it expires.

The Southwest utilities contracts allow BPA to terminate surplus firm energy deliveries and convert these contracts to capacity/energy exchange contracts under the following conditions:

- On an annual basis, following a determination by BPA under annual Pacific Northwest Coordination Agreement planning; or

- On 60-days' notice pursuant to Public Law 88-552.

These provisions relieve BPA of its energy delivery obligations and make those resources available to BPA for meeting firm energy requirements. Energy may be acquired from the following categories:

- Energy made available from the termination of energy deliveries under Southwest surplus firm energy sales; 
- Exchange energy available upon conversion of the Southwest surplus firm energy sales to capacity/energy exchanges; and

- Supplemental energy available to BPA for purchase upon conversion of the Southwest surplus firm energy sales to capacity/energy exchanges.

In the event that BPA terminates energy deliveries of these Southwest surplus sales and converts them to exchanges, provisions within the contracts, except the city of Burbank's, allow for later reversion back to surplus energy sales, depending on the availability of Federal surplus firm energy and certain other conditions.

This study assumes that, under all five forecasts, these contracts retain their power sale status throughout their terms (expiration dates range from OY 2007-08 to 2012-13). Should BPA terminate these sales and convert them to capacity/energy exchanges, exchange energy would become available t. $\mathrm{BPA}$ as a firm resource. The additional resources resulting from early conversion of these surplus firm power sales to capacity/energy exchanges are shown in Table 8,1 ines 1 and 2 , page 31 .

Supplemental Energy. If BPA terminates Southwest sales and convert them to capacity/energy exchange contracts, BPA may elect to purchase supplemental energy in that same operating year. The additional resources that would become available upon early conversion of these contracts and purchase of supplemental energy is shown in Table 8 , line 3 , page 31 .

Option Energy. BPA also has contractual rights to purchase optional energy from Southern California Edison. This contract allows BPA to purchase up to 71 average megawatts of optional energy on a rolling 5-year basis starting in OY 1992-93. BPA considers this contract as a resource option, which BPA may elect to purchase; it is not considered a firm resource in this study. BPA included Southern California Edison option energy as a firm resource in the 1990-91 Pacific Northwest Coordination Agreement operating plan. The total optional energy available to BPA under this contract is shown in Table 8 , line 4, page 31.

Pacific Northwest Surplus Firm Energy. In addition, BPA has a surplus firm sale and seasonal power exchange agreement with Puget Sound Power and Light. This contract contains provisions that allow BPA to terminate the surplus energy sale on the earlicr of:

- 5-years' written notice from BPA; or

- on July 1, 2001. 
In this event, the surplus energy sale converts to a seasonal

power-for-power exchange. BPA's right to issue 5-years' written notice is in accordance with Section 5(a) of the Bonneville Project Act; (Public Law 75-329, as amended), and Section 5(f) of the Northwest Power Act (Public Law 96-501). This study assumes that this surplus sale will extend through $O Y$ 2000-01, when the contract is required to be converted to seasonal exchange status under all five load forecasts. If BPA needs the energy earlier, the contract will be terminated as a power sale and convert to a seasonal power exchange in that year and for the remainder of the contract. The earliest that BPA can terminate surplus firm energy deliveries to Puget Sound Power and Light Company is OY 1997-98. The amount of resources available to BPA, under all load forecasts, from the conversion of this contract to a seasonal power exchange is shown in Table 8,1 ine 5 , page 31 .

\section{Non-Treaty Storage}

On July 9, 1990, BC Hydro and BPA signed an agreement increasing United States-Canadian coordination of the Columbia River system. This agreement cooperatively manages 4.5 million acre-feet of non-treaty hydro storage through June 30,2003 . Studies on the increased coordination indicate a possible increase of 300 average megawatts in firm energy for the combined Canadian and Pacific Northwest systems. Fifty percent, 150 average megawatts, is available to the United States. The Federal system share is 115 average megawatts. This energy, however, is not as valuable as a firm resource because non-treaty storage has a lower refill priority than primary storage reservoirs. Therefore, BPA intends to use the non-treaty storage as a resource option to increase flexibility in operating the hydro system. Since this firm energy may not be available every year, it is not included as a firm resource in this loads and resources study. However, it may be included as a firm resource in future studies. Non-treaty storage is included in Table 8 , line 6 , page 31 . 
Table 8

Federal System Resource Options

Energy In Average Megawat s

\begin{tabular}{|c|c|c|c|c|c|c|c|c|c|c|}
\hline OPERATING YEAR 1/ & 1993 & 1994 & 1995 & 1996 & 1997 & 1998 & 1999 & 2000 & 2001 & 2002 \\
\hline $\begin{array}{l}\text { 1. Termination of PSW } \\
\text { Surplus Power Sales }\end{array}$ & 169 & 212 & 212 & 212 & 234 & 237 & 237 & 237 & 237 & 237 \\
\hline $\begin{array}{l}\text { 2. Exchange Energy } \\
\text { from PSW }\end{array}$ & 53 & 69 & 69 & 68 & 71 & 77 & 73 & 71 & 70 & 69 \\
\hline $\begin{array}{l}\text { 3. Supplemental } \\
\text { Energy from PSW }\end{array}$ & 35 & 35 & 36 & 37 & 38 & 39 & 40 & 42 & 43 & 44 \\
\hline $\begin{array}{l}\text { 4. Optional Energy } \\
\text { from PSW }\end{array}$ & 71 & 71 & 71 & 71 & 71 & 0 & 0 & 0 & 0 & 0 \\
\hline $\begin{array}{l}\text { 5. Termination of PNW } \\
\text { Surplus Power Sale }\end{array}$ & 0 & 0 & 0 & 0 & 0 & 75 & 75 & 75 & 75 & 0 \\
\hline 6. Non-Treaty Storage & $\underline{115}$ & $\underline{115}$ & $\underline{115}$ & $\underline{115}$ & $\underline{115}$ & $\underline{115}$ & $\underline{115}$ & $\underline{115}$ & $\underline{115}$ & $\underline{115}$ \\
\hline $\begin{array}{l}\text { 7. Total Resource } \\
\text { Options }\end{array}$ & 443 & 502 & 503 & 503 & 529 & 543 & 540 & 540 & 540 & 465 \\
\hline
\end{tabular}

\begin{tabular}{|c|c|c|c|c|c|c|c|c|c|c|}
\hline OPERATING YEAR 1/ & 2003 & 2004 & 2005 & 2006 & 2007 & 2008 & 2009 & 2010 & 2011 & 2012 \\
\hline $\begin{array}{l}\text { 1. Termination of PSW } \\
\text { Surplus Power Sales }\end{array}$ & 237 & 237 & 237 & 237 & 237 & 227 & 198 & 53 & 0 & 0 \\
\hline $\begin{array}{l}\text { 2. Exchange Energy } \\
\text { from PSW }\end{array}$ & 68 & 67 & 66 & 64 & 64 & 63 & 53 & 25 & 0 & 0 \\
\hline $\begin{array}{l}\text { 3. Supplemental } \\
\text { Energy from PSW }\end{array}$ & 46 & 47 & 48 & 49 & 49 & 49 & 46 & 0 & 0 & 0 \\
\hline $\begin{array}{l}\text { 4. Optional Energy } \\
\text { from PSW }\end{array}$ & 0 & 0 & 0 & 0 & 0 & 0 & 0 & 0 & 0 & 0 \\
\hline $\begin{array}{l}\text { 5. Termination of PNW } \\
\text { Surplus Power Sale }\end{array}$ & 0 & 0 & 0 & 0 & 0 & 0 & 0 & 0 & 0 & 0 \\
\hline 6. Non-Treaty Storage & $\underline{115}$ & 0 & 0 & 0 & 0 & $\underline{0}$ & $\underline{0}$ & $\underline{0}$ & $\underline{0}$ & $\underline{0}$ \\
\hline $\begin{array}{l}\text { 7. Total Resource } \\
\text { Options }\end{array}$ & 466 & 351 & 351 & 350 & 351 & 339 & 297 & 78 & 0 & \\
\hline
\end{tabular}

1/ Operating Year (OY) is the 12-month period July 1 to June 30 . For example, oY 1993 is July 1, 1992 through June 30, 1993. 


\section{Planning to Meet Forecasted Deficits}

By selecting from among BPA's possible resource options, a number of differing load and resource scenarios can be constructed in response to projected firm energy deficits. BPA will choose from these planned resource options and acquisitions as energy needs arise. This gives BPA the flexibility to pick the resource that is most likely to be ready and which offers the best resource value at the time it is needed.

Figure 6, page 33, depicts the resource options and the acquisitions targeted under BPA's 1990 Resource Program and subsequent updates that BPA might use to satisfy firm energy deficits. As BPA signs contracts to acquire new resources, the projected deficit will be reduced. Table i, page 27, identifies 22 to $4 i j$ average megawatts of planned acquisitions and billing credits from the 1990 Resource Program. In addition, BPA subsequently increased the resource acquisition by 200 average megawatts. The 1990 Resource Program also included 800 average megawatts of contingency resource options, to be converted to firm resources when needed to serve projected Federal system firm energy deficits. BPA is in the process of acquiring these options.

It is important to note that BPA is in the process of developing the Draft 1992 Resource Program, and is evaluating resources and billing credits to acquire additional firm resources. The Draft 1992 Resource Program will also update plans for meeting future deficits for the Federal system. BPA completed the Draft Conservation Implementation Plan and intends to purchase, under its aggressive level, a total of 663 average megawatts of conservation by $O Y$ 2002-03. This amount is reduced by the conservation included in the 1990 Resource Program. The Drafl 1992 Resource Program includes the acquisition of 250 average megawatts of generation resources by OY 1997-98, along with 47 average megawatts of sperating efficiency improvements at the WNP-2 nuclear plant. BPA also has approximately 500 average megawatts of resource options that may be exercised to meet deficits. 


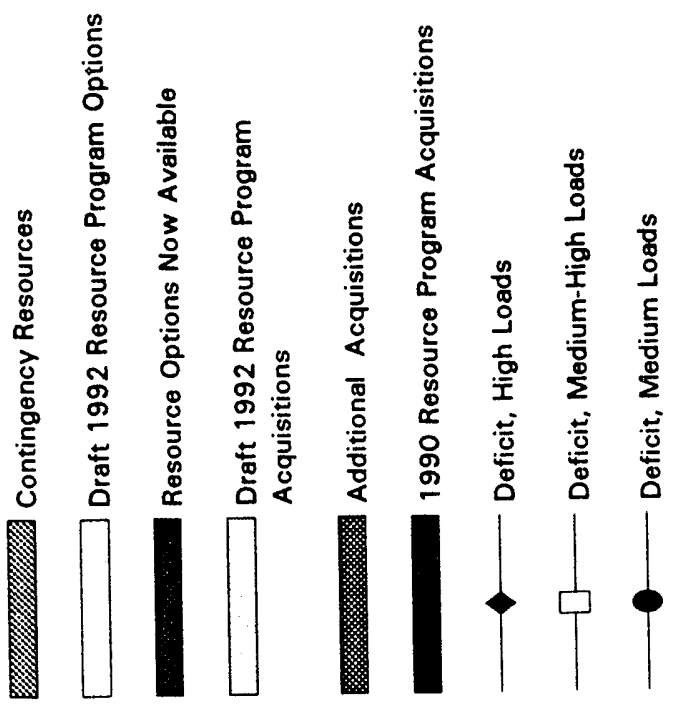

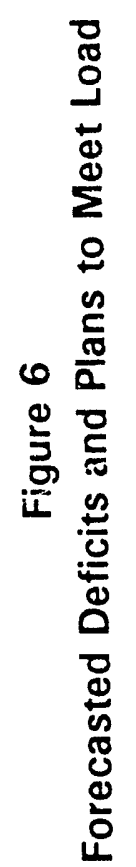

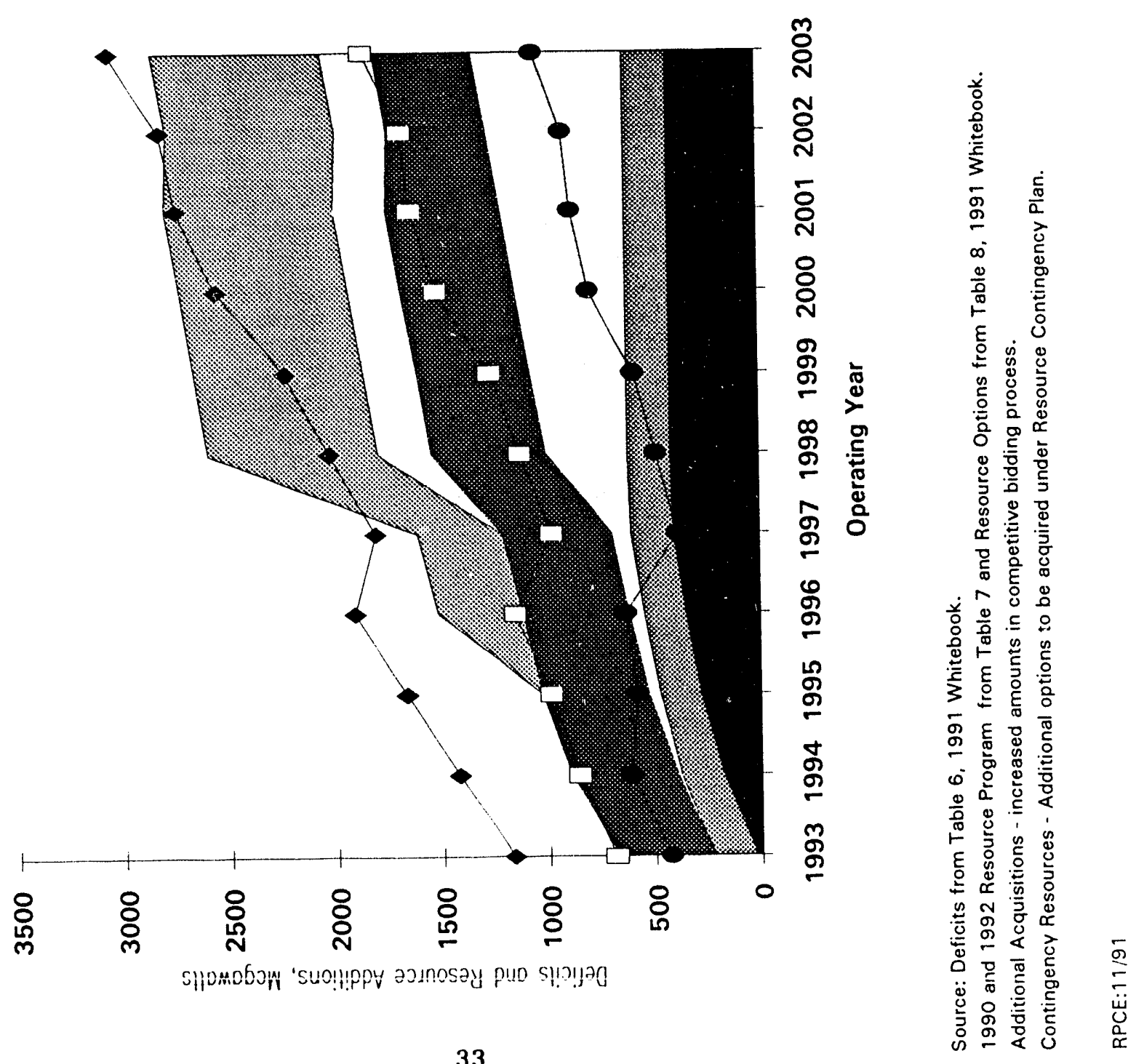




\section{Federal System Firm Capacity Surpluses/Deficits}

Figures 7 through 10 , pages 35 and 36 , show the Federal firm capacity surpluses/deficits under the high, medium-high, medium, medium-low, and low load forecasts for OY 1992-93, 1997-98, 2002-03, and 2011-12. The monthly capacity surpluses assume that the Federal system has the ability to meet a peak load of 50 hours per week with surplus capacity that is available after serving all Federal capacity needs with 1929-30 water levels.

Portland General Electric Company (PGE) has requested capacity service from BPA under its requirements power sales contract. The capacity sale will begin August 1, 1992 with deliveries of 100 peak megawatts and increases to 150 peak megawatts on August 1, 1993 through June 30, 1999. BPA has told PGE they have the right to place this capacity load on BPA based on BPA's current surplus capacity. When PGE submits this load in the annual Firm Resource Exhibit of its power sales contract, it will be included as a firm obligation on the Federal system.

BPA is currently preparing an Environmental Impact Statement (EIS) for a long-term follow-on capacity sale contract for 1,400 peak megawatts with Pacific Power and Light Company (PP\&L) for the period of September 1, 1991, or when the EIS is completed, through August 31, 2010. The current capacity contract of 1,127 peak megawatts expired August 31,1991 . If BPA signs the PP\&L contract after completing the EIS, it will be included as a firm BPA obligation and reduce available surplus capacity. BPA is currently supplying 1,100 peak megawatts of capacity to $P P \& L$ under a 1-year agreement.

These projections estimate the capacity that is surplus to the Federal system requirements. The figures assume that contractual or other provisions would be made to relieve off-peak problems when energy is returned under future capacity sales. Federal hydro constraints and low Federal nighttime loads limit the system's ability to store return energy. Depending on energy return provisions, these contracts could create forced energy sales and may reduce the Federal system's ability to meet firm loads. These potential problems are presented in the Federal System Marketable Capacity section on page 37 . See the 1991 Pacific Northwest Loads and Resources Technical Appendix: Volume 2 for more information regarding energy return considerations.

BPA is acquiring future resources as targeted in Table 7. The quantity will be determined as the new acquisitions are contracted for. This additional capacity gain will increase the quantity of surplus capacity available to be marketed.

The 20-year summary of Federal capacity surpluses/deficits, based on medium loads, is shown in Exhibit 6, page 77. The Federal system 20-year summary of capacity surpluses/deficits under high, medium-high, medium-low, and low loads is presented in Exhibits 7 through 10, pages 78 through 81. 
Figure 7

1992-93 Federal Firm Capacity Surpluses/Deficits

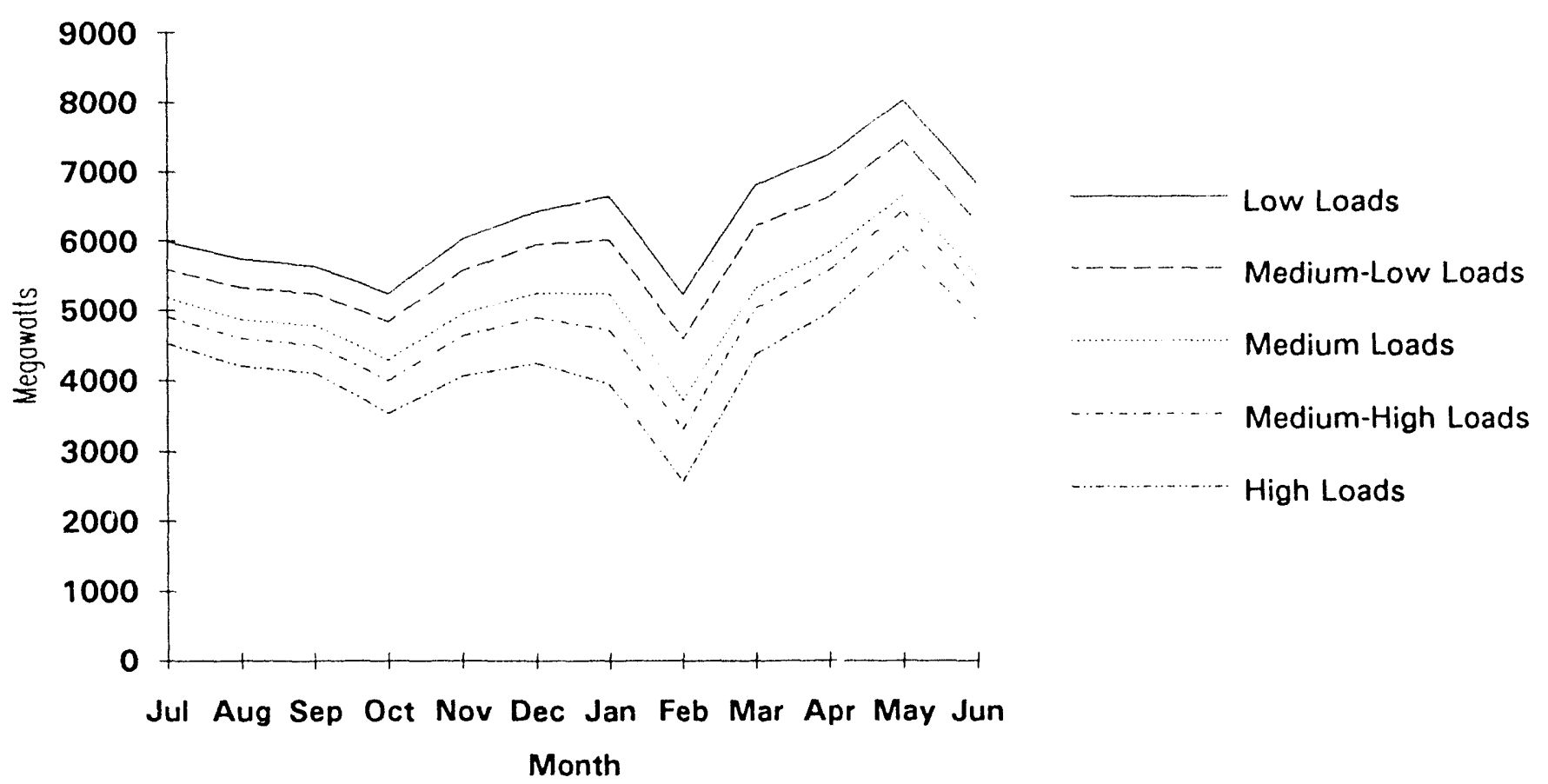

RPCE:11/91

Figure 8

1997-98 Federal Firm Capacity Surpluses/Deficits

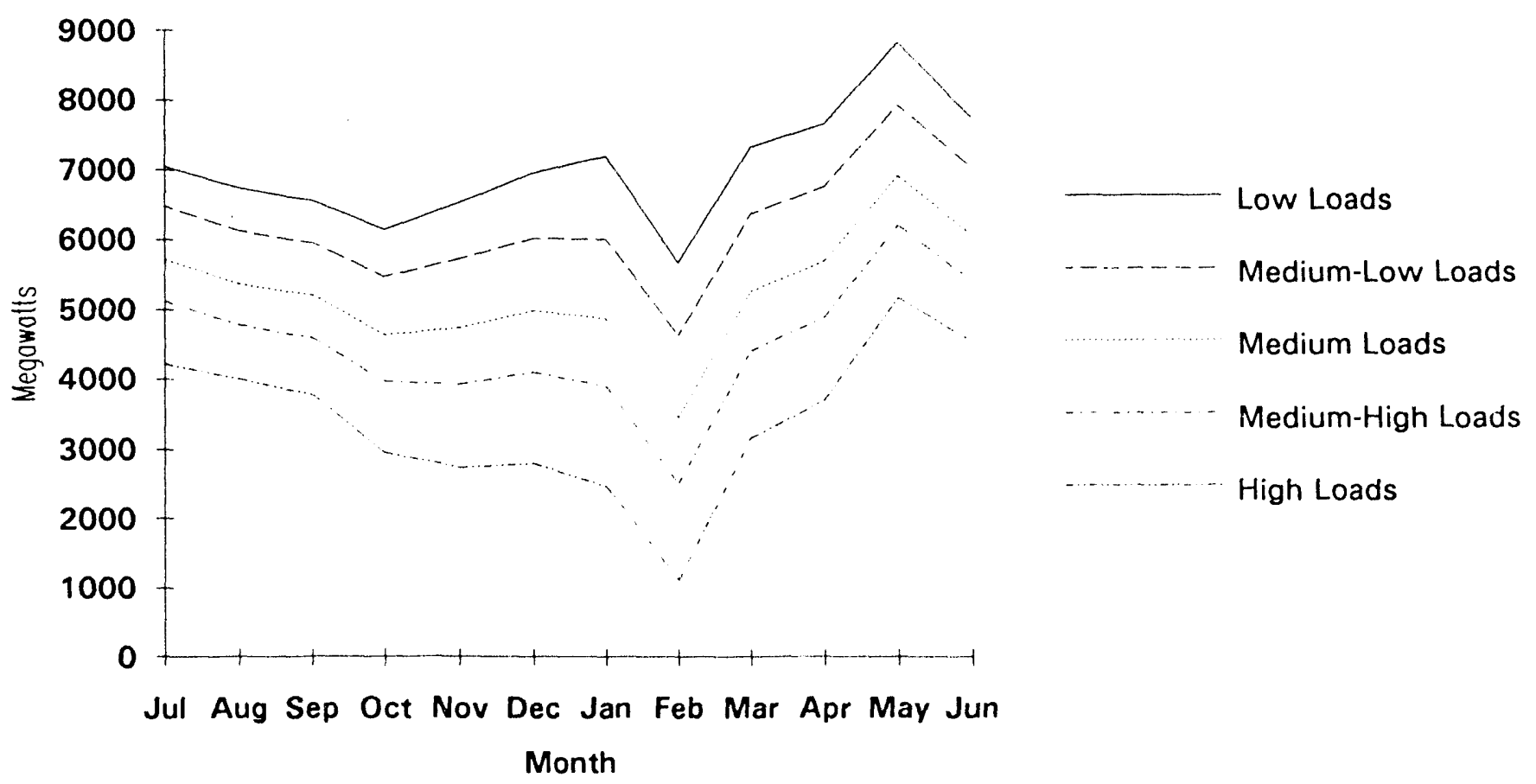


Figure 9

2.002-03 Federal Firm Capacity Surpluses/Deficits

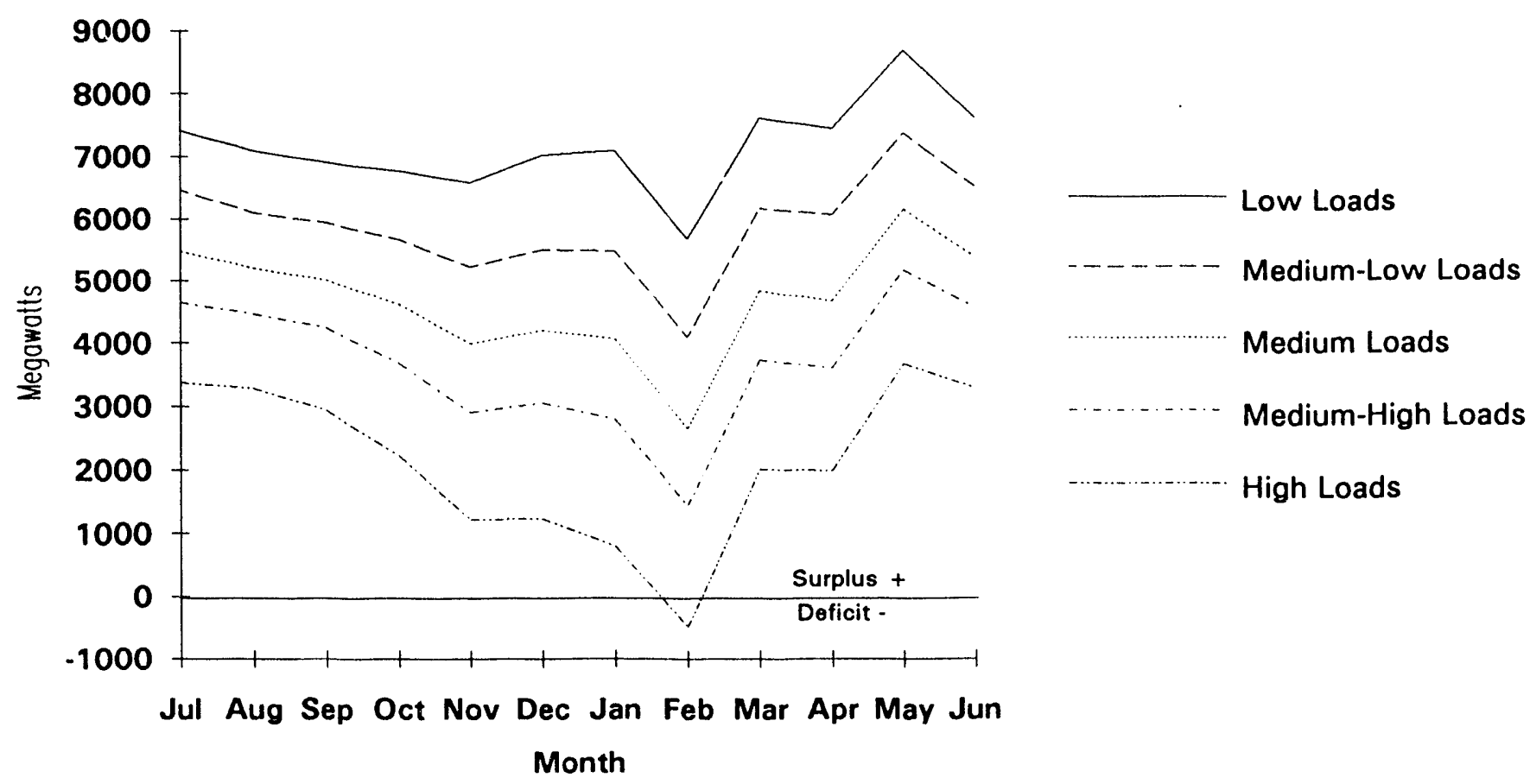

RPCE:11/91

Figure 10

2011-12 Federal Firm Capacity Surpluses/Deficits

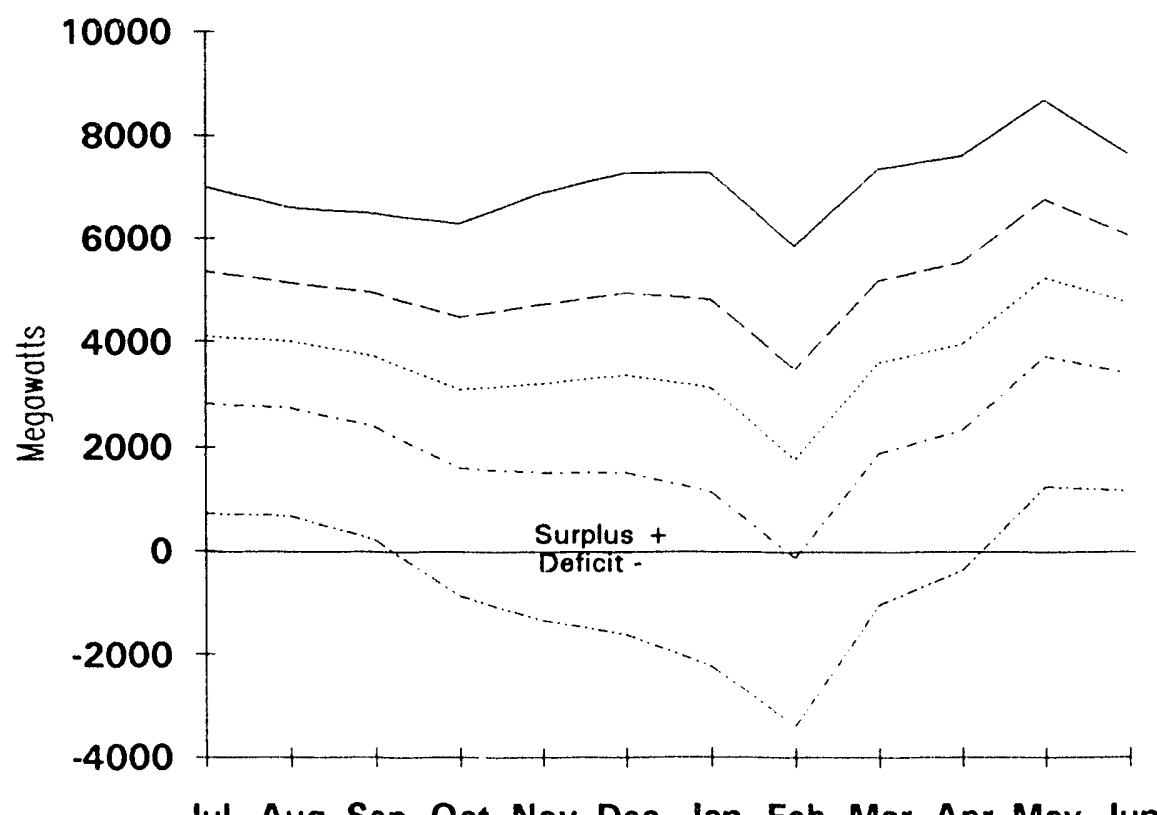

Low Loads

Medium-Low Loads

Medium Loads

Medium-High Loads

High Loads

Month 


\section{Federal System Marketable Capacity}

Despite the lack of long-term firm energy surpluses, the Federal system has surplus firm capacity lasting through the 20-year study period. Beginning with this analysis, new hydro constraints changed the monthly shape and sustained capacity of the hydro system. The changes include the following:

- The Corps and Bureau increased the minimum amount of reservoir storage in Libby, Hungry Horse, and Dworshak hydro projects. These new hydro constraints increase the probability that these reservoirs refill each year by limiting the availability of water which may be used from these projects to meet loads; and

- The adoption of the PNCA maximum shift philosophy in the first two years of the 4-year critical period. This increases loads and hydro resources in the first two years of the critical period and shapes the return of that energy into the last two years of the 4-year critical period.

These constraints decreased the flexibility of the hydro system during the critical period and changed the monthly shape of the Federal firm capacity surplus under 1929-30 water conditions.

Exhibit 6, page 77, shows the long-term 50-hours-per-week Federal surplus firm capacity under the medium load forecast. Currently, PGE has requested capacity service from BPA under its requirements power sales contract. BPA is also preparing an Environmental Impact Statement (EIS) for a long-term follow-on capacity sale contract with PP\&L. When PGE submits this load in its annual Firm Resource Exhibit of their power sales contract, and if BPA signs the PP\&L contract after completing the EIS, these contracts will become firm BPA obligations. Long-term annual surplus capacity sales will most likely be depleted with the completion of these contracts. Future BPA marketing may focus on seasonal contracts instead of annual sales. The diversity of loads in the Pacific Northwest and Southwest could allow BPA to develop a variety of capacity products to fit Southwest needs. These products may include seasonal capacity sales from 70 hours jer week to only a few hours per year.

The following assumptions were used in developing the Federal marketable capacity forecast under the medium load forecast:

- The region experiences medium load growth;

- The Pacific Northwest Coordination Agreement, which expires June 30,2003 , is replaced with a like agreement;

- BPA's power sales contracts with Pacific Northwest public and Federal agencies, IOUs, and DSIs, which expire June 30, 2001, are renewed with like agreements;

- All existing Federal contractual arrangements not included under Pacific Northwest power sales contracts expire and are not renewed;

- BPA's surplus firm power sales with Southern California Edison, Burbank, Glendale, and Pasadena remain as power sales for the duration of the contracts; 
- BPA's surplus firm power sale with M-S-R remains a power sale through October 31,2009 , then converts to a capacity/energy exchange until it expires;

- BPA's surplus firm power sale with Puget Sound Power and Light terminates and converts to a seasonal power exchange beginning in OY 2001-02, per the terms of the contract;

- The IOUs do not make long-term BPA purchases under their power sales contracts;

- Federal resource acquisitions include the Cowlitz Falls hydro project beginning in April 1994, and a seasonal purchase of PNGC's share of the Boardman coal plant through April 1995;

- Sustained capacity limits are 50 hours per week; and

- Surplus firm capacity availability does not reflect nighttime return problems.

It is important to note that the capacity surplus values do not reflect potential nighttime return problems on the Federal system. If peaking replacement energy from capacity sales is returned at night, the output of the hydro system and other Federal resources could be greater than BPA's nighttime load. Nighttime overgeneration is due to low Federal system loads, nonpower hydro constraints that require minimum streamflows, and the inability of BPA's thermal resources to cycle from day to night. These constraints restrict the ability to accept nighttime return energy, even though there is surplus generating capability during the daytime. These constraints are common in summer and fall, when BPA's nighttime loads are low and will greatly reduce sustained capacity surplus availability. Depending on provisions for return energy, capacity agreements could create forced energy sales, which may reduce the Federal system's ability to meet firm energy loads. BPA's future Federal surplus capacity transactions may include provisions to:

- Limit return energy to a percentage of contract demand;

- Defer energy returns to a time more favorable to system operations; or

- Request cash payment in lieu of return energy.

BPA's surplus firm capacity values take into account the following Federal system hydro constraints:

- Limitations on moving water between projects, including upstream storage;

- Pondage limitations due to hydraulic imbalance from reservoir to reservoir; and

- Navigation and recreation constraints, including restrictions on the rate of rise or fall of tailwater and forebay elevations. 
The Pacific Northwest Power Planning Council, BPA, and other Pacific Northwest entities are currently evaluating new ways to enhance fisheries and wild ife. These include amendments to the Council's fish and wildlife program, completion of the System Operation Review, and implementation of additional programs in support of the Endangered Species Act. The Council recently presented an amendment to cheir Columbia River Basin Fish and Wildife Program that would reduce operational firm energy load carrying capability (FELCC) by 73 average megawatts. The impacts of future proposals are unknown; they could, however, reduce the generating capability by as little as 50 or as much as several thousand average megawatts. These proposals will most likely increase constraints on the hydro system and reduce operating flexibility, change the monthly shape of streamflows, and change the availability of sustained Federal capacity. These impacts would be presented in future ana1yses.

\section{Federal System Loads and Resources Comparison}

Table 9, page 41, shows changes in the 1991 Pacific Northwest Loads and Resources Study compared to the 1990 Pacific Northwest Loads and Resources Study for OY 1992-93 through 2010-11. The table 1ists the Federal firm energy surpluses/deficits for the 1990 study and changes since last year to obtain the current firm energy surplus under the medium load forecast. Positive values in the table indicate an increase and negative values indicate a decrease in the Federal system firm energy surpluses. Federal planned resource acquisitions are not included as firm resources because they have not yet been contracted for. Similarly, resource options that BPA already has contractual rights to acquire, if needed, have not been included because $B P A$ may or may not exercise the options in any given year.

Changes were based on the following updates in loads, contracts, and resources:

\section{DSI Firm Loads}

The DSI aluminum loads assume favorable economic trends and a strong aluminum market. The near-term portion of the forecast reflects the temporary shutdown of Reynold's aluminum plant at Troutdale, Oregon, in the summer of 1991 . The long-term DSI load forecast is unchanged compared to last year's study. The non-aluminum loads increased in the short-term, due to the extended operation of Nickel Joint Venture.

\section{Sales to Generating Public Agencies}

Sales to the generating public agencies are increased by 215 average megawatts in the first year of the study, OY 1992-93, and increase by 324 average megawatts by OY 2010-11. This is the result of a 146 average megawatt increase in the load forecasts for the early 1990s, and a 286 average megawatt increase for $O Y$ 2010-11. The balance of the sales increase is due to decreases in the amount of resources dedicated by the generating public agencies to serve their loads--69 average megawatts in OY 1992-33 to 38 average megawatts by OY 2010-11--which increases BPA sales to these agencies through the 20-year study period. 


\section{Sales to Non-Generating Public Agencies}

This year's study shows increased sales to small and non-generating public agencies because higher forecasted loads result in these customers placing more load obligation on BPA. Forecasted loads are increased by 46 average megawatts in the first year, increasing by 152 average megawatts in the last year of the study. The resources BPA has estimated the non-generating utilities would use to serve their firm loads have increased by 19 average megawatts in OY 1992-93 and by 8 average megawatts by OY 2011-12 (this decreases BPA's obligation).

\section{Sales to Investor-0wned Utilities}

Puget Sound Power and Light Company, in accordance with their power sales contract with BPA, added a cogeneration resource for the period January 1 through June 30 of OY 1992-93, allowing them to reduce their OY 1992-93 purchase. The company added new purchases of 50 average megawatts for OY 1993-94 through 1997-98.

\section{Hydro Firm Energy}

Two events have changed the Federal system hydro firm energy from last year's study. First, a lower estimate of water drawn for irrigation increased streamflows, adding 39 average megawatts to Federal system firm energy. In addition, On January 28, 1991, BPA contracted for the output of the Cow1itz Falls hydro project. Cowlitz Falls has a rated capability of 70 megawatts and an annual generation of 22 average megawatts. The project is scheduled to begin operating in April 1994. The above increases were offset by decreased generation resulting from new constraints on the hydro system.

\section{Seasonal Purchase of Boardman Share}

BPA seasonally acquired the output of PNGC's share of the Boardman coal plant for October through April of OY 1991-92, and September through Apri1 for OY 1992-93 through 1994-95. BPA purchased 50 megawatts of capacity and 28 average megawatts of energy.

\section{Trojan Nuclear Power Plant}

The capacity factor on the Trojan nuclear plant was reduced from 70 percent to 65 percent for this stucy. This results in a 19-average-megawatt loss of BPA's 30-percent share of the plant. During the 1991 maintenance outage, Trojan operators discovered unexpected corrosion of mechanisms in the steam generators. Portland General Electric Company is contemplating replacing the steam generators during 1995 or 1996. The interim period will be marked by uncharacteristic operation and refueling schedules, with extended outages to facilitate steam generator inspection and repairs.

\section{Miscellaneous Changes}

The miscellaneous changes in this year's study include revised USBR and Federal agency loads, and revised transmission losses. 
Table 9

\section{Changes in Federal System Firm Surplus/Deficit Medium Load Forecast}

\section{Energy in Average Megawatts}

\begin{tabular}{|c|c|c|c|c|c|c|c|c|c|c|}
\hline Operat ing Year $1 /$ & 1993 & 1994 & 1995 & 1996 & 1997 & 1998 & 1999 & 2000 & 2001 & 2002 \\
\hline $\begin{array}{l}1990 \text { Federal Firm } \\
\text { Surplus/Deficit } 2 /\end{array}$ & -266 & -226 & -280 & -344 & -89 & -172 & -312 & -509 & -586 & -608 \\
\hline $\begin{array}{l}\text { Changes: } \\
\text { DSI Firm Loads }\end{array}$ & 7 & -124 & -47 & 0 & 0 & 0 & 0 & 0 & 0 & 0 \\
\hline Sales to Generating & & & & & & & & & & \\
\hline $\begin{array}{l}\text { Publics } \\
\text { Sales to Nongen Publics }\end{array}$ & $\begin{array}{r}-215 \\
-27\end{array}$ & $\begin{array}{r}-212 \\
-18\end{array}$ & $\begin{array}{r}-202 \\
-30\end{array}$ & $\begin{array}{r}-209 \\
-27\end{array}$ & $\begin{array}{r}-218 \\
-31\end{array}$ & $\begin{array}{r}-226 \\
-37\end{array}$ & $\begin{array}{r}-230 \\
-45\end{array}$ & $\begin{array}{r}-236 \\
-51\end{array}$ & $\begin{array}{r}-236 \\
-56\end{array}$ & $\begin{array}{r}-246 \\
-62\end{array}$ \\
\hline Sales to IOUs & 62 & -50 & -50 & -50 & -50 & -50 & 0 & 0 & 0 & 0 \\
\hline Hydro Firm Energy & -1 & 7 & 20 & 20 & 20 & 20 & 20 & 20 & 20 & 20 \\
\hline Boardman & 28 & 28 & 28 & 0 & 0 & 0 & 0 & 0 & 0 & 0 \\
\hline Trojan Adjustment & -19 & -19 & -19 & -19 & -19 & -19 & -19 & -19 & -19 & -19 \\
\hline Miscellaneous Changes & 4 & 1 & -1 & -1 & 1 & -1 & 1 & -1 & $\underline{0}$ & $\underline{0}$ \\
\hline TOTAL CHANGES & -161 & -387 & -301 & -286 & -297 & -313 & -273 & -287 & -291 & -307 \\
\hline $\begin{array}{l}1991 \text { Federal Firm } \\
\text { Surplus/Deficit }\end{array}$ & -427 & -613 & -581 & -630 & -386 & -485 & -585 & -796 & -877 & -915 \\
\hline
\end{tabular}

\begin{tabular}{|c|c|c|c|c|c|c|c|c|c|}
\hline Operating Year $1 /$ & 2003 & 2004 & 2005 & 2006 & 2007 & 2008 & 2009 & 2010 & 2011 \\
\hline $\begin{array}{l}1990 \text { Federal Firm } \\
\text { Surplus/Deficit } 2 /\end{array}$ & -713 & -916 & -1007 & -1168 & -1307 & -1386 & -1394 & -1356 & -1329 \\
\hline $\begin{array}{l}\text { Changes: } \\
\text { DSI Firm Load }\end{array}$ & 0 & 0 & 0 & 0 & 0 & 0 & 0 & 0 & 0 \\
\hline Sales to Generating & & & & & & & & & \\
\hline Publics & -265 & -268 & -271 & -284 & -278 & -288 & -302 & -298 & -324 \\
\hline Sales to Nongen Publics & -71 & -78 & -87 & -96 & -106 & -112 & -114 & -114 & -144 \\
\hline Sales to IOUs & 0 & 0 & 0 & 0 & 0 & 0 & 0 & 0 & 0 \\
\hline Hydro Firm Energy & 20 & 20 & 20 & 20 & 20 & 20 & 20 & 20 & 20 \\
\hline Boardman & 0 & 0 & 0 & 0 & 0 & 0 & 0 & 0 & 0 \\
\hline Trojan Adjustment & -19 & -19 & -19 & -19 & -19 & -19 & -19 & -19 & -19 \\
\hline Miscellaneous Changes & 0 & -1 & 2 & -2 & -1 & 1 & -49 & -42 & 64 \\
\hline TOTAL CHANGES & -335 & -346 & -355 & -381 & -384 & -398 & -464 & -453 & -403 \\
\hline $\begin{array}{l}1991 \text { Federal Firm } \\
\text { Surplus/Deficit }\end{array}$ & -1048 & -1262 & -1362 & -1549 & -1691 & -1784 & -1858 & -1809 & -1732 \\
\hline
\end{tabular}

$1 /$ Operating Year (OY) is the 12 -month period July 1 to June 30. For example, OY 1992 is July 1, 1991 through June 30, 1992.

2/ 1990 Pacific Northwest Loads and Resources Executive Summary, Table 6, page 26. 


\section{REGIONAL ANALYSIS}

The regional loads and resources analysis is based on the following assumptions :

- The Pacific Northwest Coordination Agreement, which expires June 30,2003 , is replaced with a like agreement;

- BPA's power sales contracts with Pacific Northwest Federal and public agencies, IOUs, and DSIs, which expire June 30, 2001, are renewed with like agreements;

- Al1 existing regional contractual arrangements not included under Pacific Northwest power sales contracts expire and are not renewed; and

- A11 Federa1 Southwest surplus firm power sales, except M-S-R, are shown as power sales through their expiration. $M-S-R$ is shown as a power sale through October 31,2009 , then converts to a capacity/ energy exchange until it expires.

\section{Regional Firm Energy Loads}

The regional firm energy load projections for OY 1992-93 through 2011-12 under the high, medium-high, medium, medium-low, and low load growth scenarios are shown in Figure 11, page 43. The load forecast is based on the 1991 Joint Forecast prepared by BPA and the Council. The 1991 Joint Forecast reflects updated long-range projections of economic activity, fuel and electricity prices, and other factors influencing electricity use. The 1991 Joint Forecast contains more optimistic projections of regional employment, slightly lower retail electricity prices, and relatively unchanged fossil fuel price projections, and is generally higher than the 1990 Joint Forecast. The exception is in the high case, where a slightly lower DSI forecast, coupled with savings attributable to Federal Appliance Standards and the adoption of the Model Conservation Standards (MCS) in Oregon and Washington, result in a slightly lower high case forecast through 2000. The load projections also include all intra-regional contracts made by Pacific Northwest utilities and the Federal system. The average annual rates of growth for the period from OY 1992-93 through 2011-2012 are summarized in Table 10, page 44. The regional firm energy loads for the medium forecast are presented in Exhibit 11, line 5, pages 84 and 85 . The regional firm energy loads under the high, medium-high, medium-1ow, and low forecasts are presented on line 5 of Exhibits 12 through 15, pages 86 through 93. 

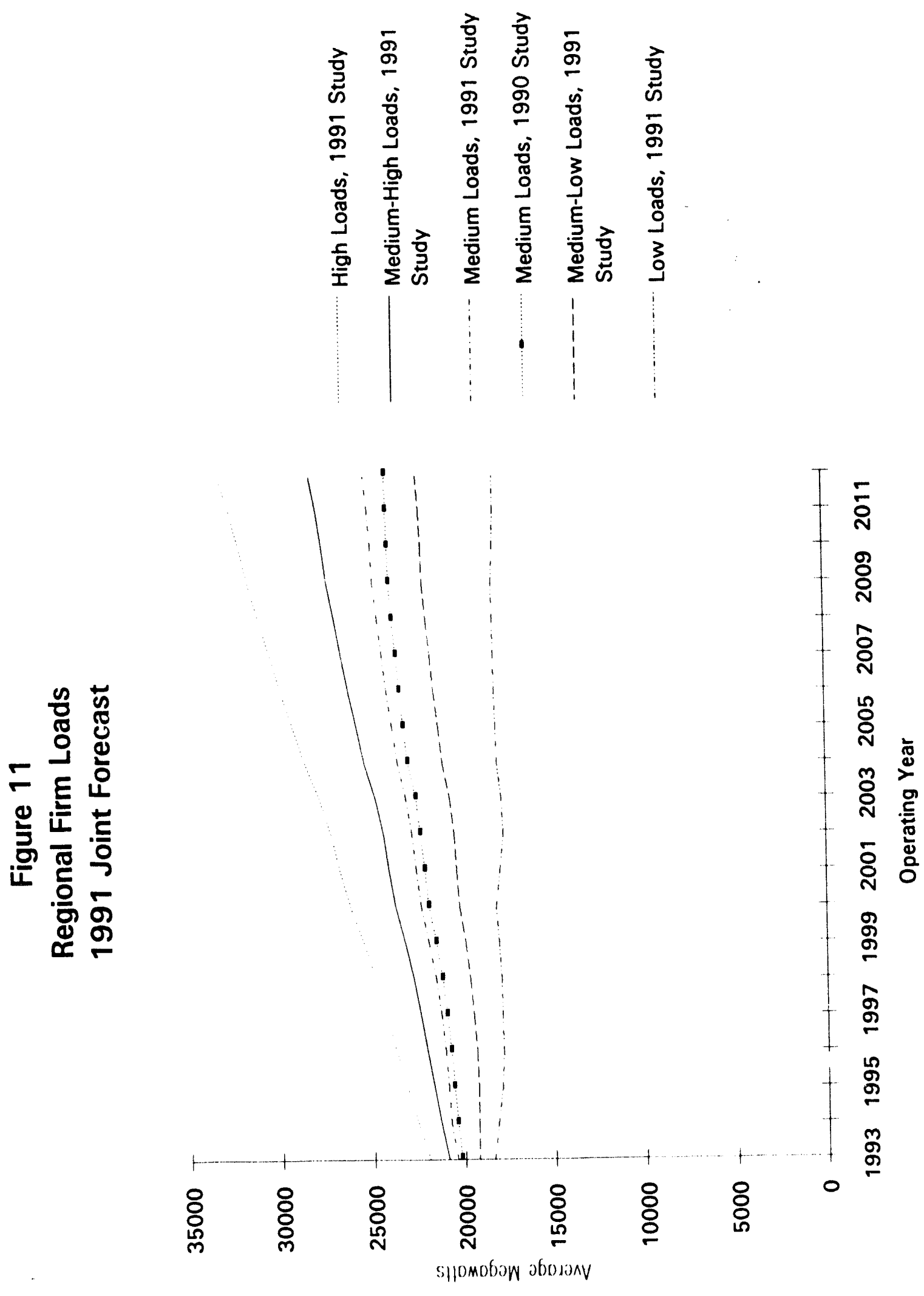
Table 10

Regional Firm Loads

Energy in Average Megawat ts

\begin{tabular}{|c|c|c|c|c|c|c|c|}
\hline \multirow[b]{2}{*}{$\begin{array}{l}\text { Load } \\
\text { Forecast }\end{array}$} & \multicolumn{3}{|c|}{ OY 1992-93 1/ } & \multicolumn{3}{|c|}{ OY 2011-12 } & \multirow{2}{*}{$\begin{array}{l}\text { System Firm } \\
\text { Load Growth } \\
\text { (Avg \%/yr) }\end{array}$} \\
\hline & $\begin{array}{l}\text { System } \\
\text { Loads }\end{array}$ & $\begin{array}{c}\text { Firm } \\
\text { Exports }\end{array}$ & $\begin{array}{l}\text { Firm } \\
\text { Loads }\end{array}$ & $\begin{array}{l}\text { System } \\
\text { Loads }\end{array}$ & $\begin{array}{c}\text { Firm } \\
\text { Exports }\end{array}$ & $\begin{array}{l}\text { Firm } \\
\text { Loads }\end{array}$ & \\
\hline High & 21,144 & 796 & 21,940 & 32,395 & 798 & 33,193 & 2.2 \\
\hline Medium-High & 20,117 & 796 & 20,913 & 27,357 & 798 & 28,155 & 1.3 \\
\hline Medium & 19,627 & 796 & 20,423 & 24,388 & 798 & 25,186 & 1.1 \\
\hline Medium-Low & 18,455 & 796 & 19,251 & 21,484 & 798 & 22,282 & 0.8 \\
\hline Low & 17,598 & 796 & 18,394 & 17,263 & 798 & 18,061 & -0.1 \\
\hline
\end{tabular}

1/ Operating Year (OY) is the 12-month period July 1 to June 30. For example, OY 1993 is July 1, 1992 through June 30, 1993.

\section{Regional Firm Peak Loads}

Figure 12, page 45, illustrates the regional firm peak loads under the medium load forecast for OY 1992-93, 1997-98, 2002-03, and 2011-12, based on the 1991 Draft Joint Forecast. The forecasted peak load is the expected maximum 1 -hour peak demand for each month. There is a 50 percent probability that the actual load will be either higher or lower at some time during the month. The projected regional peak loads include all intra-regional contracts made by Pacific Northwest utilities, including the Federal system. The peak projections are decreased by a diversity factor due to the fact that all peak electrical demands do not occur simultaneously throughout the region. 
Figure 12

Regional Firm Peak Loads

Medium Loads

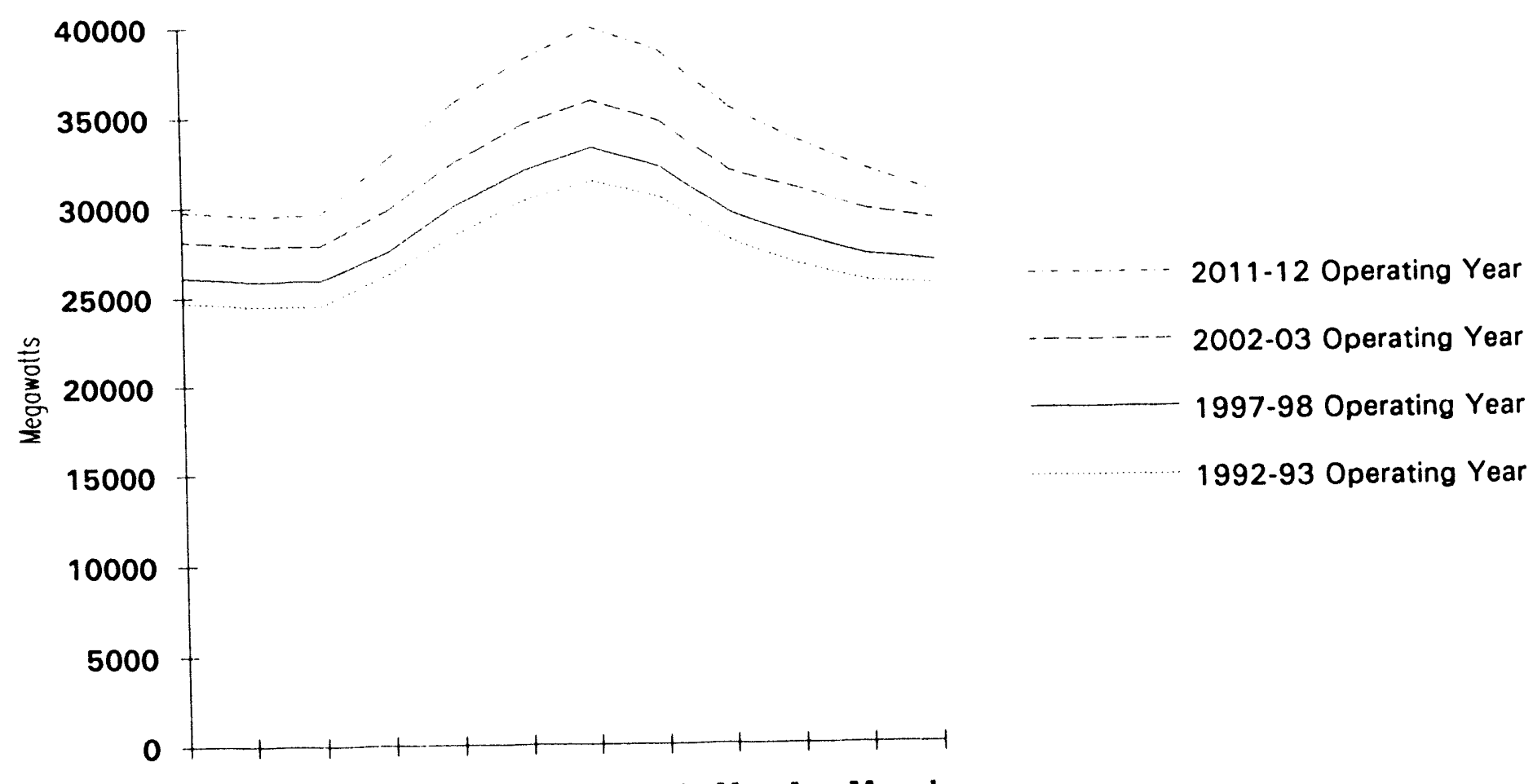

Jul Aug Sep Oct Nov Dec Jan Feb Mar Apr May Jun

Month

\section{Regional Firm Resources}

Table 11, page 46, summarizes the regional system resources for oY 1992-93. Hydro-electric resources make up a smaller percentage of the regional resources than of the Federal system resources because most of the thermal resources are owned by utilities in the region. These thermal resources are composed primarily of IOU-owned coal and nuclear plants. A detailed listing of all regional generating resources is contained in the 1991 Pacific Northwest Loads and Resources Technical Appendix: Volume 2 . 
Table 11

\section{Regional Firm Resources}

for OY 1992-93 1 '

\begin{tabular}{lcccc}
\hline $\begin{array}{c}\text { Project } \\
\text { Type }\end{array}$ & $\begin{array}{c}\text { Generating } \\
\text { Peak Capacity } \\
\text { (MW) }\end{array}$ & $\begin{array}{c}\text { Generating } \\
\text { Peak Capacity } \\
\text { \% of Total }\end{array}$ & $\begin{array}{c}\text { Firm Energy } \\
\text { (aMW) }\end{array}$ & $\begin{array}{c}\text { Firm Energy } \\
\% \text { of Total }\end{array}$ \\
\hline & & & & \\
Hydro & & & & \\
Coa1 & 32,071 & 74 & 12,442 & 62 \\
Nuclear & 4,384 & 10 & 3,670 & 18 \\
Imports & 2,199 & 5 & 1,433 & 8 \\
Combustion Turbines & 2,453 & 6 & 1,597 & 2 \\
Miscellaneous & 1,466 & 3 & 485 & 3 \\
Total Resources & $\mathbf{7 9 9}$ & $\underline{2}$ & $\mathbf{5 9 4}$ & $\mathbf{3}$ \\
\hline
\end{tabular}

1/ Operating Year (OY) is the 12-month period July 1 to June 30 . For example, OY 1993 is July 1, 1992 through June 30, 1993.

\section{Regional Nonf irm Resources}

As previously discussed, BPA uses critical water flows to compute the regional hydro firm energy for resource planning. Nonfirm energy is created when the region's hydro projects experience water flows greater than critical period levels.

Regional planning does not include nonfirm energy in the loads and resources balance. Nonfirm energy can vary from zero in the worst water year, to as much as 8,300 average megawatts in the best water year. The average annual nonfirm energy increases regional resources by about 3,800 average megawatts when averaged over 50 years of historical water flows, and is larger when averaged over 102 years of historical water flows. 


\section{Regional Firm Energy Surpluses/Deficits}

Figure 13, shown below, illustrates the variability of the regional firm energy loads and resources under the high, medium-high, medium, medium-low, and low load forecasts. The resources change over time due to yearly scheduled maintenance and the expiration of intra-regional contracts.

The regional firm energy surpluses/deficits for the various load forecasts for OY 1992-93 through 2011-12 are presented in Table 12, page 48, and graphically in Figure 14, page 49. The region experiences firm energy deficits in OY 1992-93 under the medium, medium-high, and high load forecasts, and in OY 1999-2000 under the medium-low load case. The region remains firm energy surplus under the low load forecast.

\section{Figure 13}

\section{Regional Firm Energy Loads and Resources}

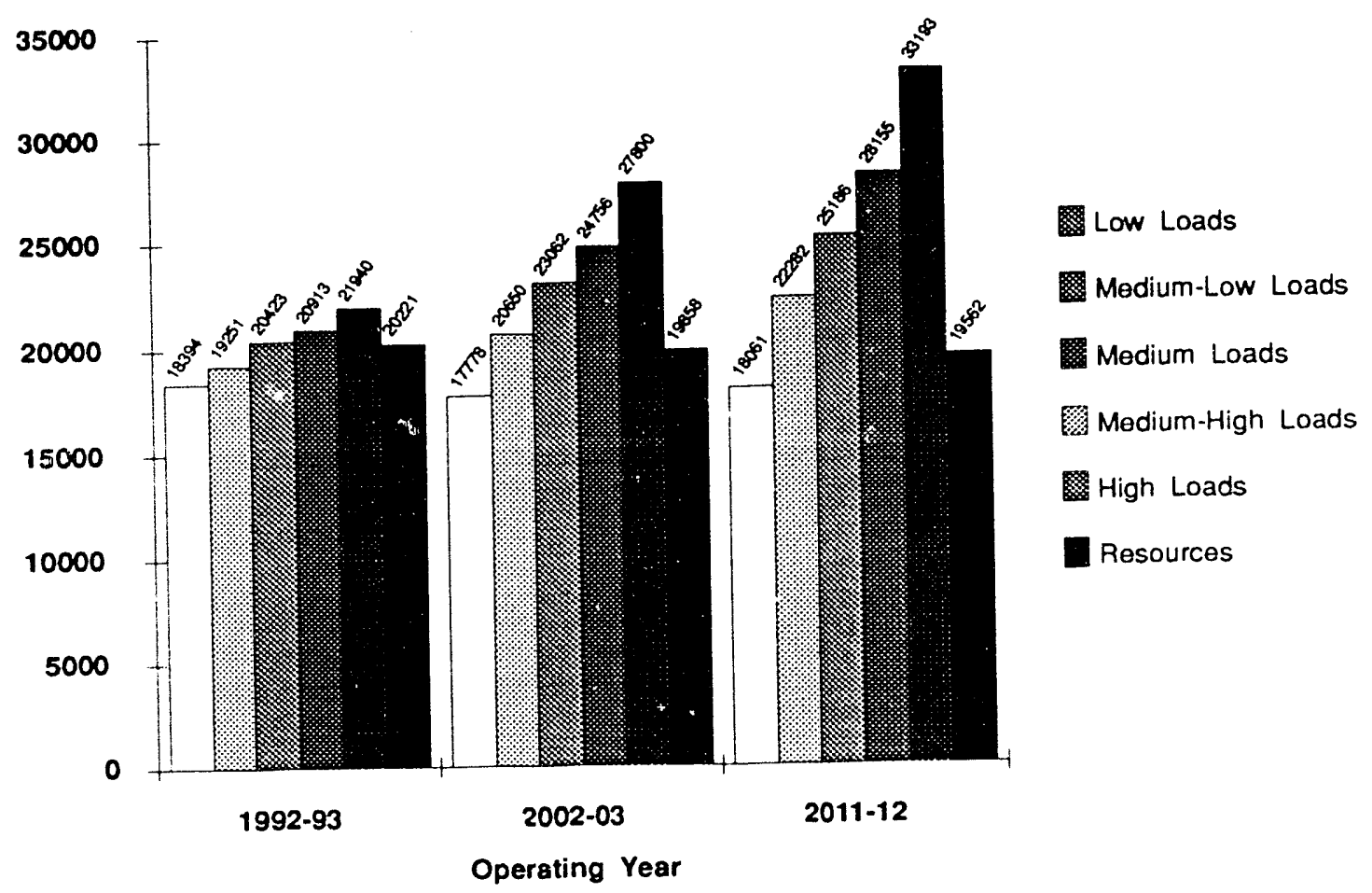

RPCE: $: 1 / 91$

The components of the regional energy loads and resources balances for the five load scenarios are presented in Exhibits 11 through 15 , pages 84 through 93. The regional firm energy surpluses/deficits, based on the medium forecast, are presented in Exhibit 11, 1 ine 34, pages 84 and 85 . The 20-year regional firm energy surpluses/deficits under the high, medium-high, medium-low, and low load forecasts are shown on line 34 of Exhibits 12 through 15 , pages 86 through 93. 
Table 12

\section{Regional Firm Energy Surpluses/Deficits}

Assuming Existing Contracts

Energy in Average Megawatts

\begin{tabular}{lrrrrrrrrrr}
\hline OPERATING YEAR 1/ & $\mathbf{1 9 9 3}$ & $\mathbf{1 9 9 4}$ & $\mathbf{1 9 9 5}$ & $\mathbf{1 9 9 6}$ & $\mathbf{1 9 9 7}$ & $\mathbf{1 9 9 8}$ & $\mathbf{1 9 9 9}$ & $\mathbf{2 0 0 0}$ & $\mathbf{2 0 0 1}$ & $\mathbf{2 0 0 2}$ \\
\hline & & & & & & & & & & \\
High Loads & -1678 & -2301 & -2932 & -3632 & -4100 & -4621 & -5315 & -6017 & -6557 & -7137 \\
Medium-High Loads & -688 & -1116 & -1495 & -1972 & -2234 & -2587 & -3129 & -3635 & -3963 & -4384 \\
Medium Loads & -214 & -599 & -750 & -1033 & -1162 & -1403 & -1844 & -2259 & -2495 & -2849 \\
Medium-Low Loads & 922 & 873 & 858 & 640 & 575 & 429 & 99 & -210 & -350 & -615 \\
Low Loads & 1755 & 1927 & 2157 & 2088 & 2148 & 2120 & 1915 & 1772 & 1987 & 2067 \\
& & & & & & & & & & \\
\hline
\end{tabular}

1/ Operating Year (OY) is the 12 -month period July 1 to June 30 . For example, OY 1993 is July 1, 1992 through June 30, 1993. 


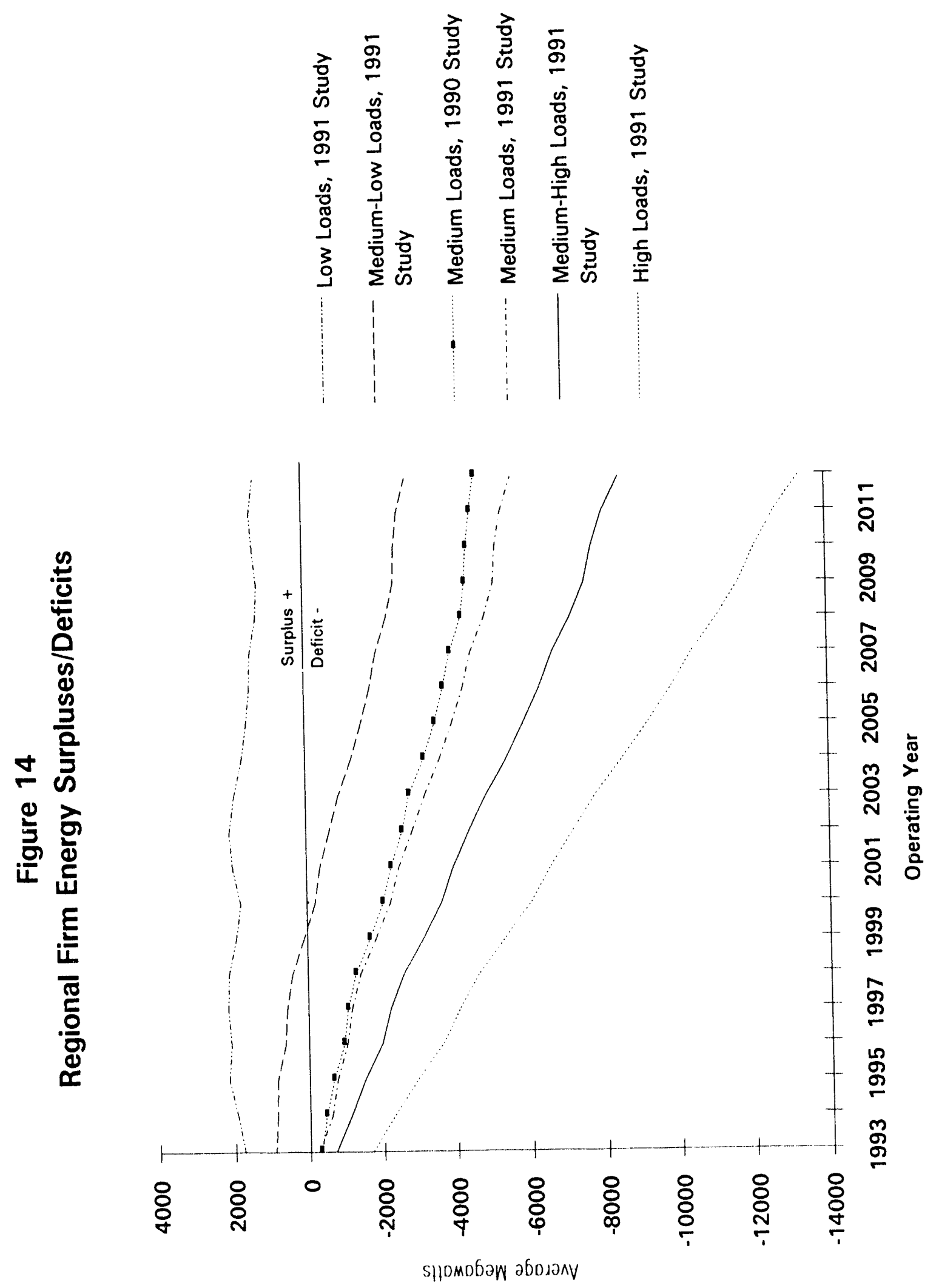




\section{Regional Firm Capacity Surpluses/Deficits}

Figures 15 through 18, pages 51 and 52, show the region's firm 50-hour-perweek capacity surpluses/deficits under the high, medium-high, medium, medium-10w, and low load forecasts for OY 1992-93, 1997-98, 2002-03, and 2011-12. The monthly capacity surpluses/deficits assume that the region has the ability to meet a capacity load of 50 hours per week using surplus capacity that is available after serving all regional capacity needs with 1929-30 water levels.

These projections estimate the 50-hours-per-week capacity that is surplus to regional requirements. The figures assume that contractual or other provisions would be made to relieve off-peak problems when energy is returned under future capacity sales. Regional hydro constraints and low nighttime loads limit the system's ability to store return energy. One of the most frequent constraints on capacity sales is the nighttime return of energy when the hydro system is forced to maintain minimum streamflows. This is especially critical during summer and early fall months, when regional loads are low. Depending on energy return provisions, these contracts could create low-priced forced energy sales and may reduce the region's ability to meet firm loads.

The hydro analysis for this year's study used all operating constraints currently adopted by the hydroelectric project owners. Many of these constraints were added to the system in support of the Pacific Northwest Power Planning Council's fish flow program. Constraints placed on the hydro system over the past 10 years to enhance fish flows have decreased the firm energy by approximately 400 average megawatts.

The Pacific Northwest Power Planning Council, BPA, and other Pacific Northwest entities are currently evaluating new ways to enhance fisheries and wildlife. These include amendments to the Council's fish and wildlife program, completion of the System Operation Review, and implementation of additional programs in support of the Endangered Species Act. The Council recently presented an amendment to their Columbia River Basin Fish and Wildlife Program that would reduce operational firm energy load carrying capability (FELCC) by 73 average megawatts. The outcome of future proposals are unknown; they could, however, reduce the generating capability by as 1 ittle as 50 or as much as several thousand average megawatts. BPA does not expect the potential impacts to approach the high end of the range of estimates. These proposals, however, will most likely increase constraints on the hydro system and reduce operating flexibility, change the monthly shape of sustained capacity availability. These impacts would be presented in future analyses.

The 20-year summary of regional capacity surpluses/deficits, based on medium loads, is shown in Exhibit 16, page 97. The regional 20-year summaries of capacity surpluses/deficits under high, medium-high, medium-low, and low loads are presented in Exhibits 17 through 20, pages 98 through 101. 
Figure 15

1992-93 Regional Firm Capacity Surpluses/Deficits

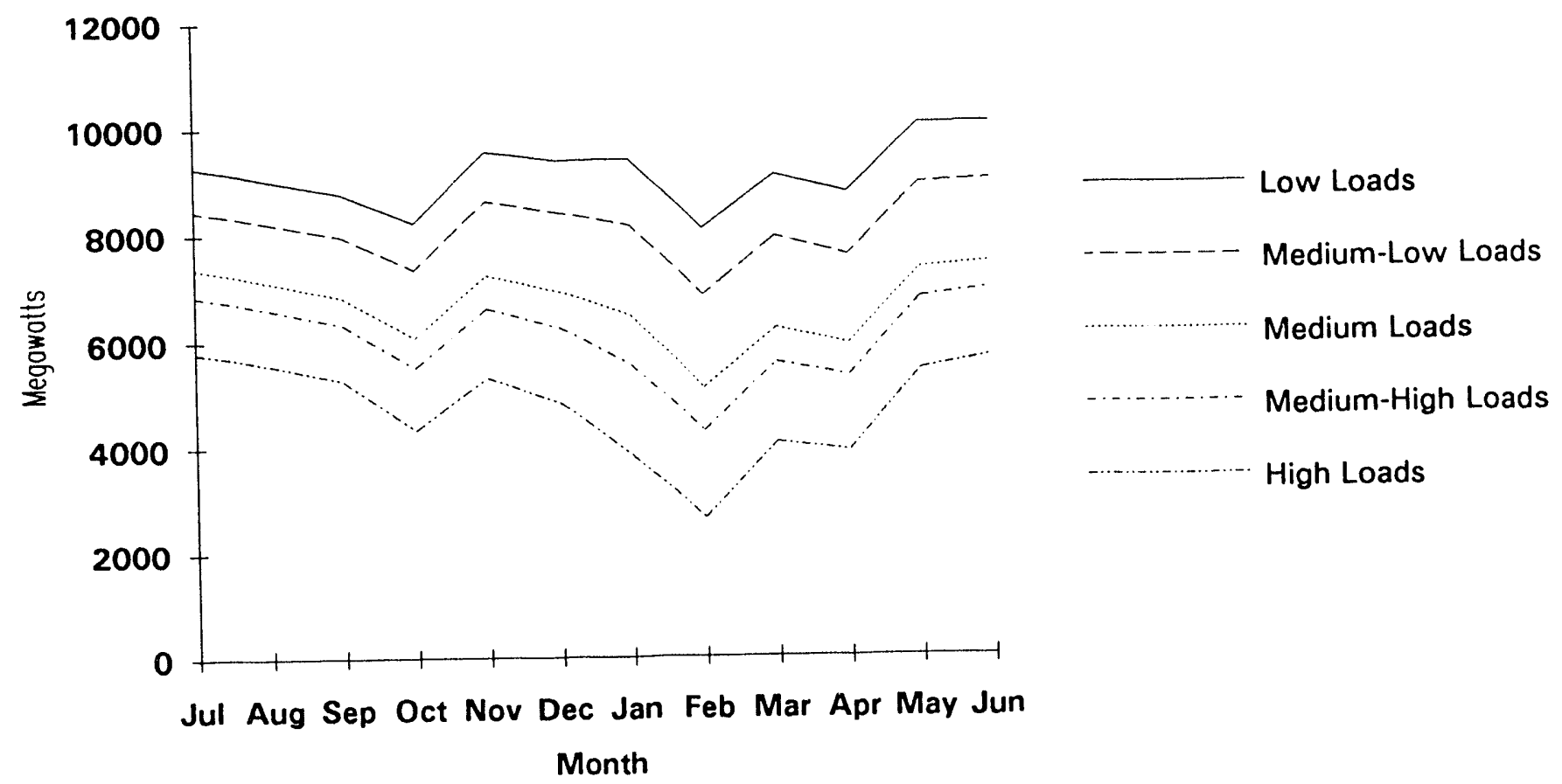

RPCE:11/91

Figure 16

1997-98 Regional Firm Capacity Surpluses/Deficits

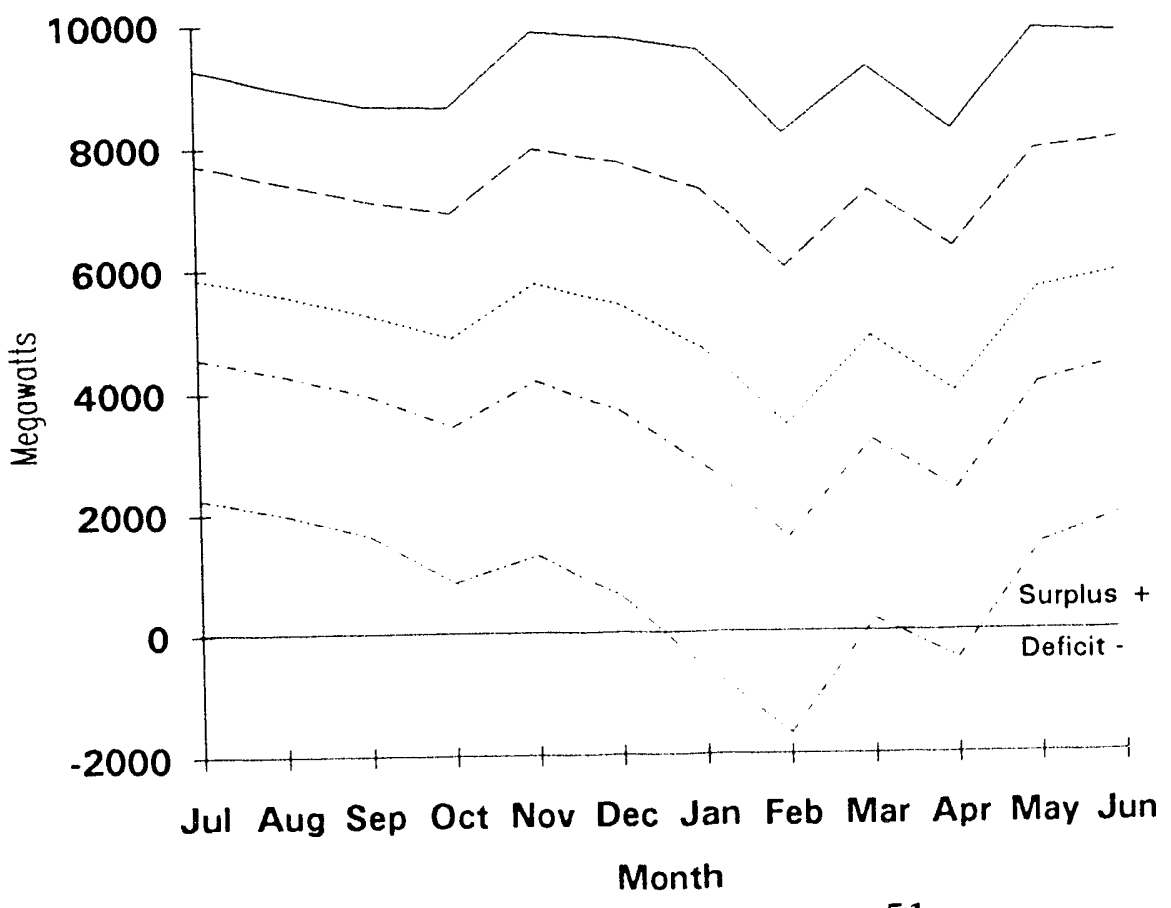

Low Loads

Medium-Low Loads

Medium Loads

Medium-High Loads

High Loads 
Figure 17

2002-03 Regional Firm Capacity Surpluses/Deficits

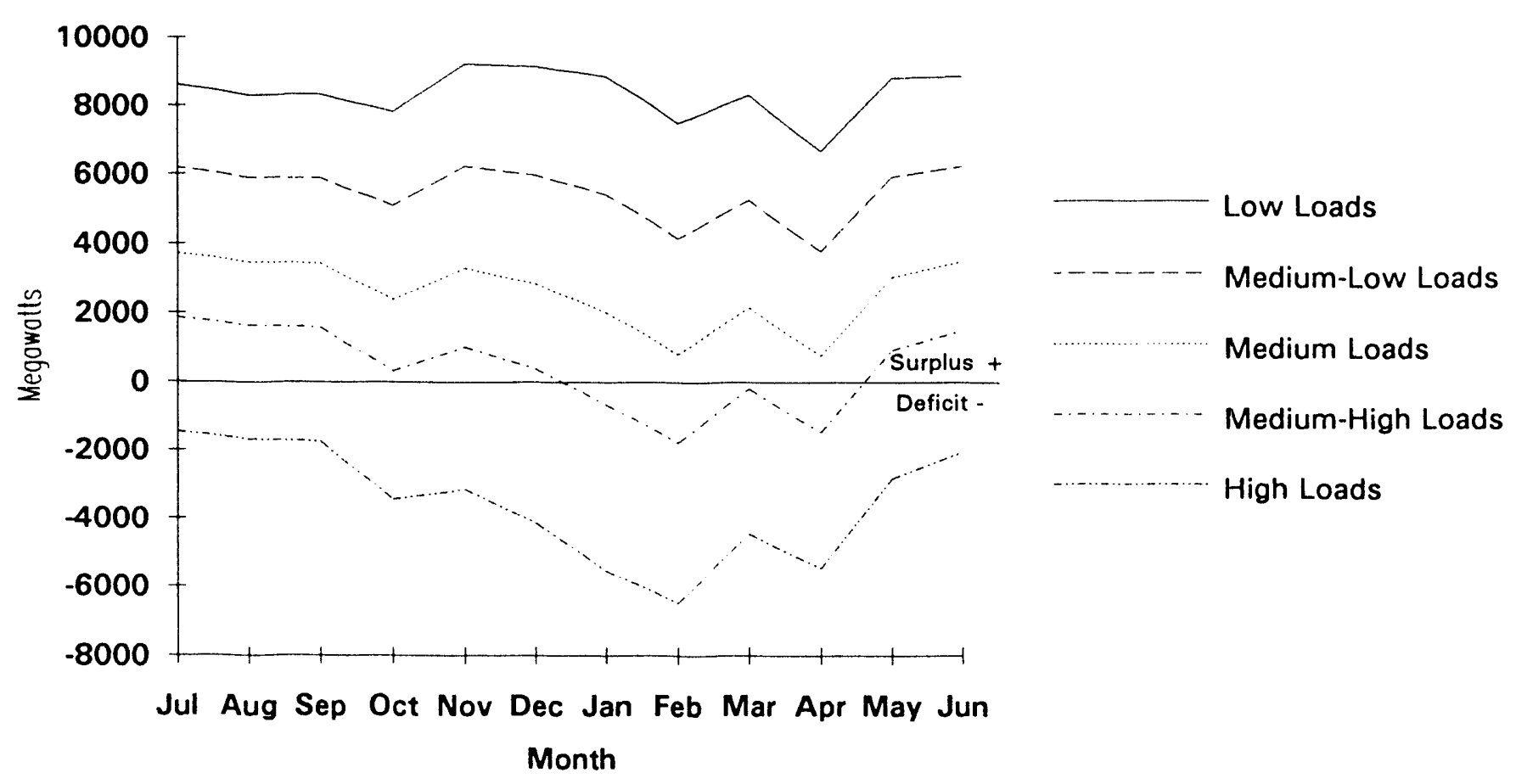

RPCE: $11 / 91$

Figure 18

2011-12 Regional Firm Capacity Surpluses/Deficits

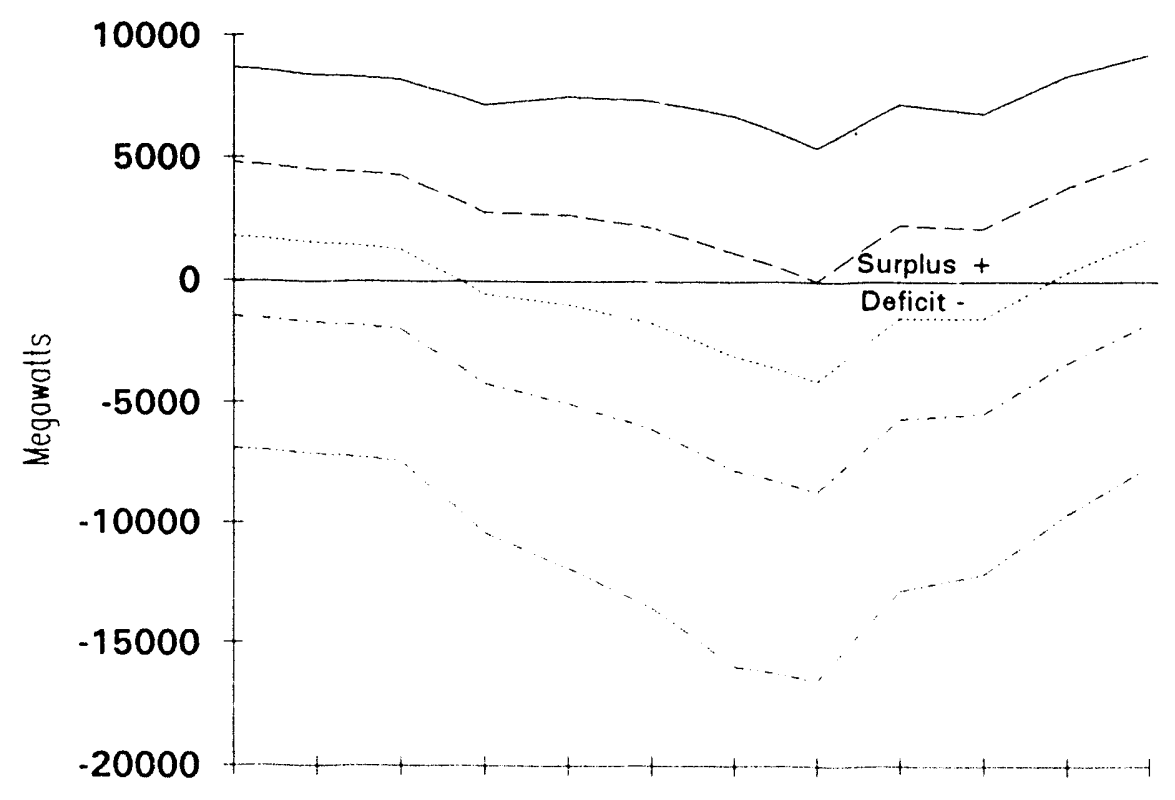

Low Loads

Medium-Low Loads

Medium Loads

Medium-High Loads

High Loads

Jul Aug Sep Oct Nov Dec Jan Feb Mar Apr May Jun

Month 


\section{SECTION VI}

FEDERAL SYSTEM EXHIBITS 


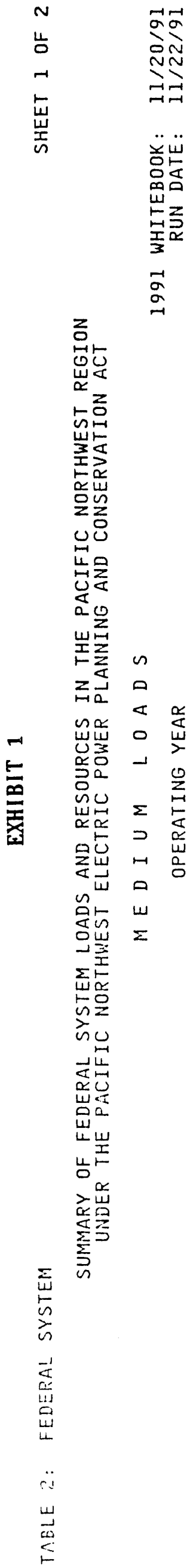

$N$ I anomston Im

@:

กีt

nnim $m$

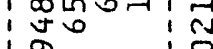

号

i

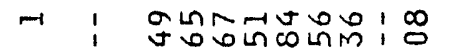

ज̦

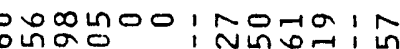

官帘

InM $m$

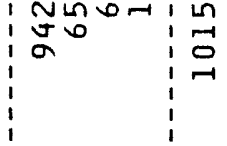

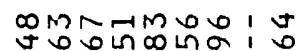

0

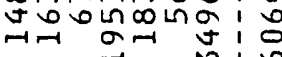

à

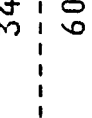

งกำกับ

ज्ञ며:

เกตกN

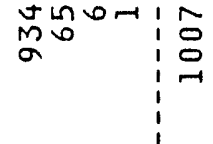

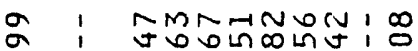

का

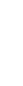

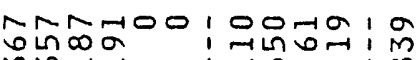

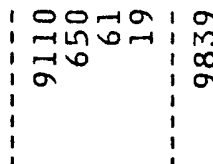

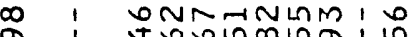

i!

a

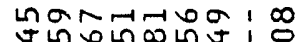

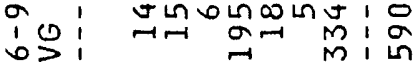

ڤखㅝ

$\rightarrow$

o

1

TLก

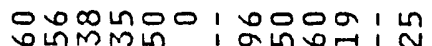

NMNN $: a^{2}$

nूय

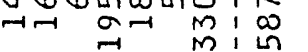

m $N$ NoO

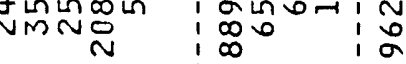

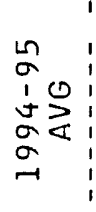

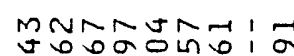

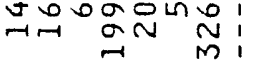

5
$\vdots$
1
2
2
$a$
1

Non

NoñõOLIO

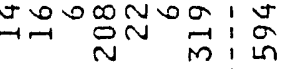

NNㄴํำ

Nỡ

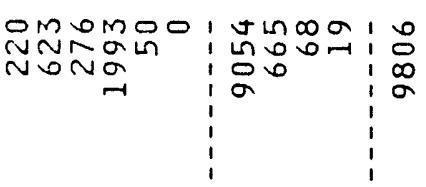

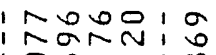

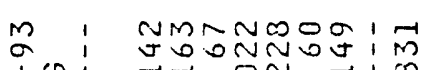

인

$\rightarrow-\stackrel{O}{N} \vec{m} !$

onNoOO

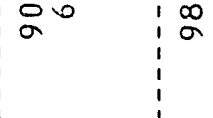

\begin{tabular}{l|l|l}
$r \operatorname{lin} \sigma$ & $\infty$ & $\infty$ \\
& $\infty$ & 0
\end{tabular}
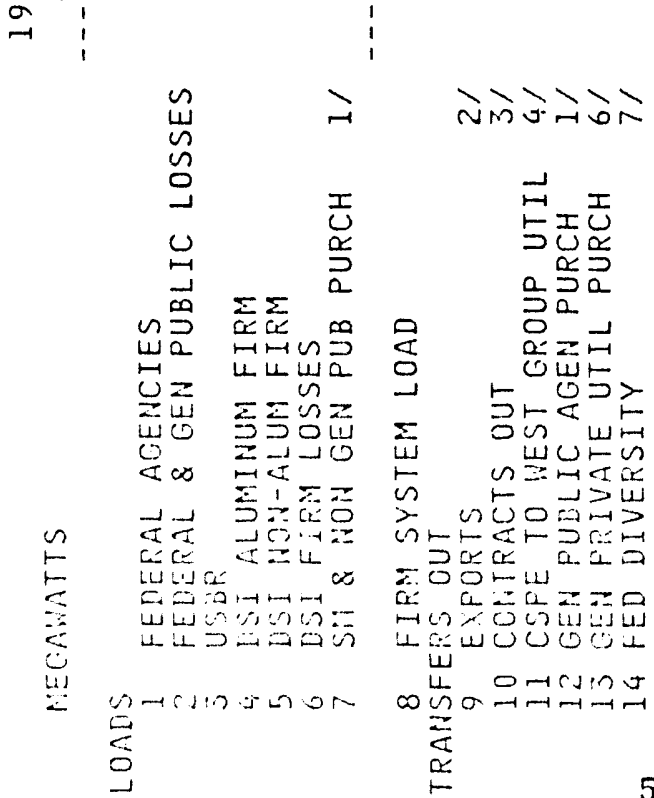

\rangle$\left._{\infty}\right\rangle$

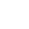

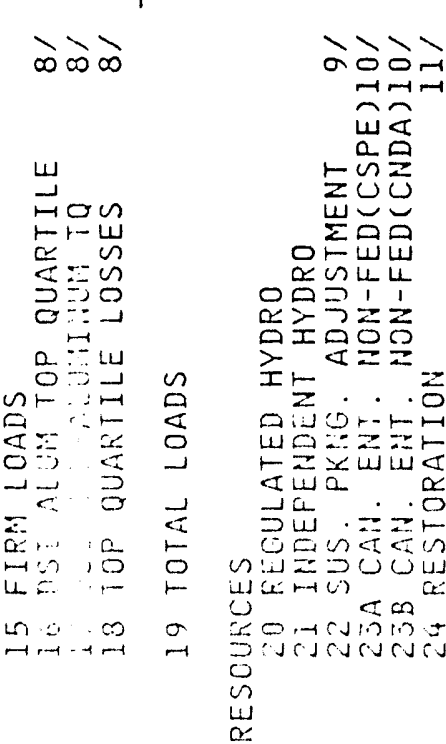

54

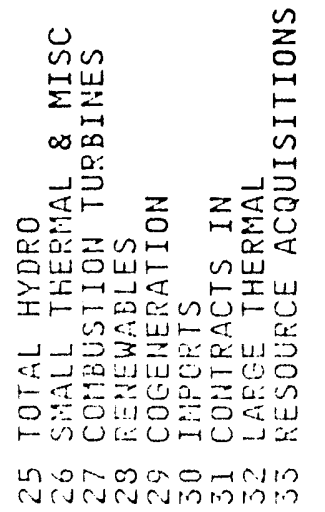

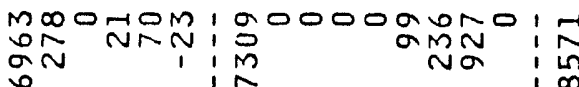

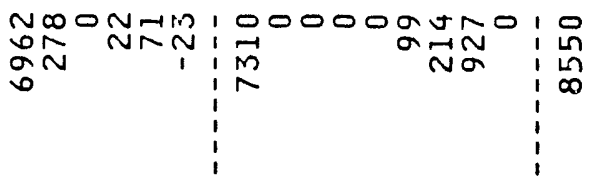

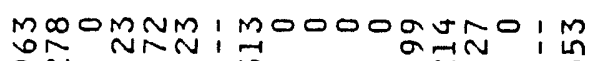

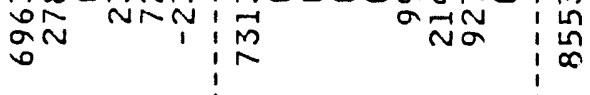

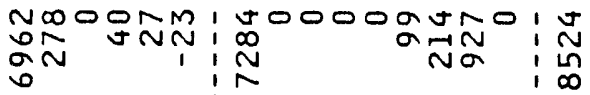

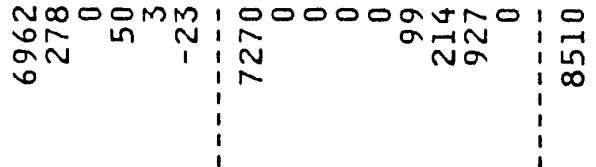

NoOUDM:

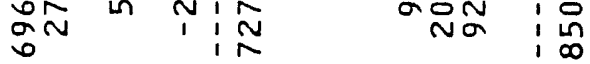

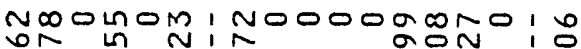

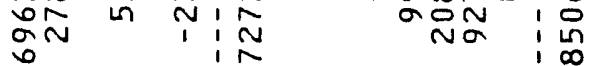

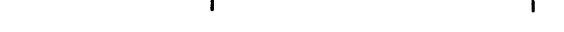

No0000m, LOOOOOGMLO, N

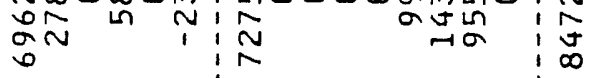

NONOM, 00000 OMLOI

å

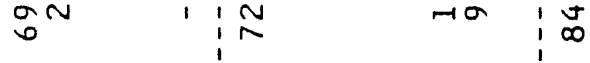

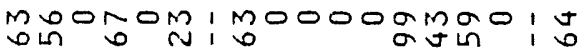

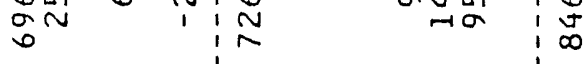<smiles>C1CCCCC1</smiles>

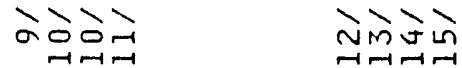

근-1

更品

늘

崖它

윤다

음ำ1

종으은

a id 0.5

$0=x \omega$ 出

ध山а

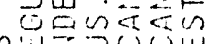

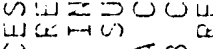

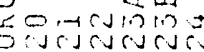

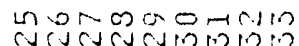

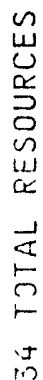




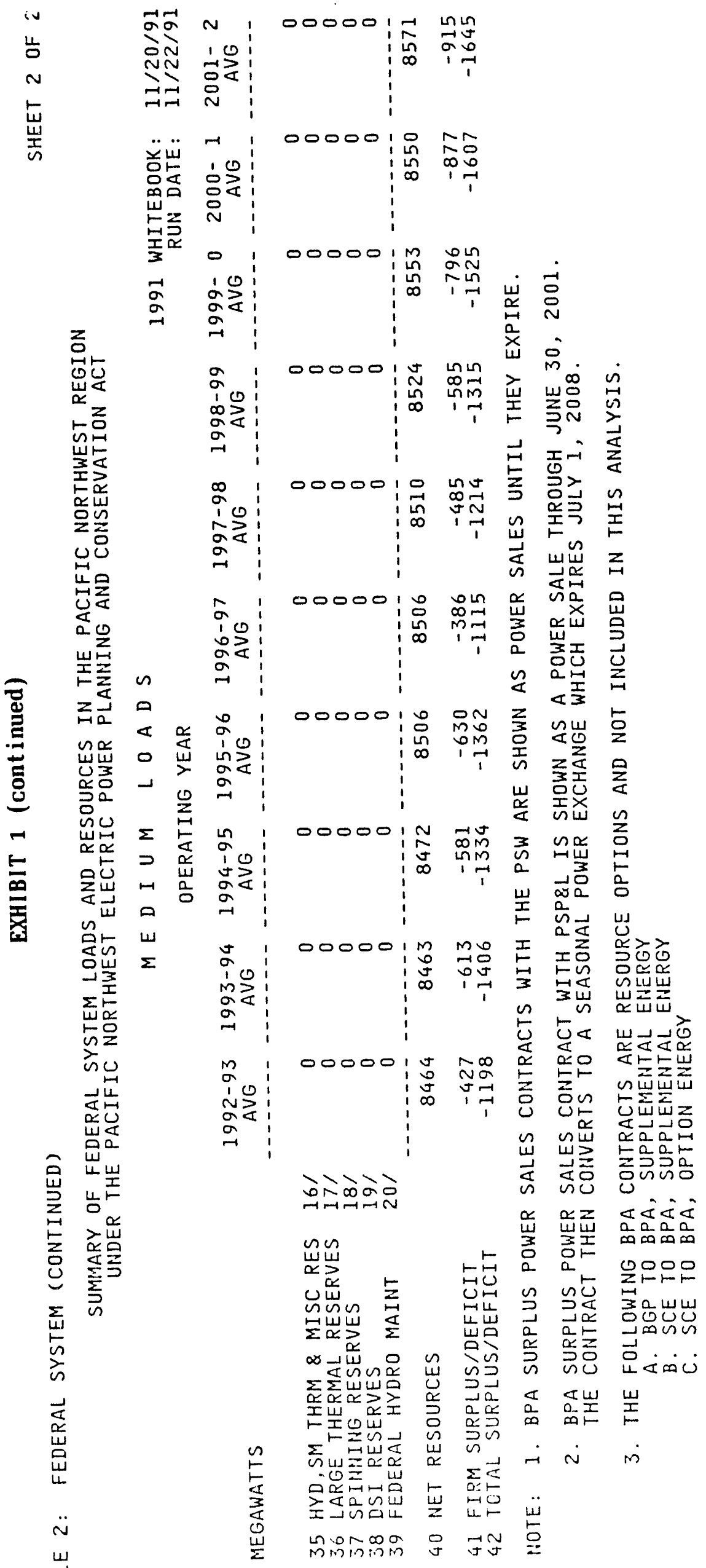




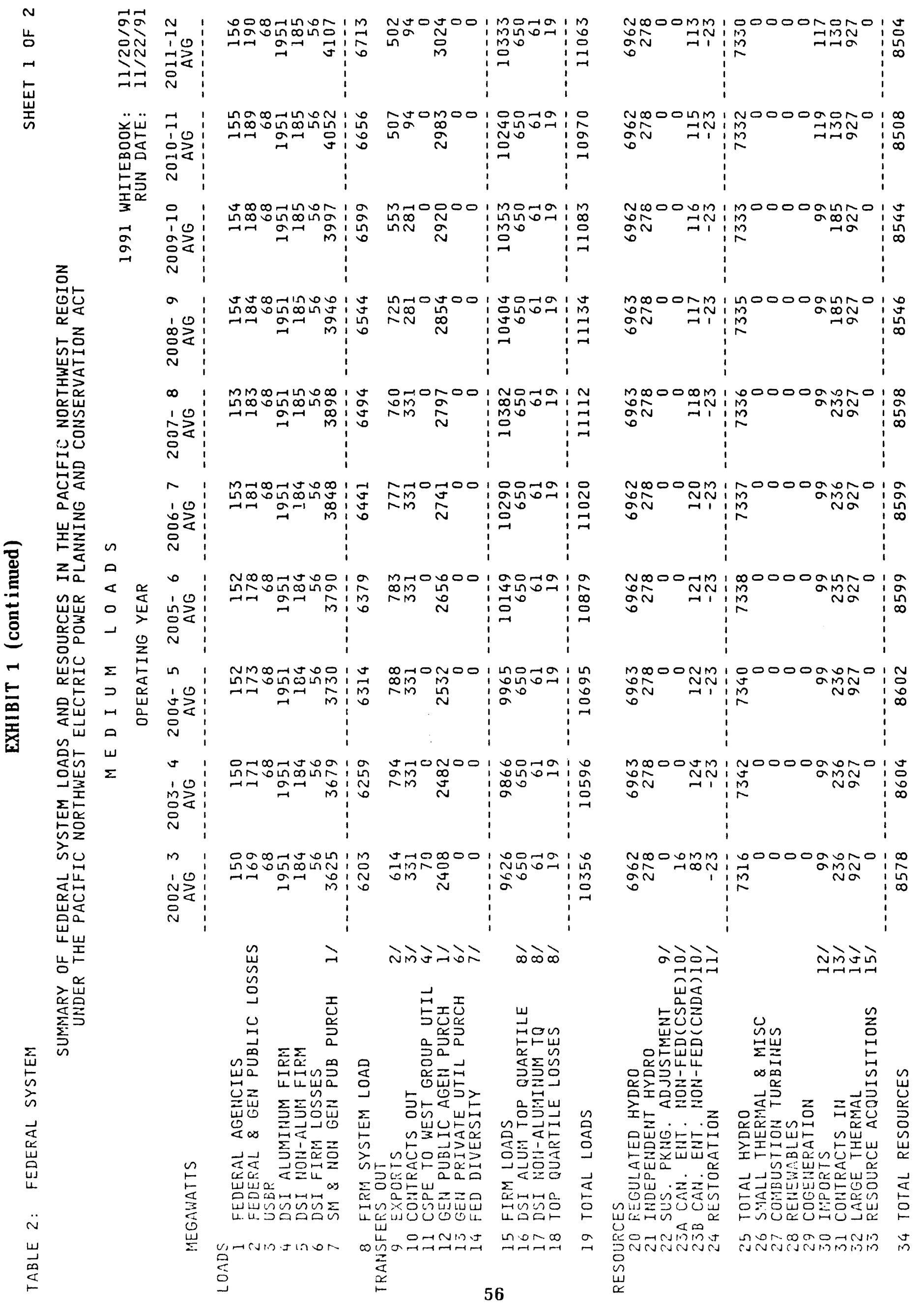




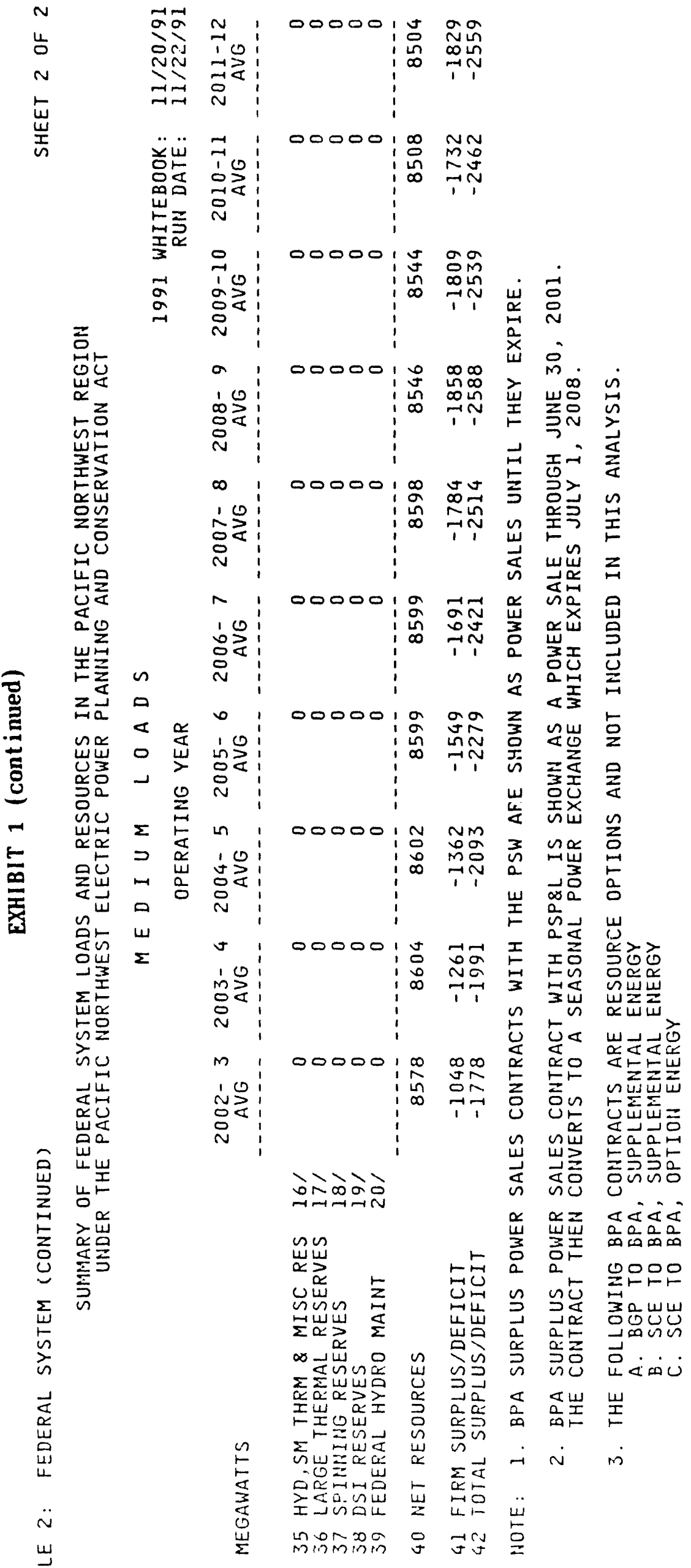




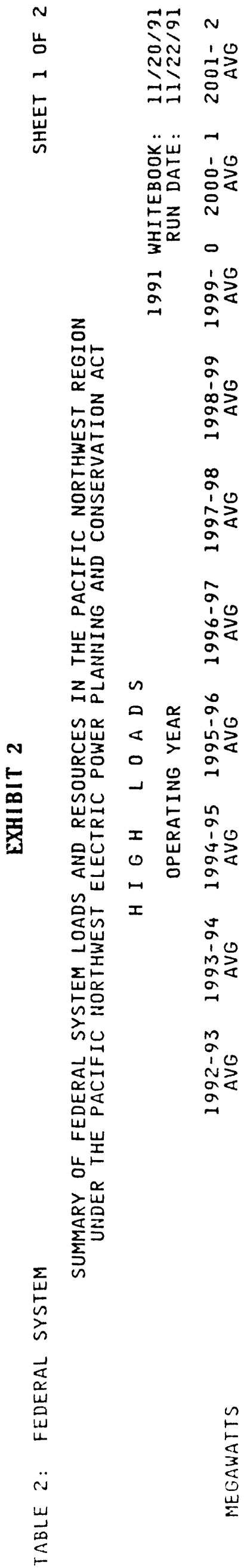

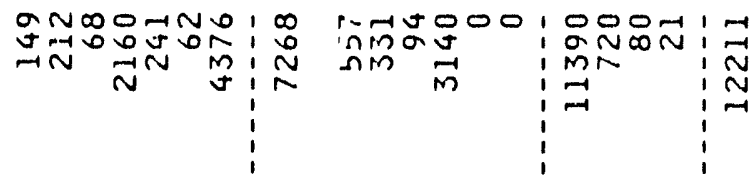

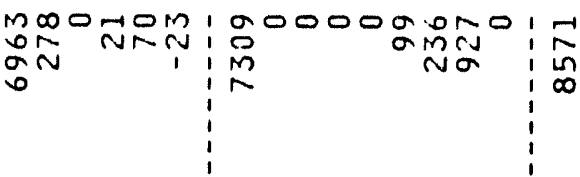

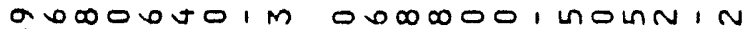

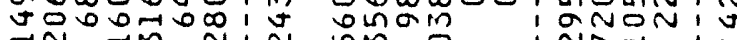

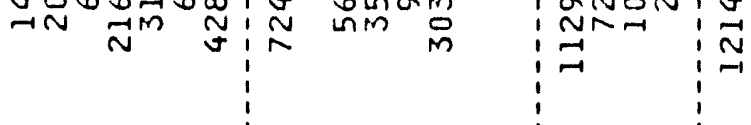

m-1

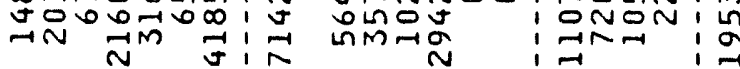

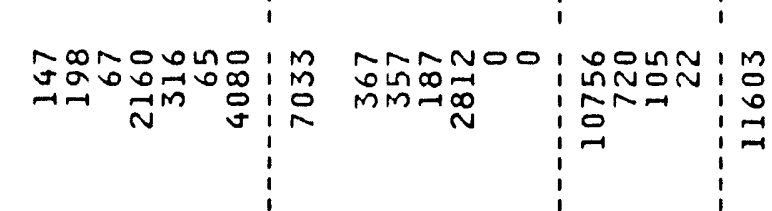

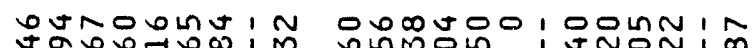

10: जa

å?

$n^{m}$ in

nonogun i n

N

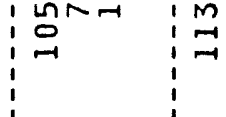

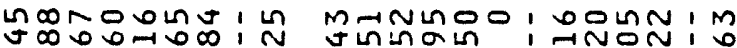

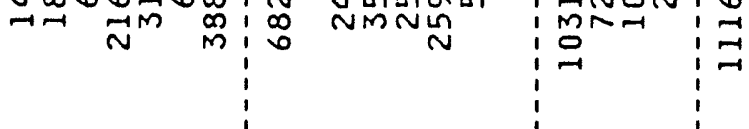

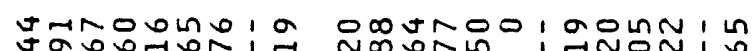

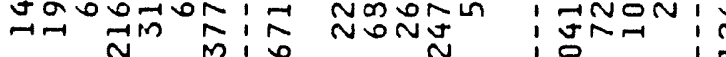

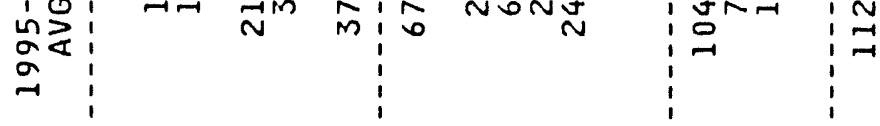

n 1 moñonin IN OMOOOO

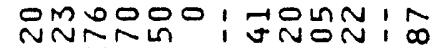

$\rightarrow \pi$ M

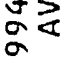

娄

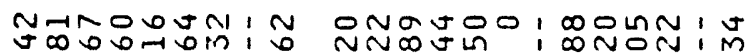

$\rightarrow-\pi m$ in!

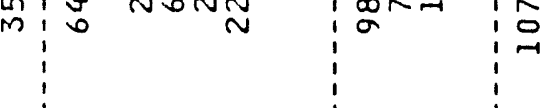

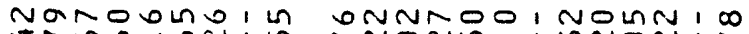

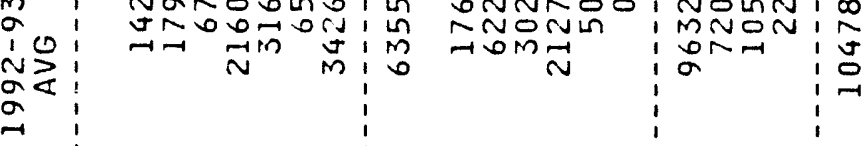

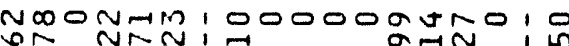
ปूñN NN?:T !

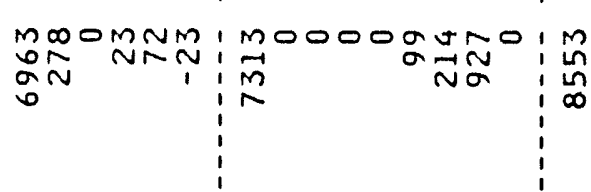

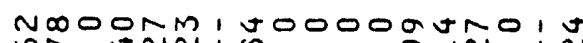
añ जN I: $\begin{array}{l:l:l}\text { gुN } & N & \text { Na }\end{array}$

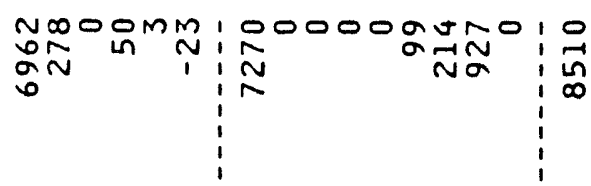

NDO JOM I HOOOOGONO: W

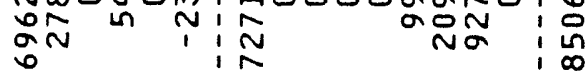

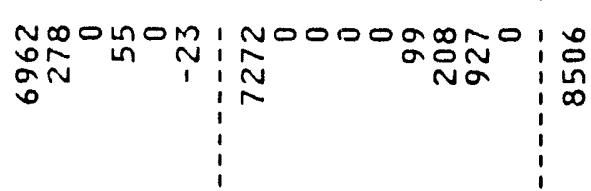

No0000m, LnO0000mino: N

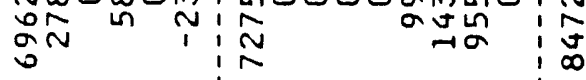

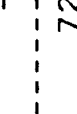

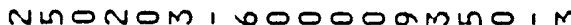
Do $0 N$ i a

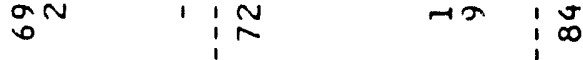
NOONOM, NOOOOOMAOIM ลัก 政

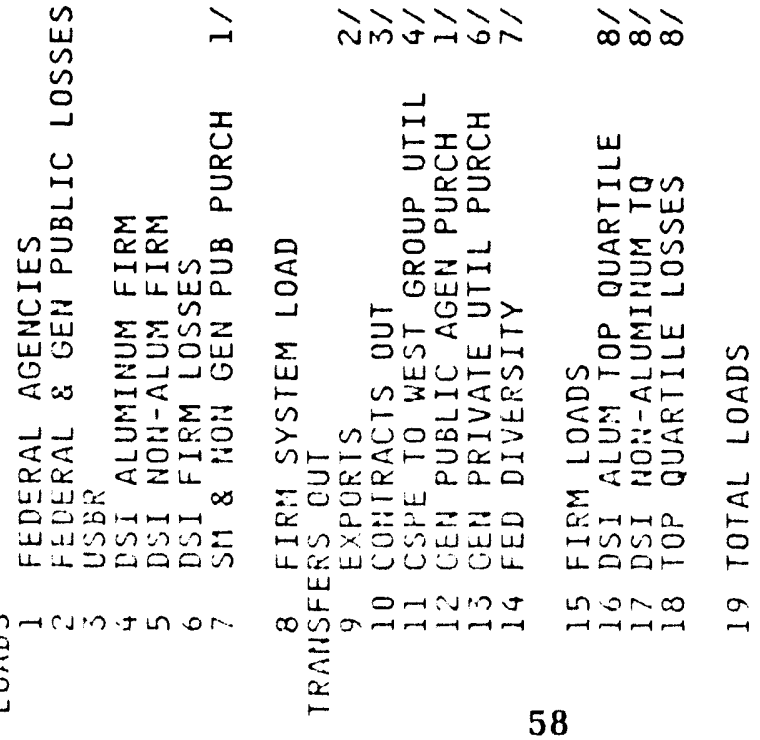

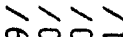
드믐

तेलेखेड जे

山४ 은은

$\sum_{u} \bigcup$

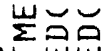
유. 乐出出 虽文包完至

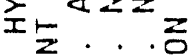

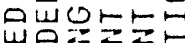

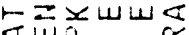

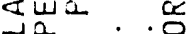

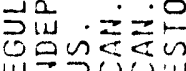

出岂导心出

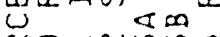

xomasing i
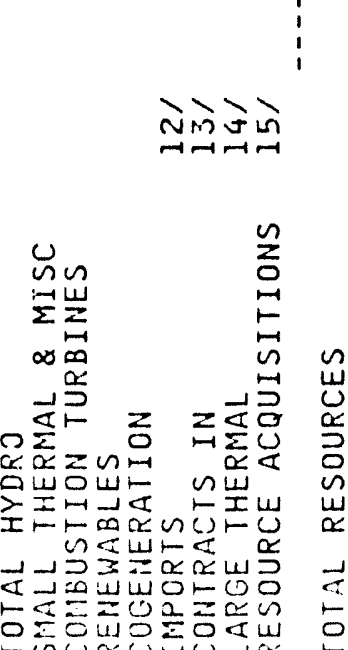


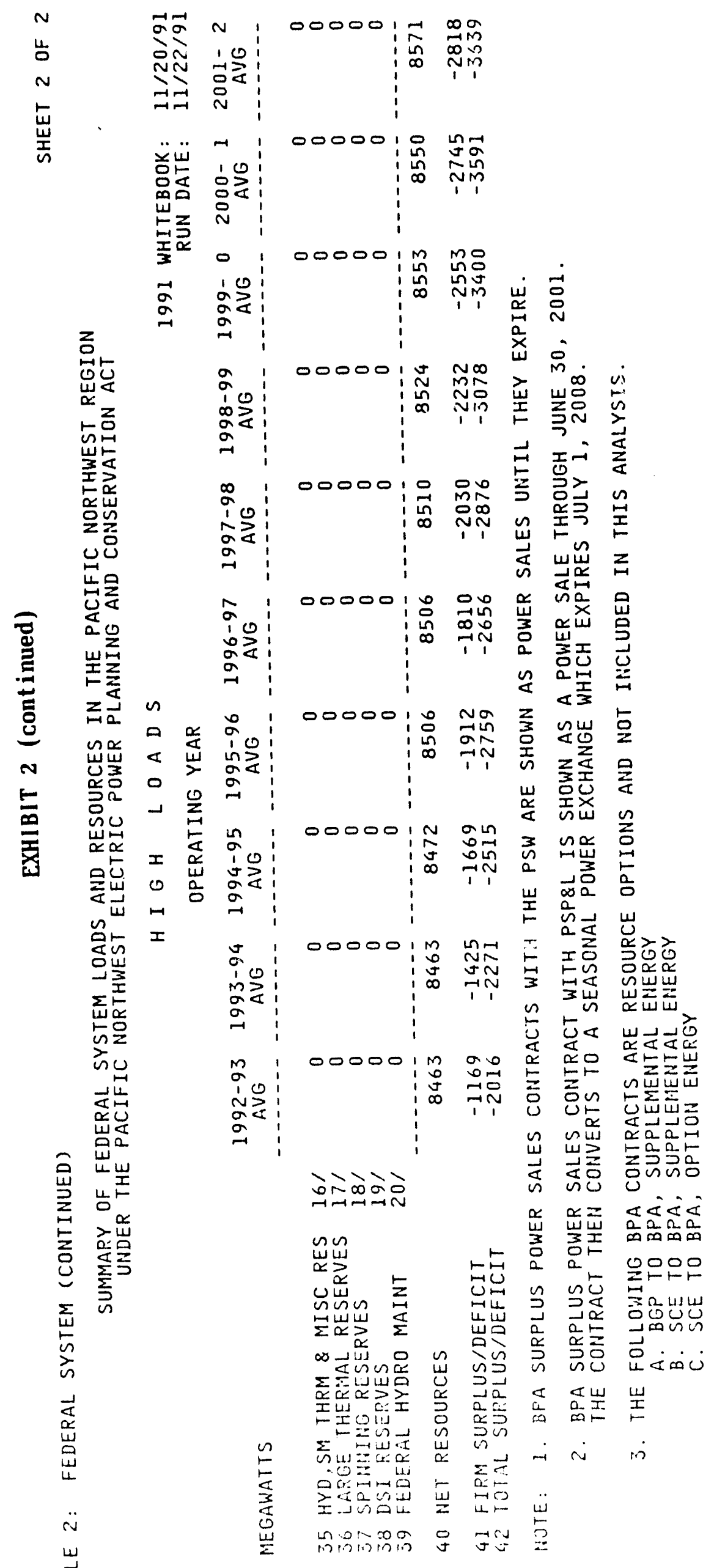




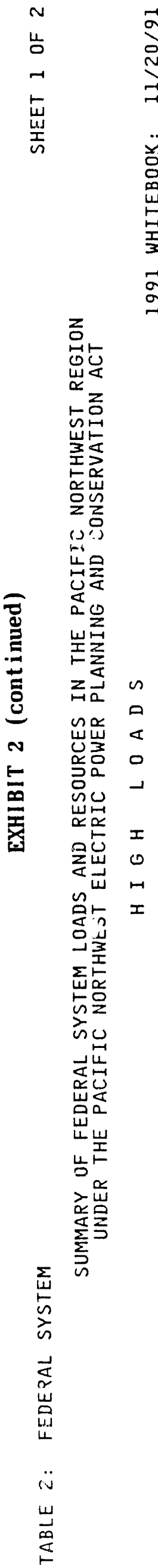

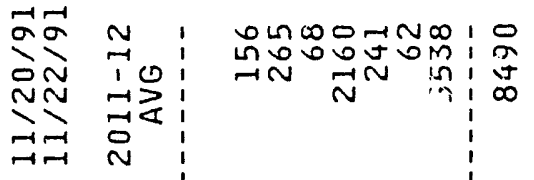

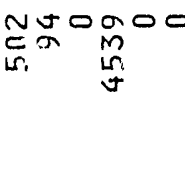

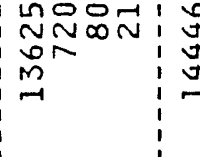

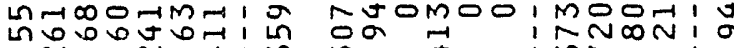

苨

品吉

思

Е引

일

2

iv

a

至

$\infty$

$\stackrel{2}{1}$

㗂

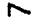

(פ)

品

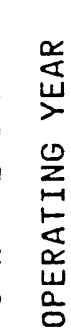

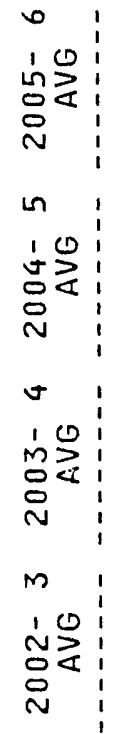

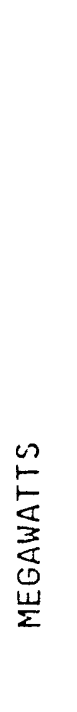

$\vec{N}^{N}$ 苟:

i

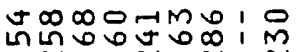

$\rightarrow \underset{N}{N} \underset{\sim}{\infty}: \underset{\infty}{\infty}$

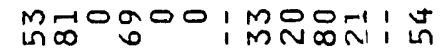

$\operatorname{nn} \underset{N}{N}$

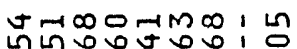

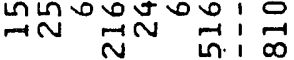

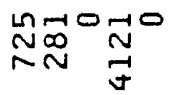
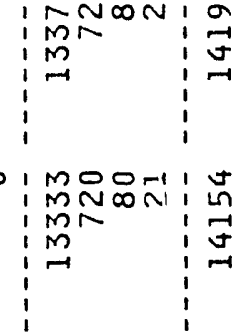

mono-4moin

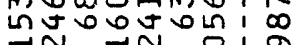

$\pi \vec{n}^{n}$ 品:

욤ำ

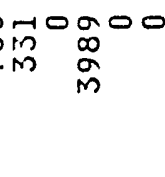

$m \rightarrow \infty 0 \pi N$ N

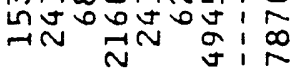

$\hat{N}_{m}^{-10}$

NUDO-TMm :

m-10000: 유유:

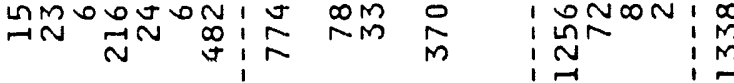<smiles>[3H][InH]</smiles>

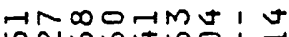

$\rightarrow \underset{n}{n} \sqrt{n}$

70007ma! N

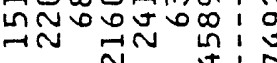

$\infty$

$\infty_{m}^{-10}$

100,140

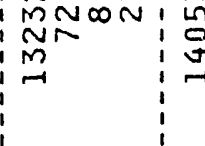

ธิกัณำ:

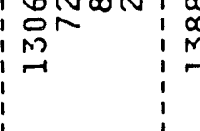

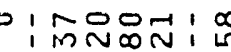

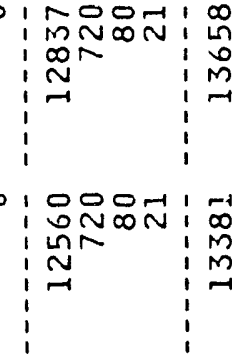

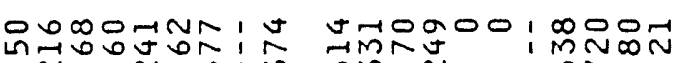

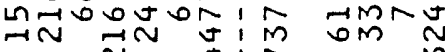

$2 \rightarrow 0000$

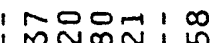

iNN

i

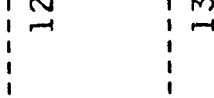

a

ڤึ

$\stackrel{2}{\sim}$

U

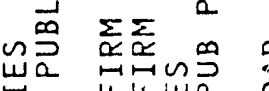

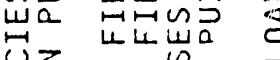

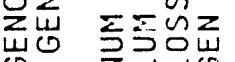

$ष \infty$

다

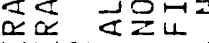

㟔岩品

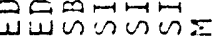

प以

ñNmutan

$\stackrel{n}{\stackrel{\Xi}{\Xi}}$

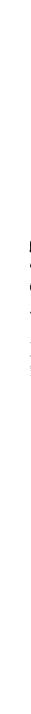

票

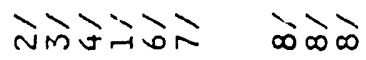

! ํㅗ요유:

i i

$i_{\substack{1 \\ n}}^{\infty}$

$\exists$

in 


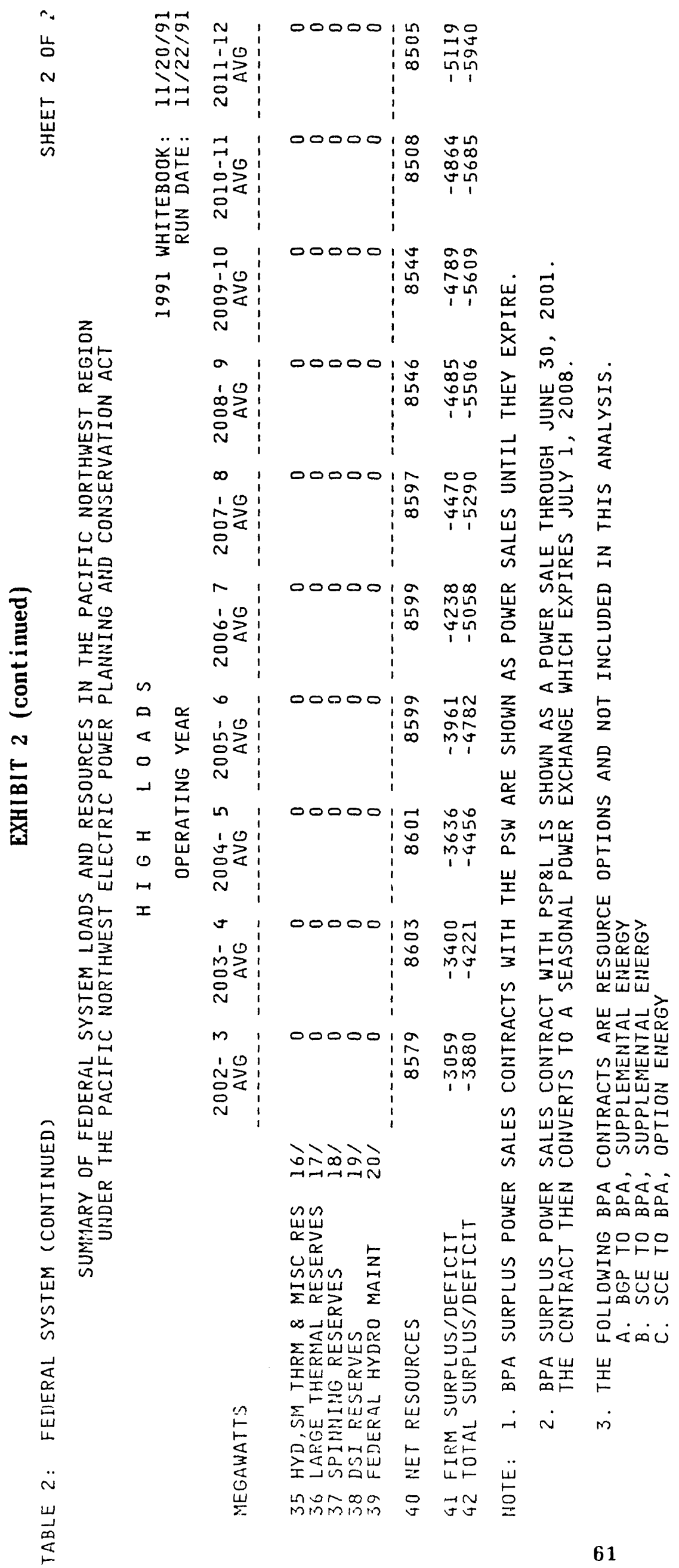




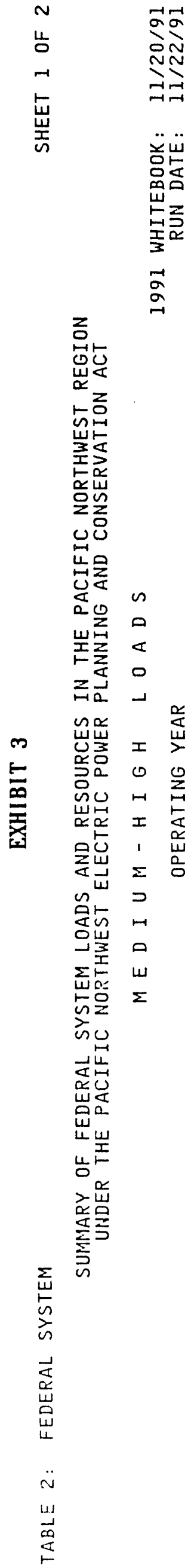

N

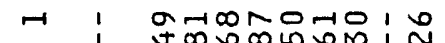

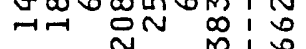

官究

N

$\frac{1}{3} \approx$

0

ूूญ

a I NNNGHA1

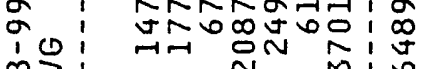

$\infty$

$-1$

$\infty$ i DInNGTNIN

is

ลूँ

(a)

In

प्ञ-

مूष

a

$\propto 2$

ถูก

बूँ

in

$\stackrel{2}{2}$

a

5
1
1
2
2
-1

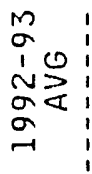

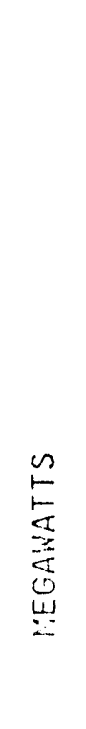

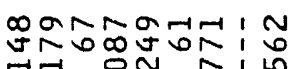

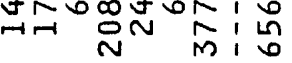

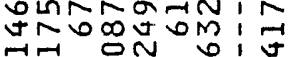

$N m i c$

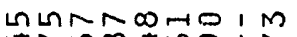

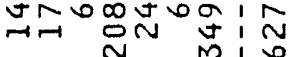

M№์

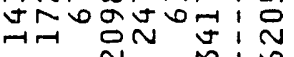

NONMNNG,

ra $\pi^{N} m: \vec{m}$

NanmNNin i in

0

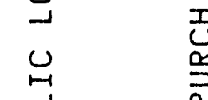

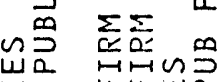

出 แ山顸

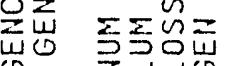

必

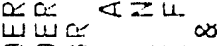

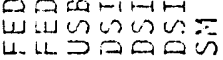

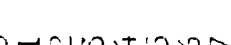

号
TNNNOO

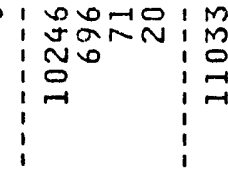

O $000 \ln 00$

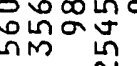

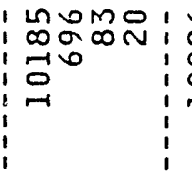

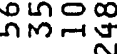

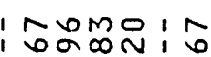

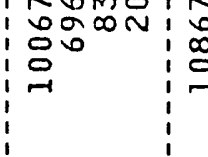

Ñ̂̃OOO

Mimm

जoomo:

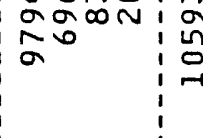

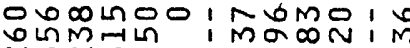

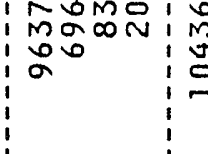

mantoo

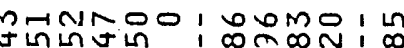

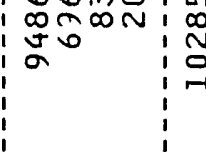

옹ำ

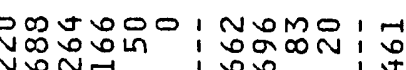

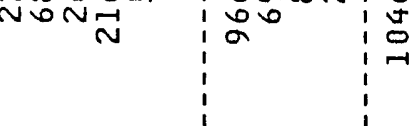

กNNT융

Nูก̃̃

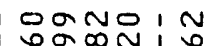

vă

a<smiles>[AlH][IH]</smiles>

MOONGTOMIM

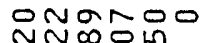

$\stackrel{m \infty N-1}{N \infty}$

$a^{m}$

TOONGNLI L

$\rightarrow-n N \underset{n}{N}: 0$

roma

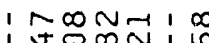
$a^{1}$

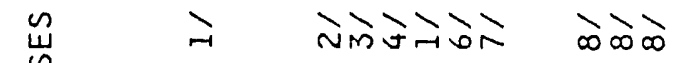

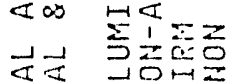

주 $\frac{1}{\alpha}$ 은

\section{तो}

画志兄

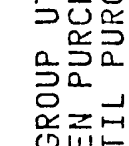

品岕ら

与怘つる

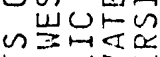

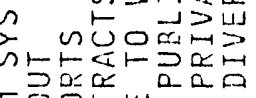

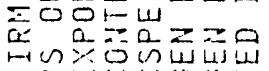

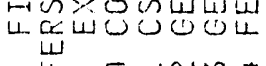

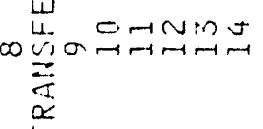

62
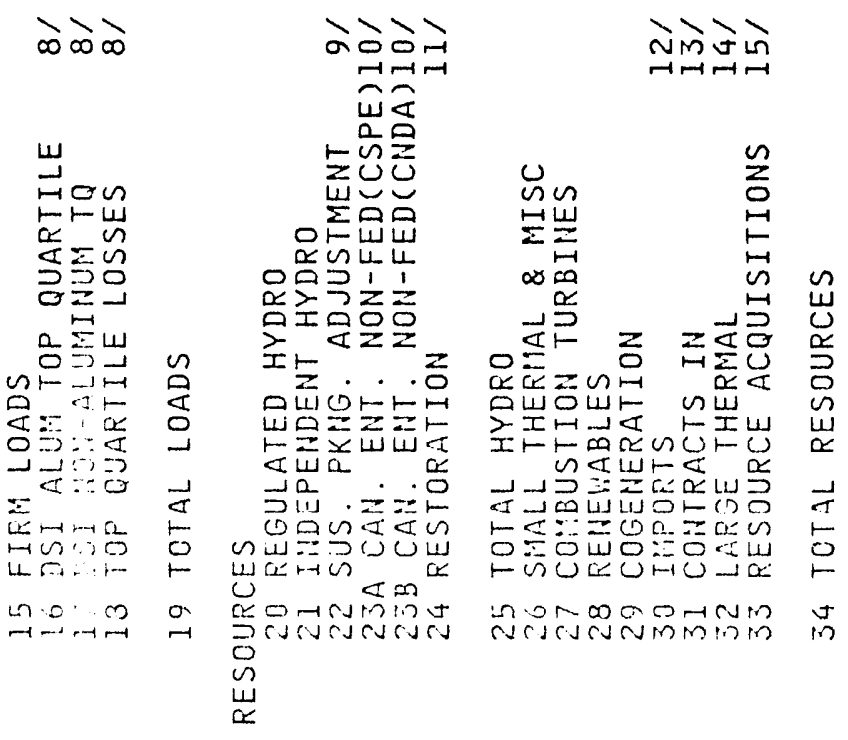

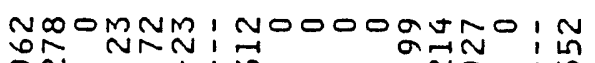

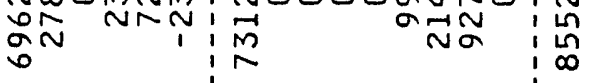

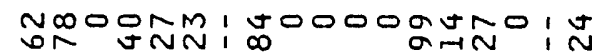

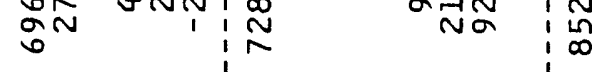

NoOOMm: $000000 \mathrm{~N}$ O

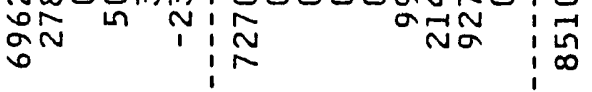

NonO

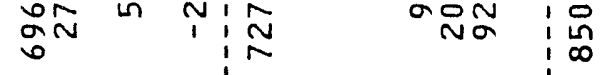

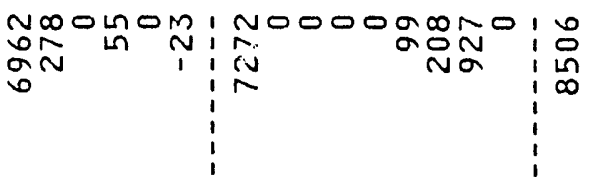

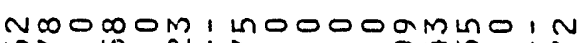
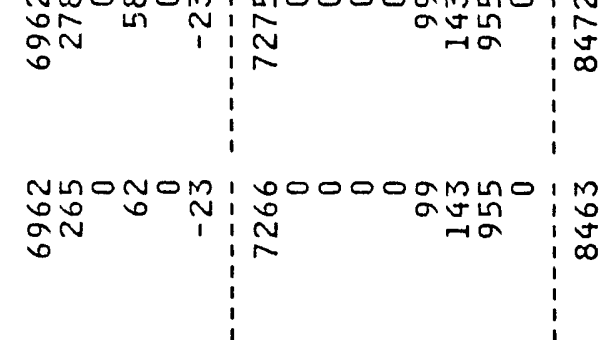

NOONOM, NOOOOOMGOIM

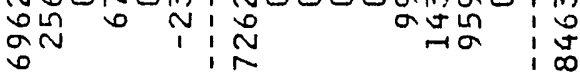

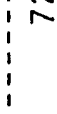




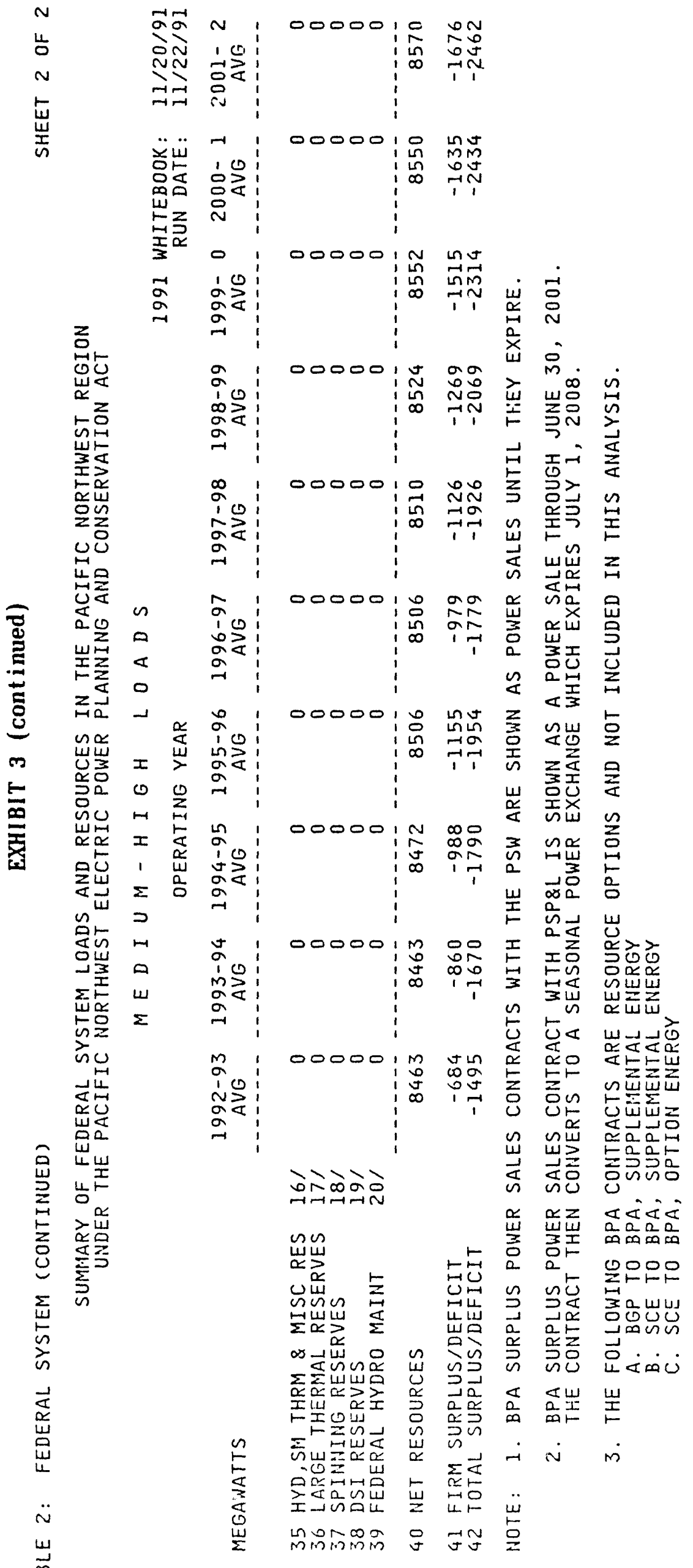




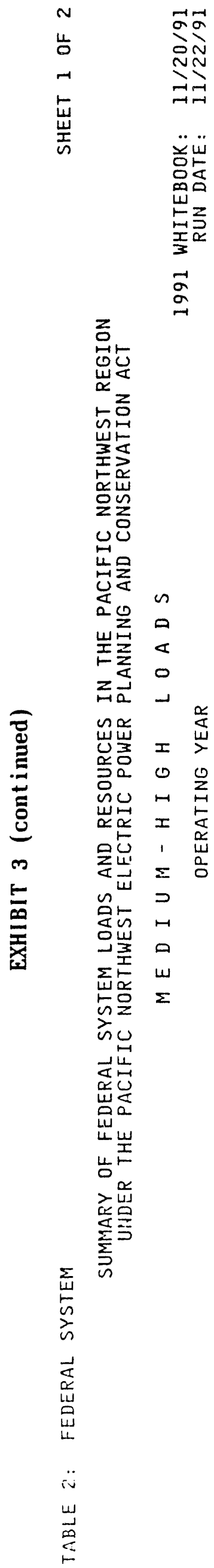

竞

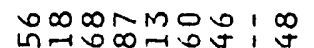

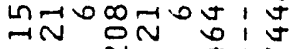

nu№n:

只

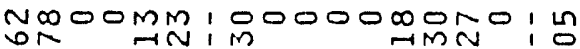

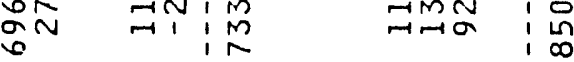

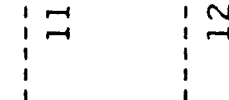

MODNMON 1

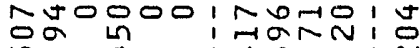

To

$\ln \rightarrow 0 \infty \pi 00$, क्ष

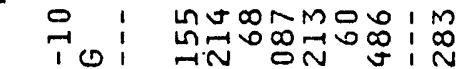

IN⿻心

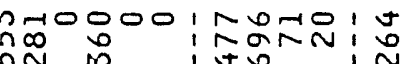

ơ⿱

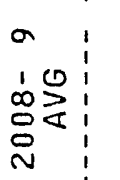

sanimonia

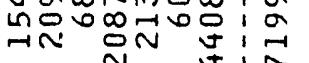

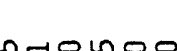

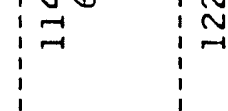

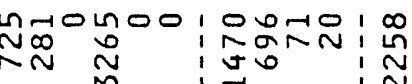

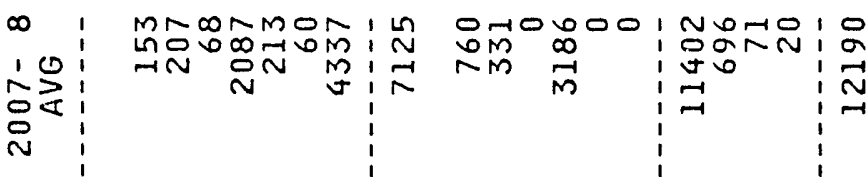

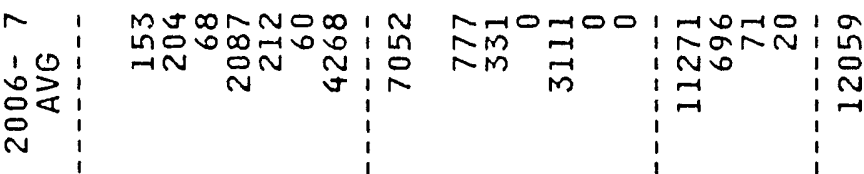

品

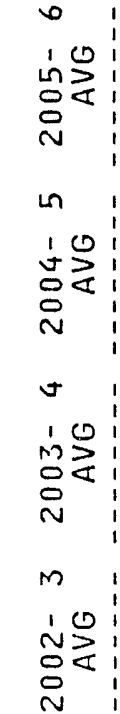

NODNNOH!O MHOYOO

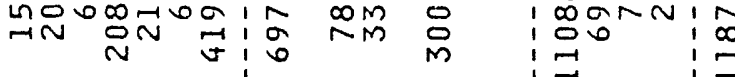

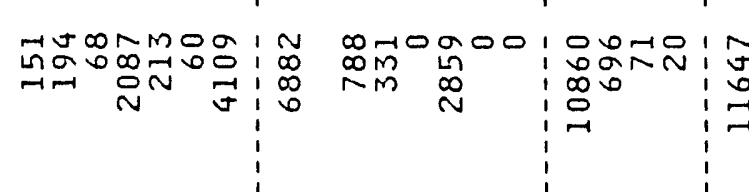

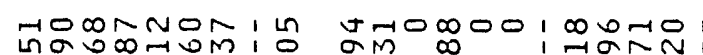

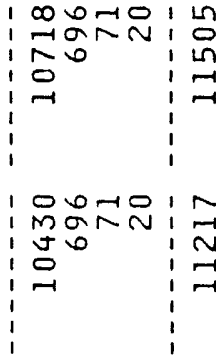

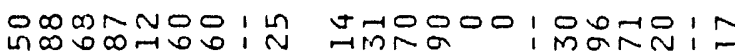

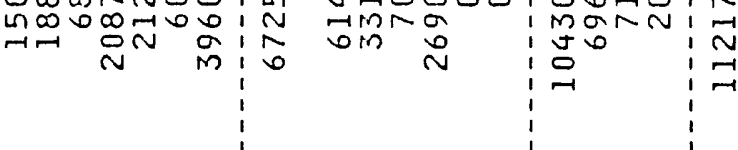

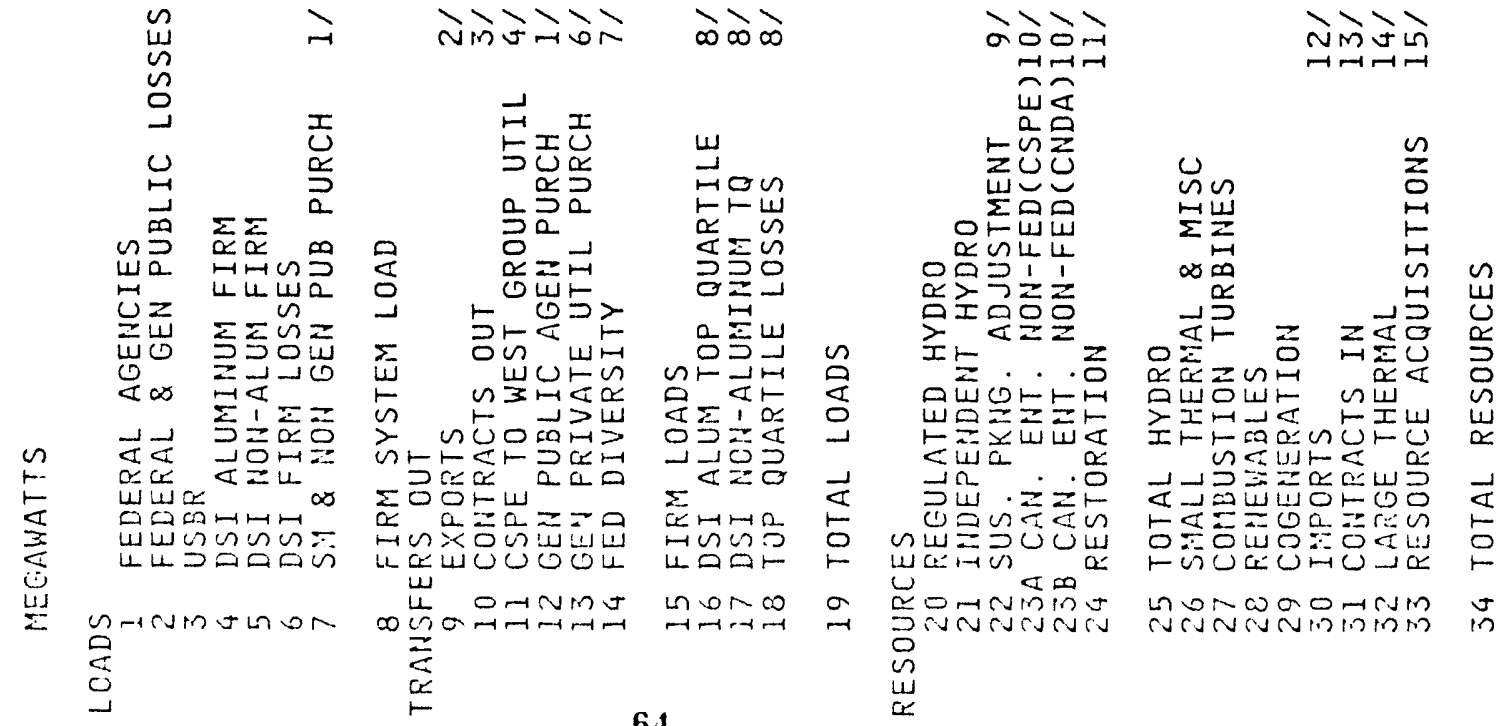

NoOOLM NOOOOOONO NO

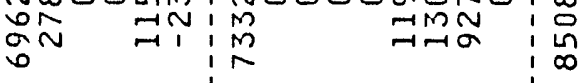

No000m, mooooglñ i t

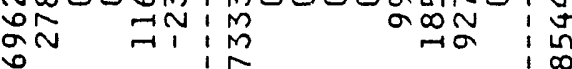

\begin{tabular}{l|l} 
in & 1
\end{tabular}

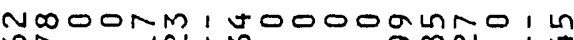

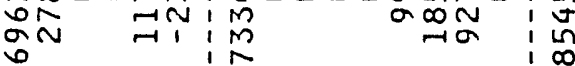

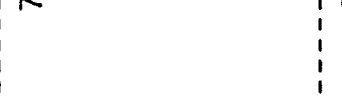

Nonoomin: $\ln ^{\infty} 0000$ añNo:

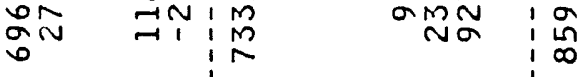

Nono0ON:

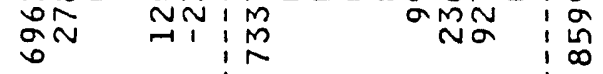

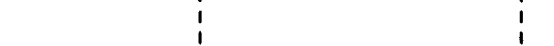

NoD00

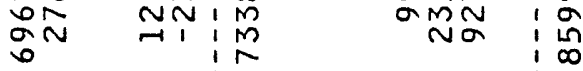

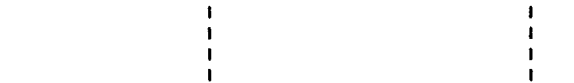

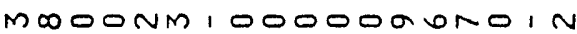

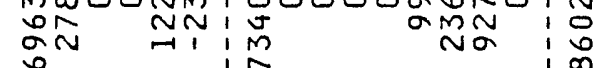

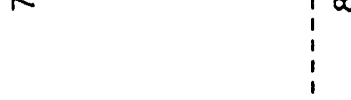

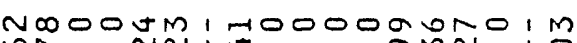

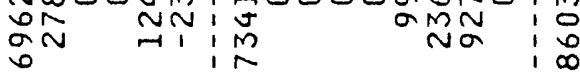

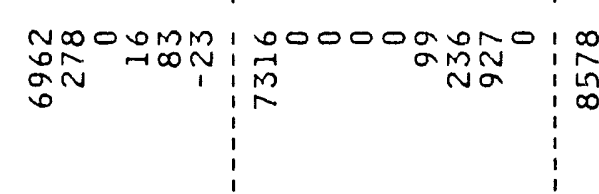




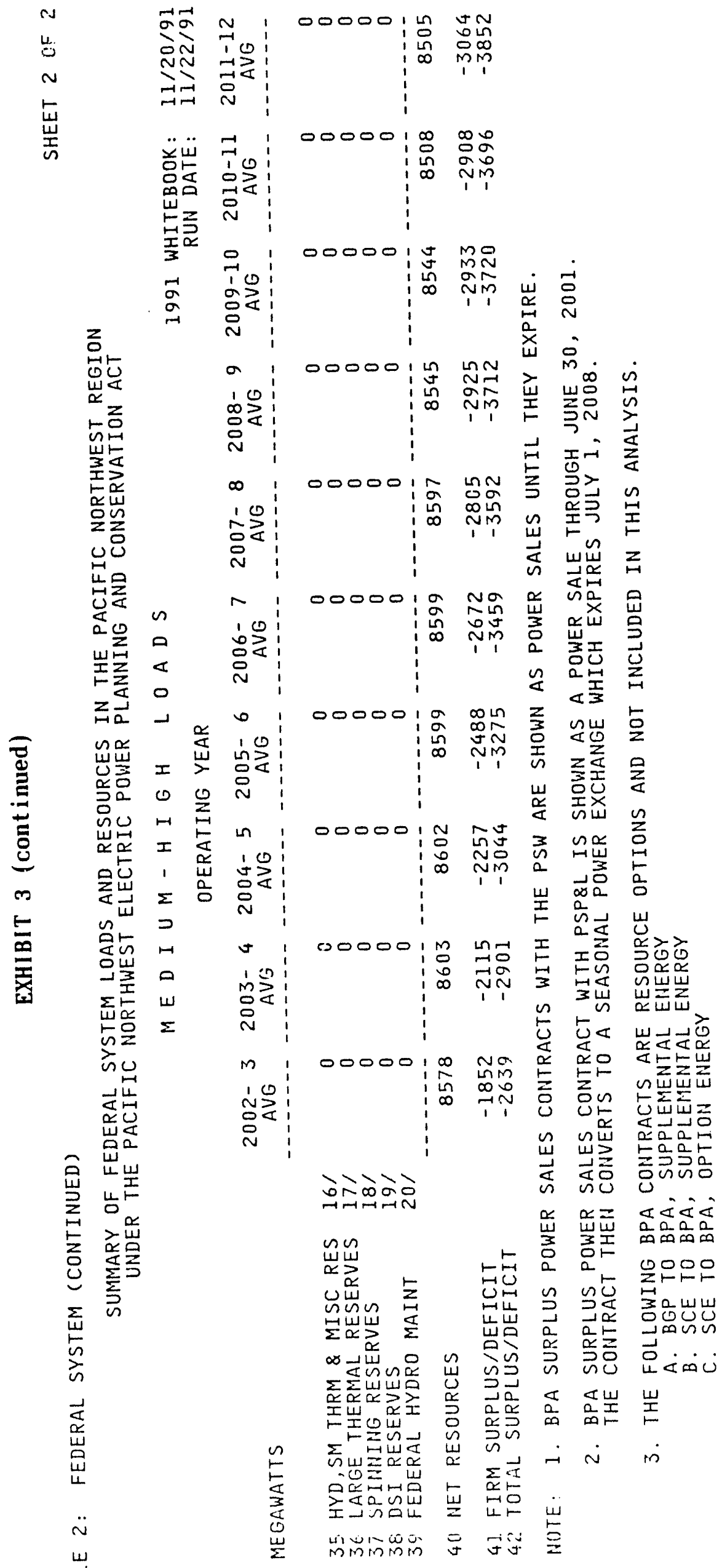




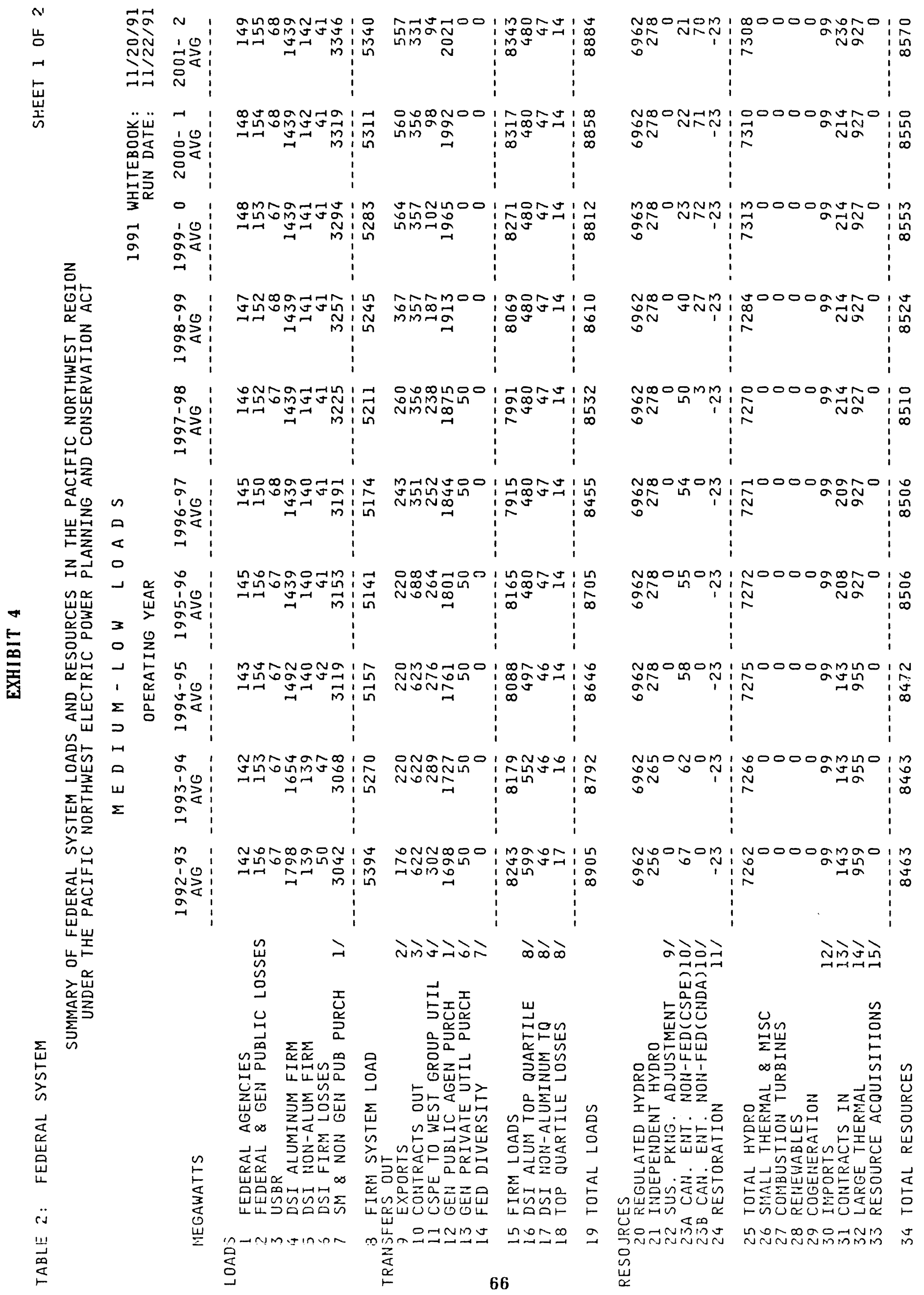




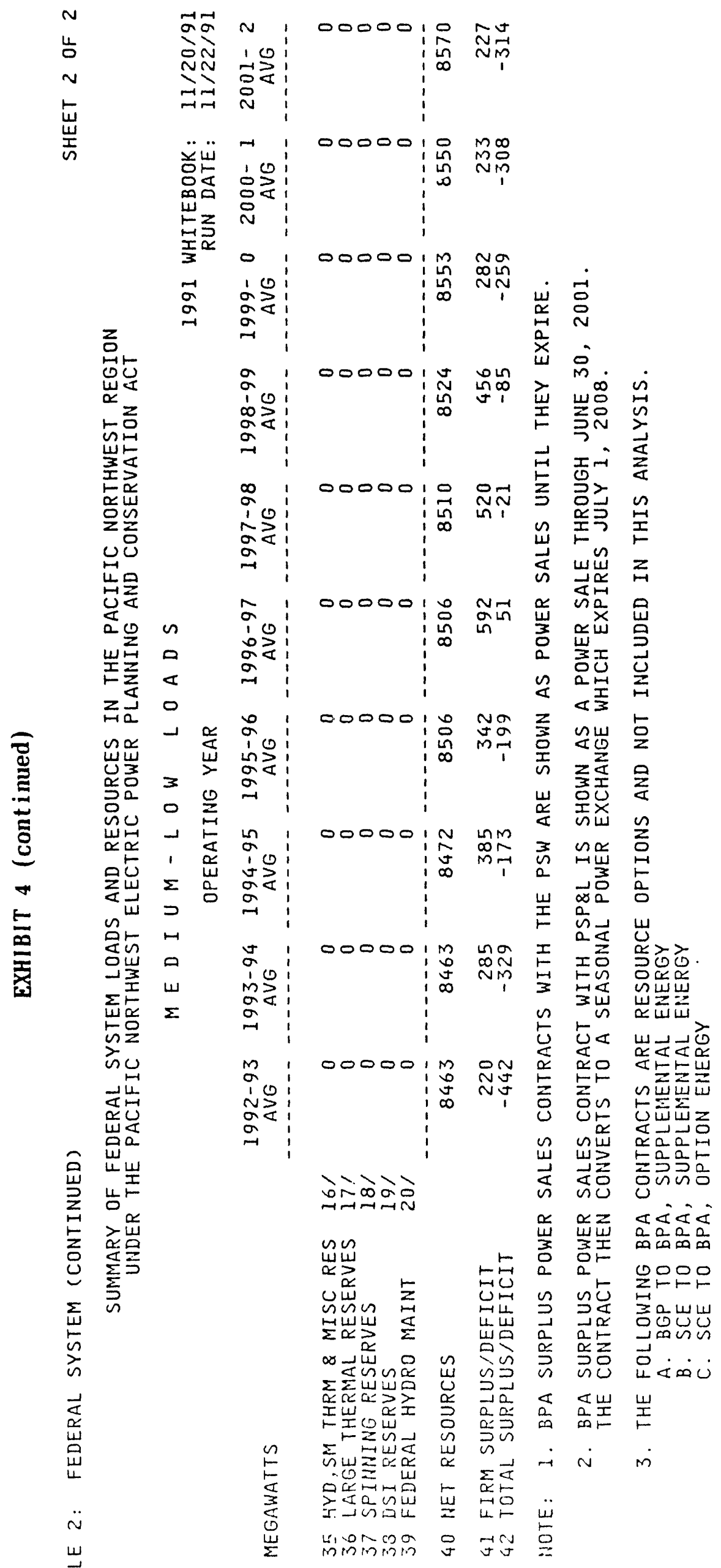




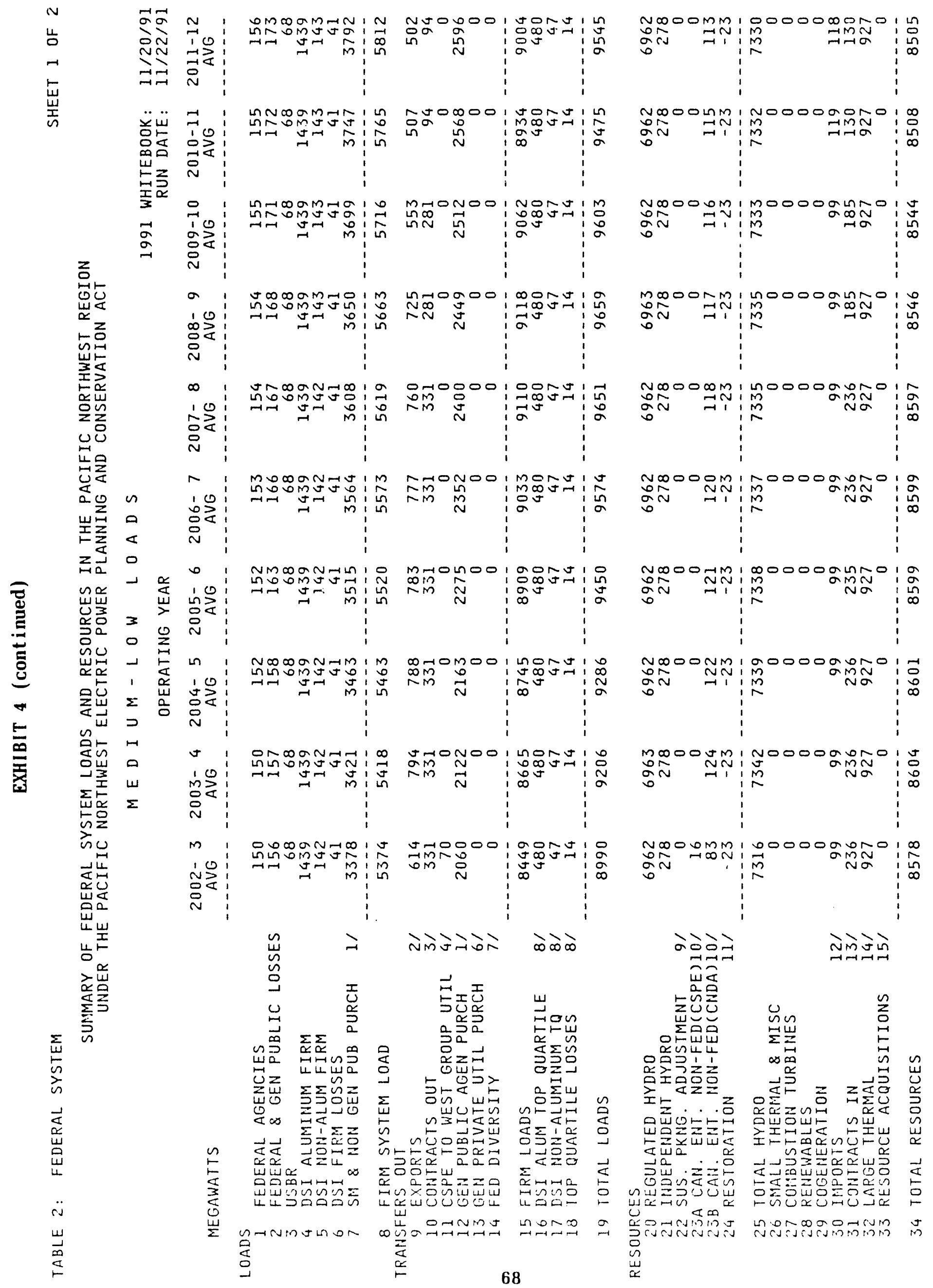




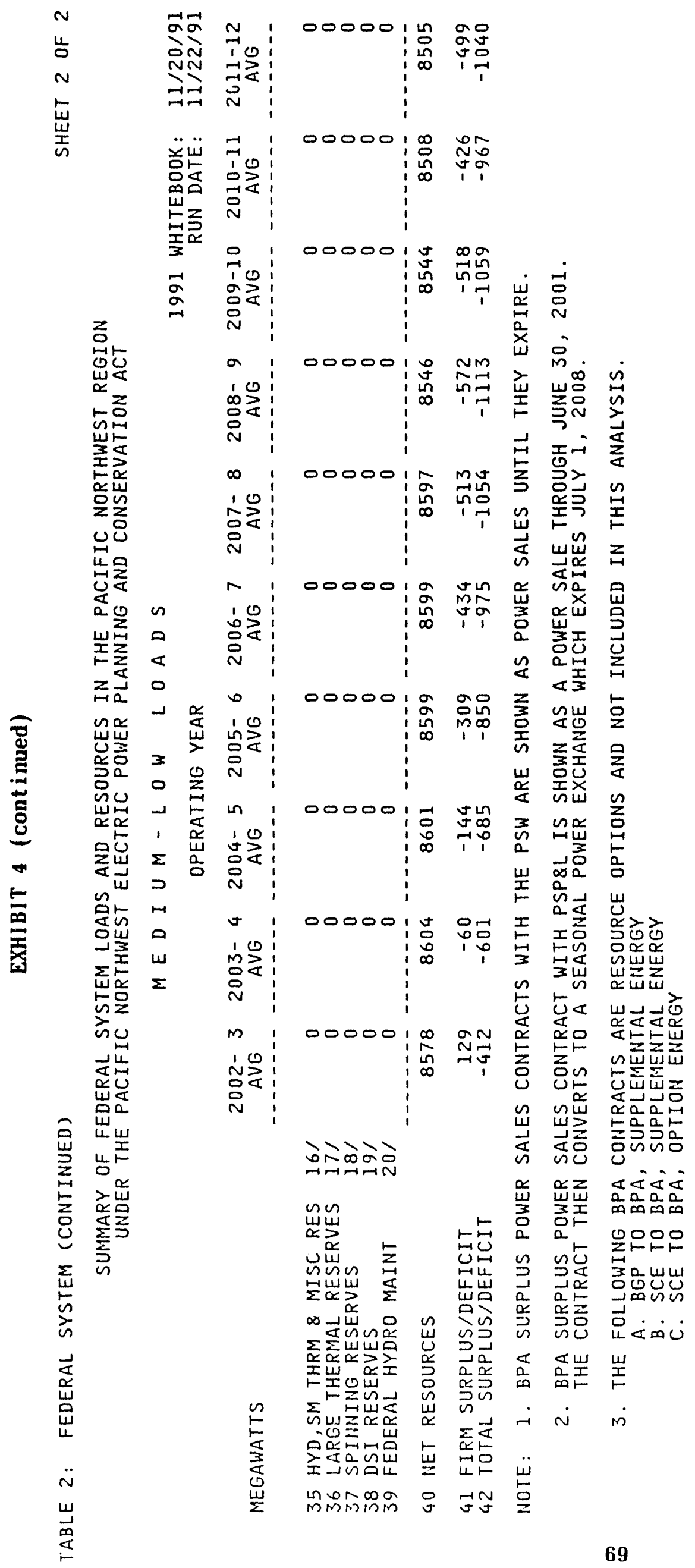




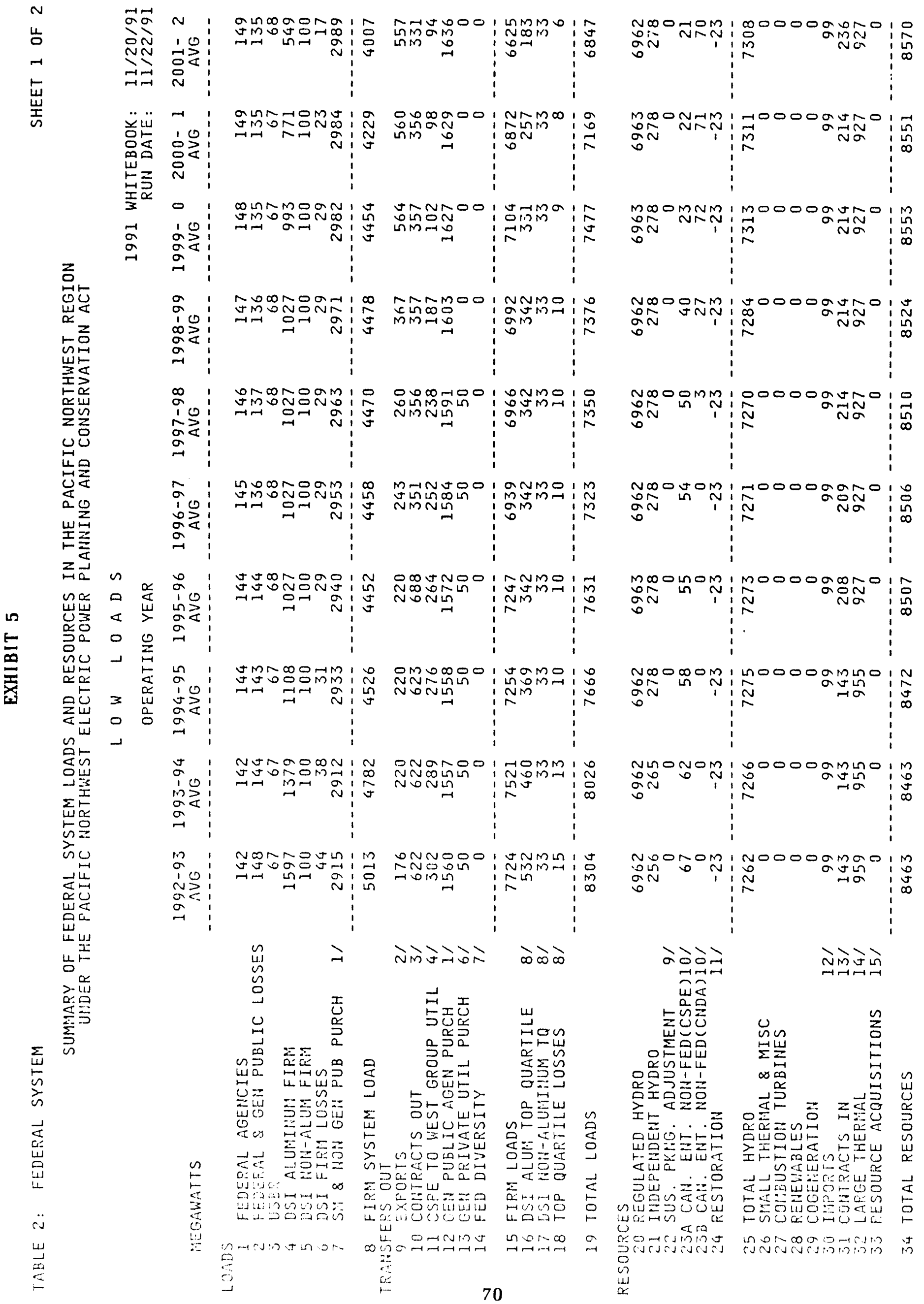




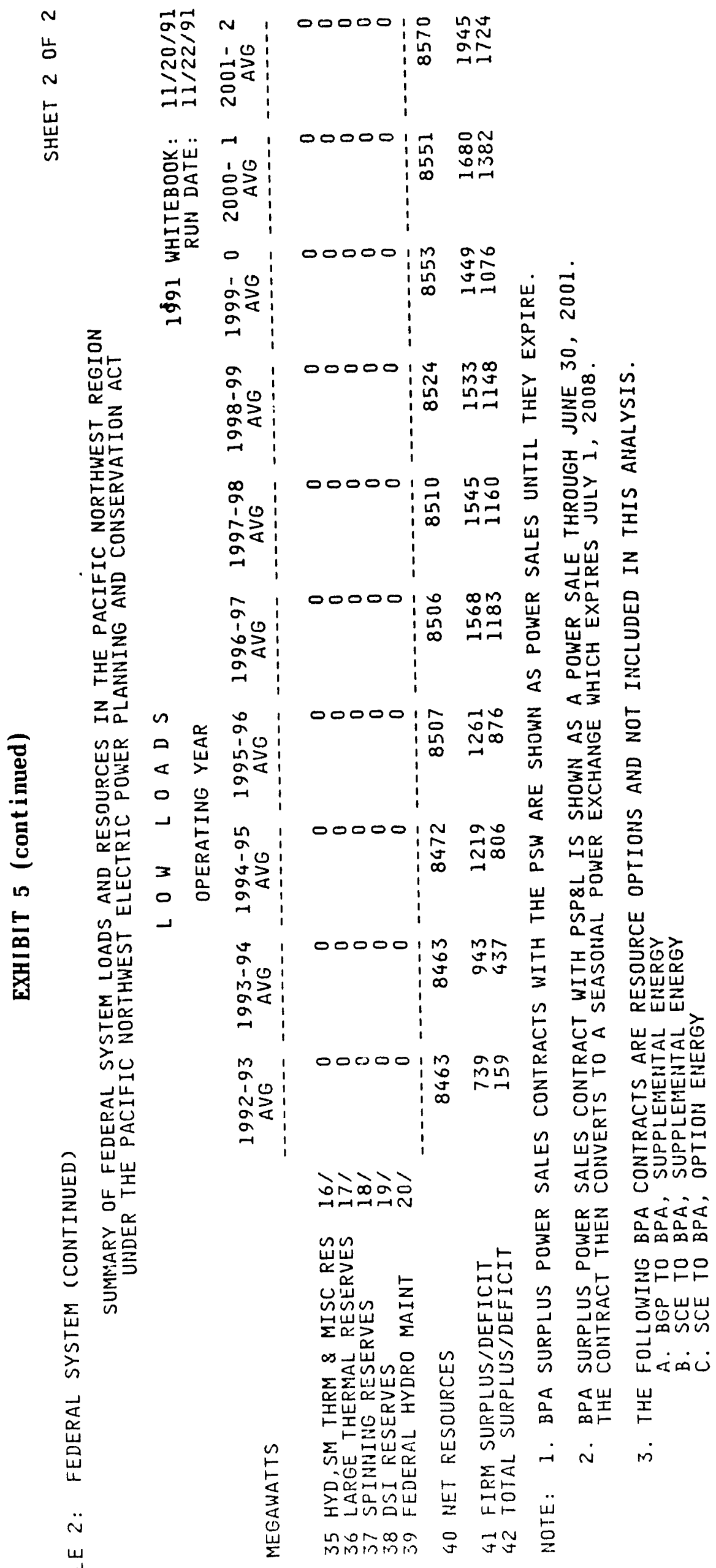




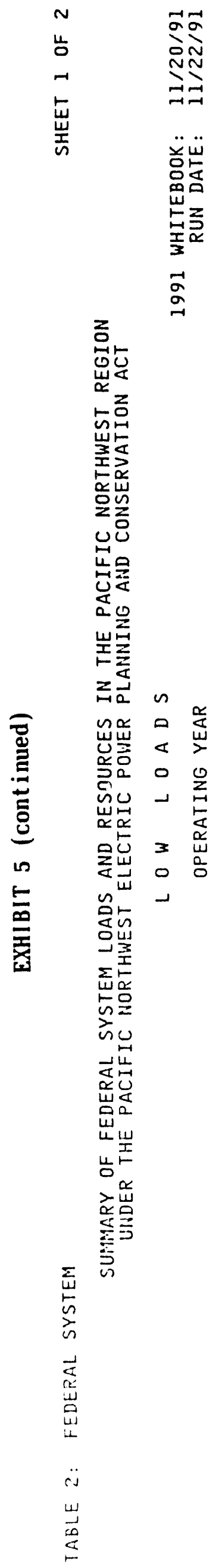

党

นำกำ

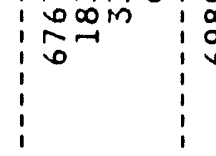

NoOOOMI, OOOOONONO I

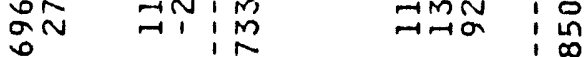

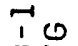

InNDOONNIM

일

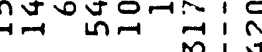

(1)

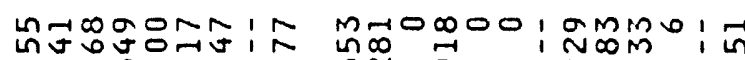

它乌

N i

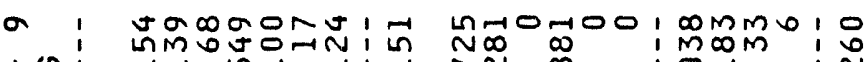

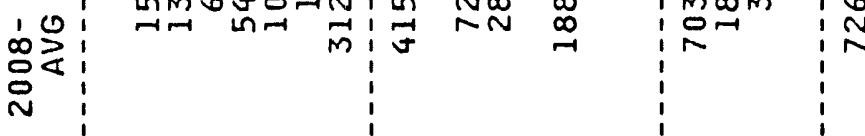

$\infty$

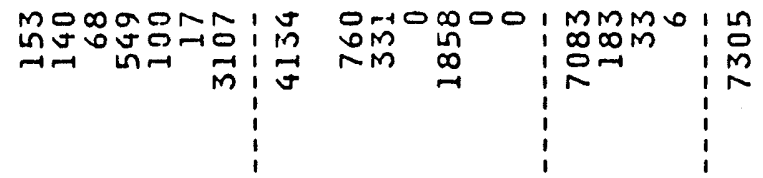

突完

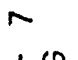

Macoono: D NMOOOO: JMMO:

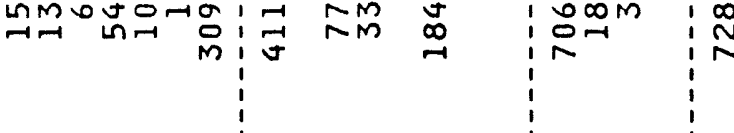

㗄

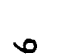

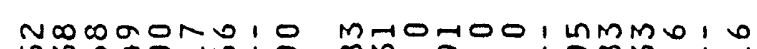

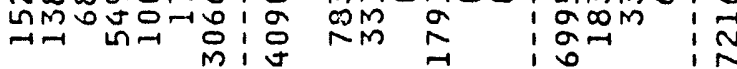

ㄴํㅇำ

\%

Ln
$\vdots$
0
0
0

$\checkmark$

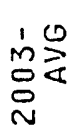

$m$
$\stackrel{1}{N} \overbrace{}^{\circ}$
N

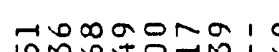

$\ln m$ inonis:

(n)
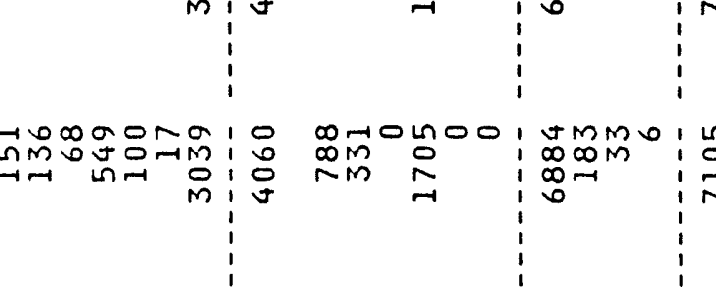

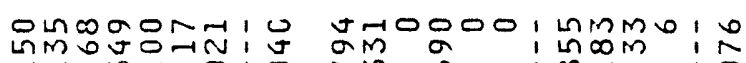

$\begin{array}{r:l:l:l} & & \end{array}$

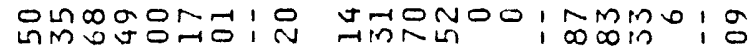

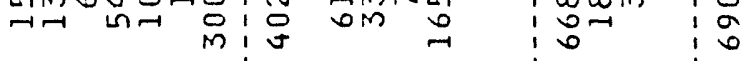
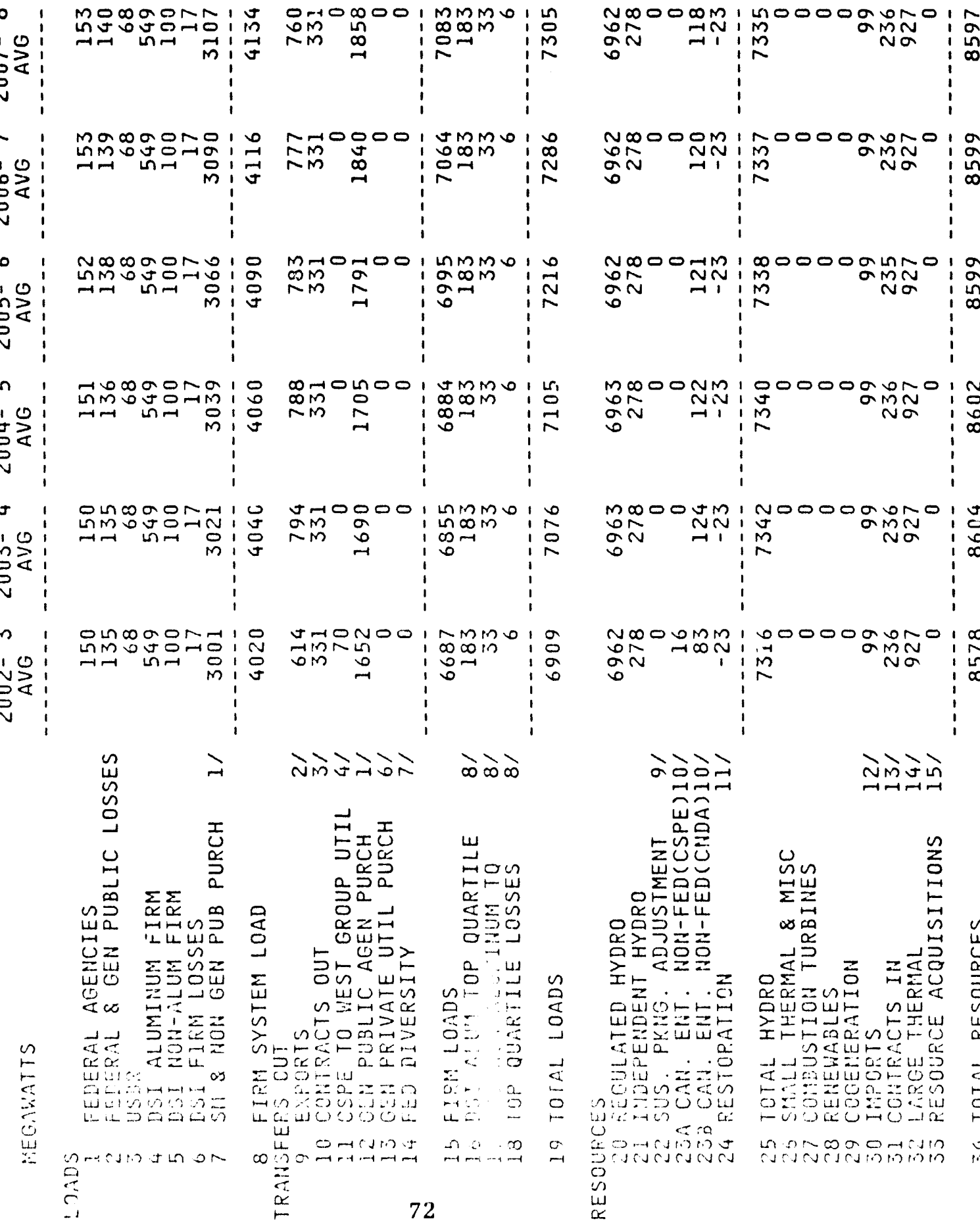

No0000M: N00000N0̃: مूN NN:

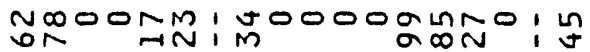

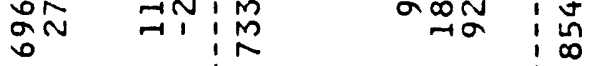

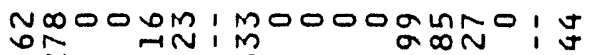
ãn

NoDOOLM N NOOOOOONO:

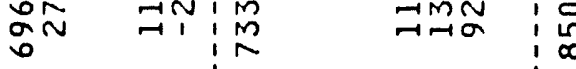

NoDOOHM: مूN NiN:
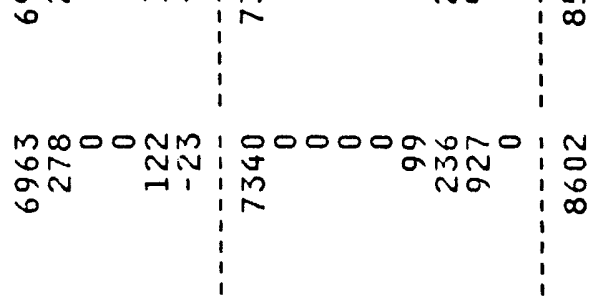

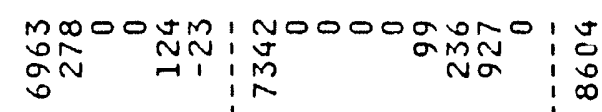

No00Mm: $00000 \%$ ONO: LूN $\rightarrow \infty$ : $\begin{array}{l:l:l}0 & m & 1\end{array}$

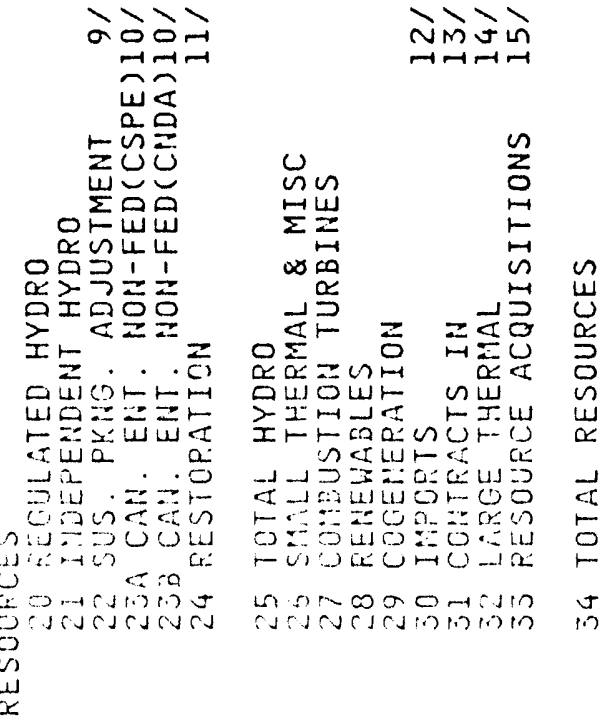




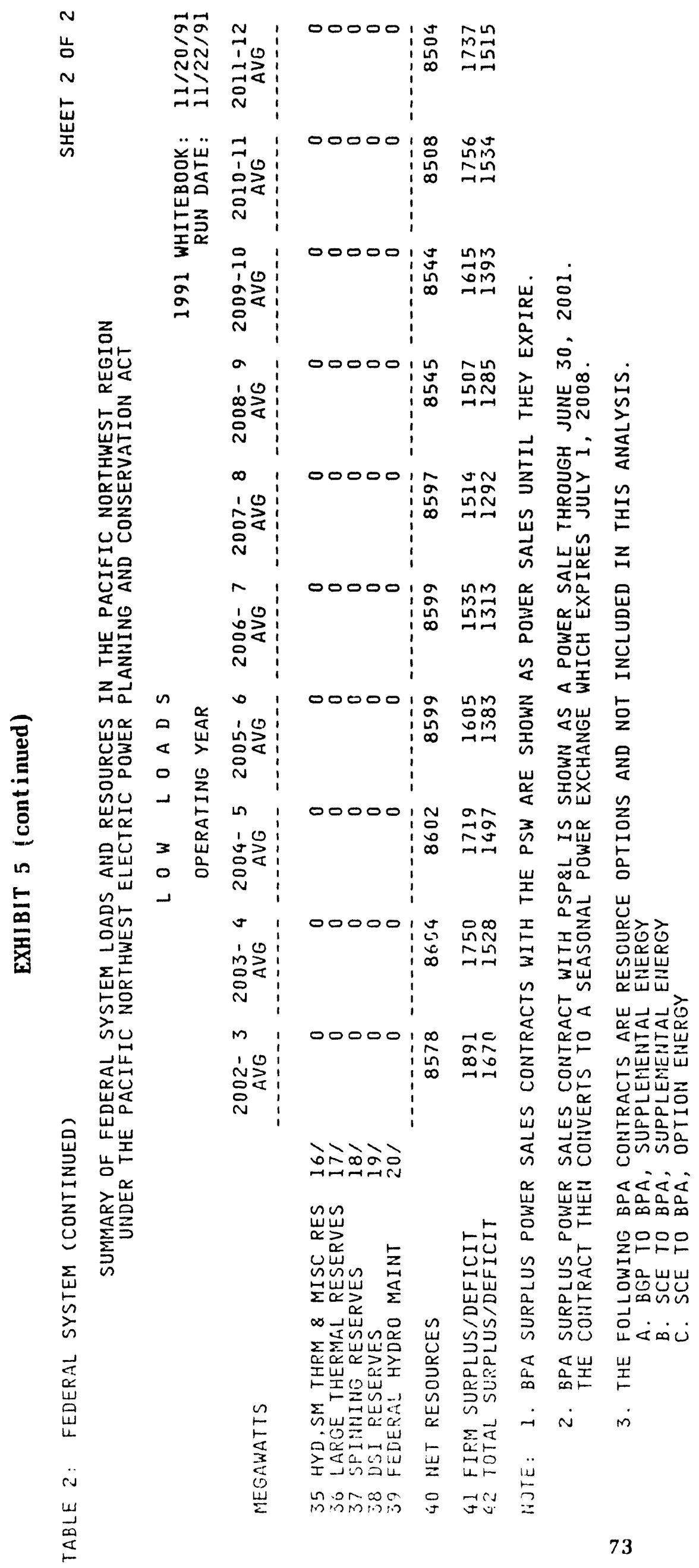




\section{FEDERAL SYSTEM FOOTNOTES}

\section{For Exhibits 1 through 5}

1/ BPA's small and nongenerating public agencies' purchases are requirements which these agencies place on BPA under their power sales contracts and BPA's partner hip program. BPA's obligation is each agency's net firm load require ents not served by its own dedicated resources.

2/ BPA's exports include BPA's contracts for a surplus firm power sales to Southern California Edison and the cities of Burbank, Glendale, and Pasadena; BPA's surplus firm power sale with M-S-R Public Power Agency through October 31, 2009, which ther converts to a capacity sale; BPA's capacity sales to the cities of BC Hydro for Canadian Entitlement beginning April 1998; and Northwest-Southwest intertie losses.

3) BPA's contracts out include BPA's contracts of Canadian Entitlement capacity and supplemental capacity to public agencies and IOUs; BPA's contracts with Clark County PUD and other public agencies (Packwood Lake); BPA's WNP-1 obligation contract with Montana Power Company, Pacific Power and Light, Portland General Electric, Puget Sound Power and Light, and Washington Water Power; BPA's WNP-3 settlement contract with Pacific Power and Light, Portland General Electric, Puget Sound Power and Light, and Washington Water Power; BPA's power transfer for its Southern Idaho load through Pacific Power and Light's system; BPA's capacity sale with Montana Power; BPA's surplus firm power sale to Puget Sound Power and Light, which converts to a seasonal exchange in OY 2001-02; and BPA's Baker Head loss replacement with Puget Sound Power and Light.

4/ Columbia Storage Power Exchange (CSPE) is the sale of the Canadian share of downstream benefits under the Treaty with Canada to a group of Northwest utilities, expiring April 1, 2003.

5/ BPA's generating public agencies' purchases are requirements which these agencies place on BPA under their power sales contracts and BPA's partnership program. BPA's obligation is each agrncy's net firm load requirements not served by its own dedicated resources.

6/ Generating private utility purchase is the contracted peak and en gy requirement placed on the Federal system under the IOUs' power sales contracts with BPA. Puget Sound Power and I.ight is the only IOU purchasing energy from BFA through June 30, 1998.

I/ Federal diversity is a percentage reduction applied to the Federal system non-coincidental peak utility requirements. This is due to the fact that all peaking electrical loads do not occur simultaneously throughout the region. 
8/ DSIs' aluminum and nonaluminum top quartile load and associater 1 ine losses are BPA's interruptible loads.

9/ Sustained peaking adjustment is a percentage reduction applied to the Federal hydro system to meet a capacity load of 50 hours per week. This adjustment also includes reductions for Federal hydro maintenance, spinning reserves, and forced outage reserves.

10/ Canadian Entitlement Return non-Federal (CSPE) reflects the public agencies' and IOUs' obligation of Canadian Entitlement allocation to the Northwest entities of the CSPE, which expires March 31, 2003. Canadian Entitlement Return non-Federal (Canada) reflects the Federal system, pub1ic agencies', and IOU' 'ob1igation of Canadian Entitlement allocation to Canada, which begins April 1, 1998.

11/ Restoration deals with the losses and gains of the hydro system due to Canadian storage under the terms of the Pacific Northwest Coordination Agreement. It is an obligation to those utilities that gained generation from the addition of Canadian storage, and a resource gain to utilities which lost generation from Canadian storage.

12/ BPA's imports include exchange energy from the cities of Anaheim and Riverside, and from M-S-R when its surplus firm power sale converts to a capacity/energy exchange on November 1, 2009; and power from Pacifiac Power and Light's Wyoming Nivision to serve BPA's Southern Idaho load.

13/ Contracts include Montana Power Company's return of exchange energy under its capacity/energy exchange contract with BPA; BPA's WNP-3 settlement contract with Pacific Power and Light, Portland General Electric, Puget Sound Power and Light, and Washington Water Power; and Puget Sound Power and Light's seasonal power exchange after conversion in OY 2001-02.

14/ Federal large thermal includes the generation from WNP-2, operated by WPPSS, and 30 percent of Portland General Electric's Trojan nuclear power plant, and a $8 \%$ seasonal purchase PNGC share of Bordman through operating year 1994-95.

15/ Resource acquisitions are resources which BPA identified for future purchase. When these resources are contracted for and/or on-line, they are included in the loads and resources balance.

16/ Hydro, small thermal and miscellaneous resources, and combustion turbine reserve requirements are estimated at 5 percent of the Federal capacity of these resources.

17/ Large thermal reserve requirements are estimated at 15 percent of the Federal share of Pacific Northwest thermal resources.

18/ Federal spinning reserve is the reserve generating capacity maintained to provide a regulating margin for the automatic generation and frequency contro? of power generation. 
$19 /$ Direct service industrial reserve requirements are two-thirds of the industrial firm load, or the sum of the reserve requirements for Federal hydro, small thermal and miscellaneous resources, combustion turbines and large thermal, whichever is smaller.

20/ Hydro maintenance is the sum of the Federal hydro maintenance based on the mean of the 1983-84 through 1988-89 schedules submitted to the Northwest Power Pool. 


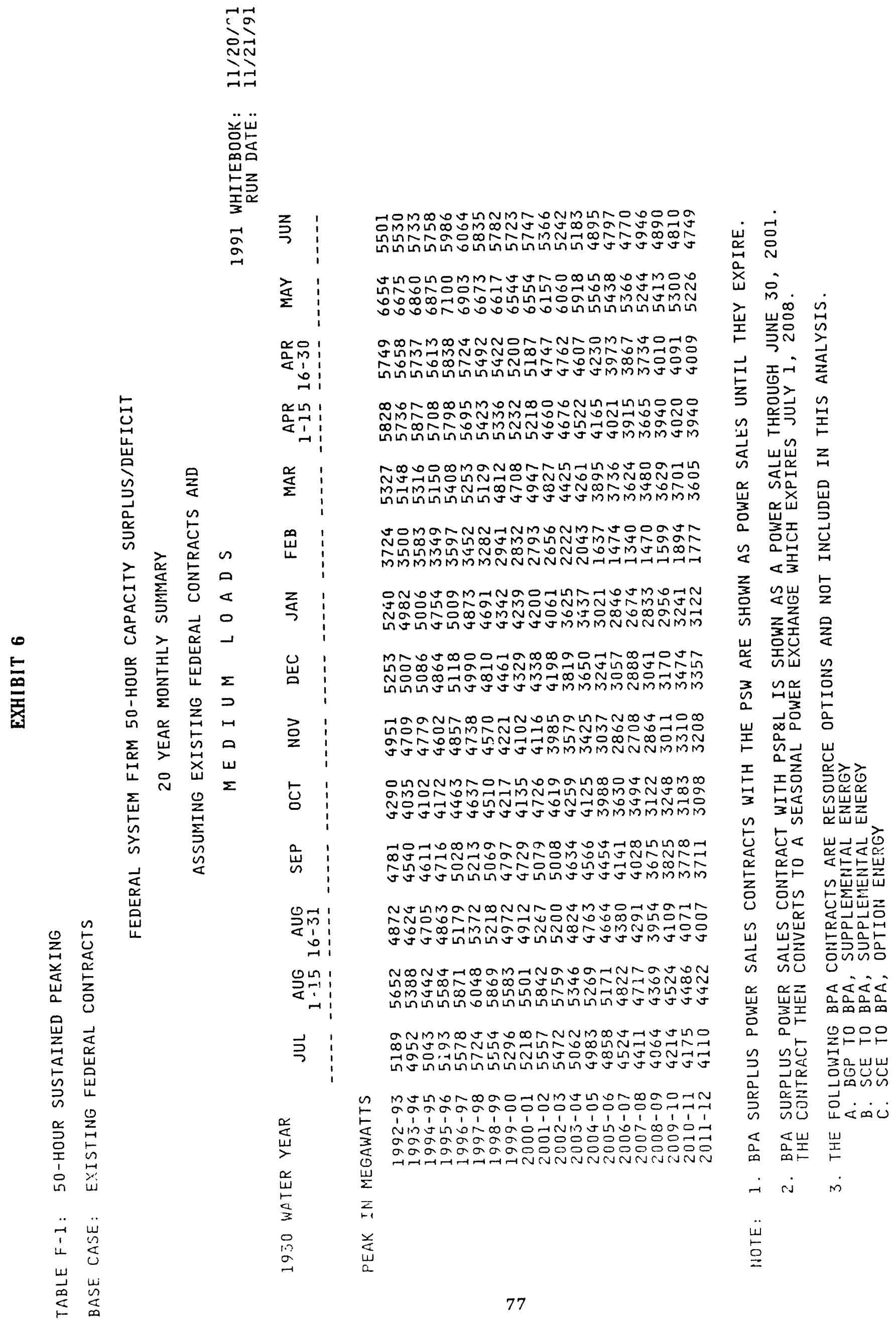




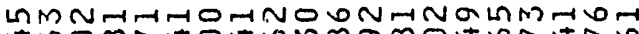
JoOn

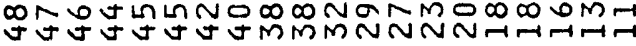

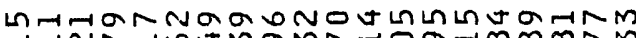

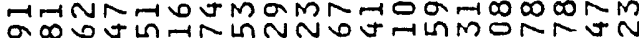

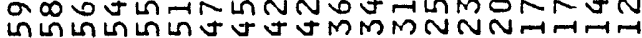

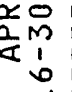

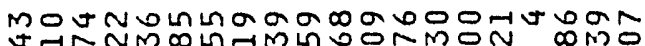

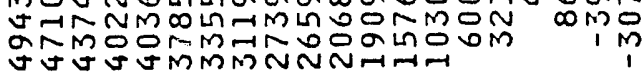

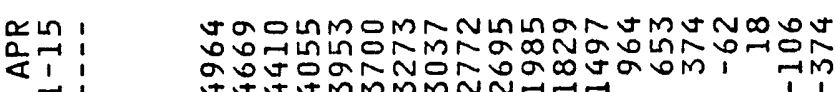
GummMNNT-1

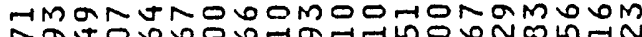
กิง

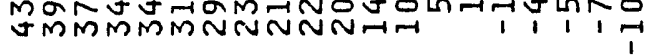

DHNDMHONNOMOTOULTHNN

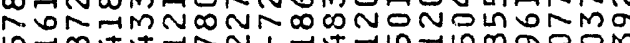

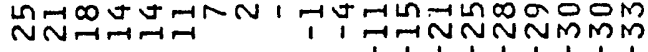

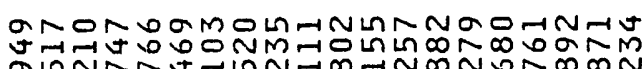

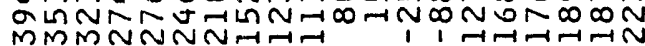
MMMNNNNATA $11,1,1,1$

㟔

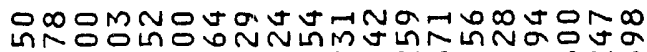

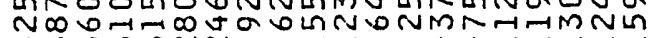
जMMMMNNAन्ता । 1

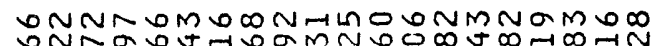

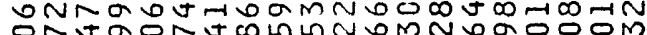

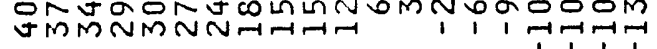

MHNGNNLINONMLIRMLUTMOOM MNTRNLIN

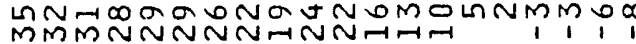

MNMMLROMDOUOONMUNOLO $\rightarrow \infty L 10 N$ N

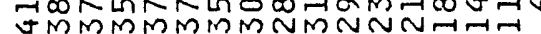

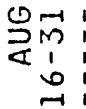

HIMOLMLDUGMULAMANMDNT OD ज以MMMUMMMMMNNNA-1

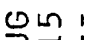

$\stackrel{2}{2}$

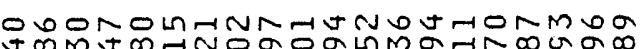

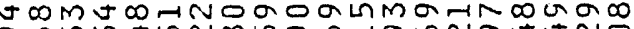
GUU

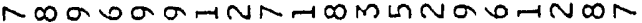
NNMLIMHOOONR In THOHMMNA

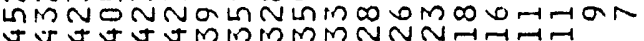

MULONDOHNMULUNDOHN

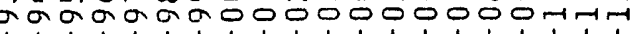
Nin

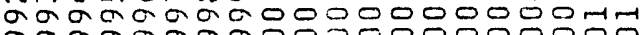
ãagagăoD 
ANMNGUNDLRULRMLDMODNL

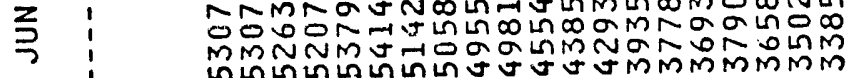

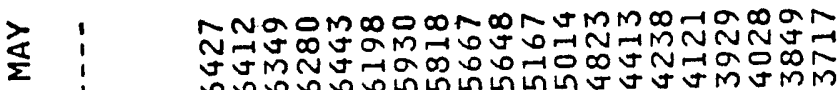

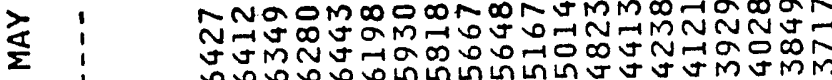

L 1 OUMHODOONOHMNNLINMNN

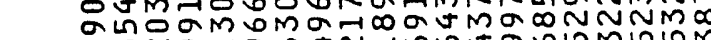

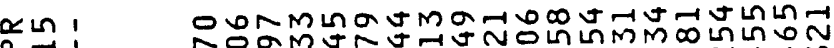
द:

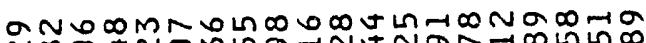

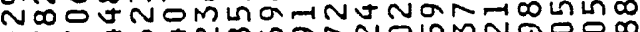

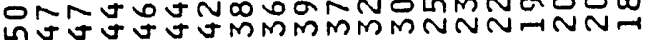

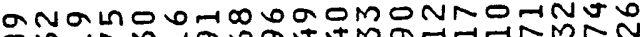

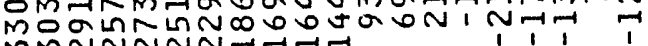

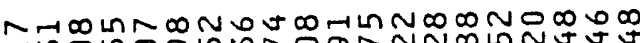
AMOLORLINTOKNNNDLNNGU

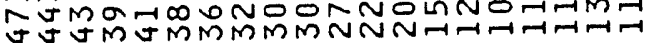

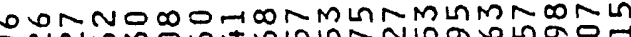
2NomOOU

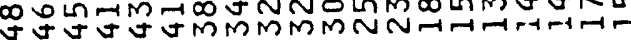

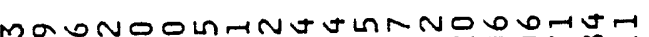
MaOOMMaGroOMONNOOND

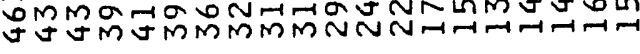

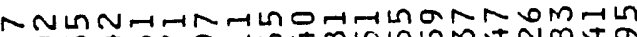
OOLU

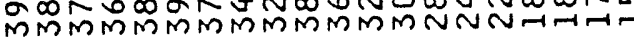

ง $\infty$ LnN

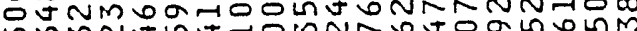
LMMNGUG 乌̈:

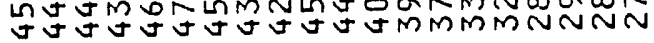

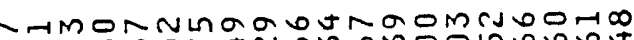
ri:

$\sum_{2}^{0} \underset{1}{1-1}$

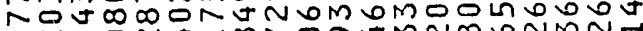

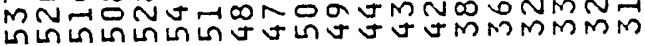

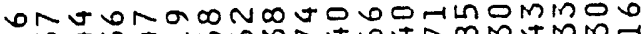
○ी

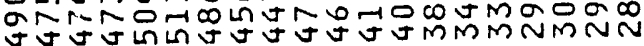

MULก N

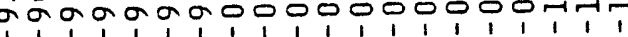
Nmún 类

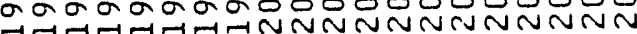

$i$

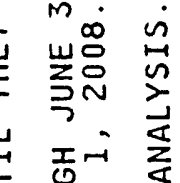

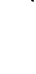

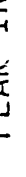$$
\text { - }
$$ 


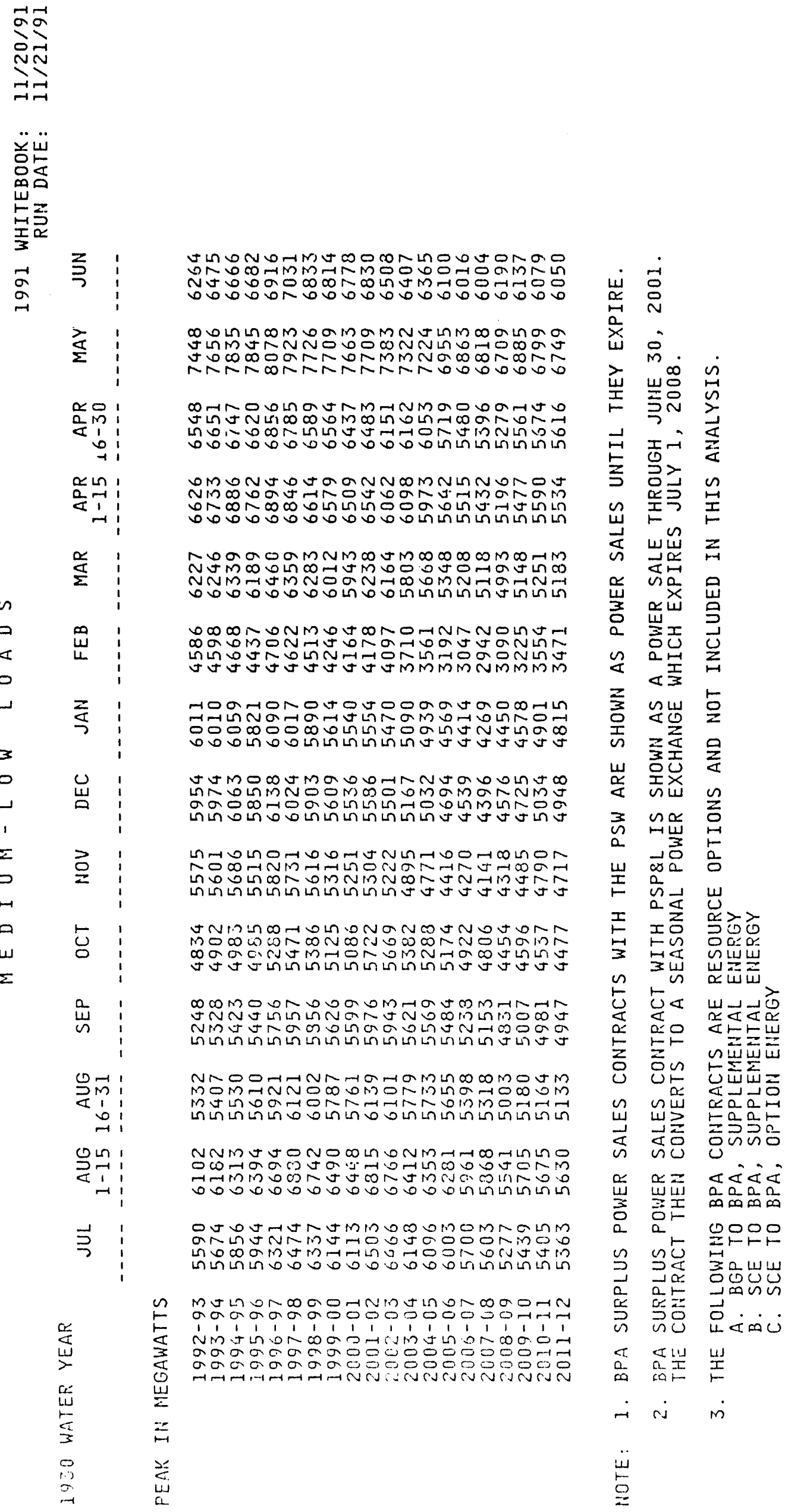




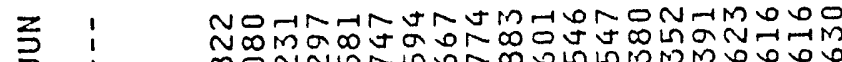

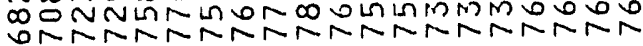

THUDOONNMNDOMOUMNTOD

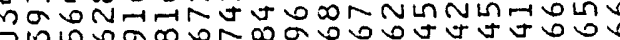
$\infty \infty \infty \infty \infty \infty \infty \infty \infty \infty \infty \infty \infty \infty \infty \infty \infty \infty \infty \infty \infty \infty \infty \infty \infty \infty)$

TO I DNNMAOLIRMNGIIONGNANON am

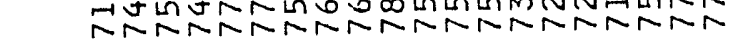

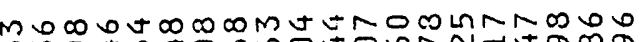

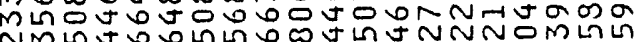

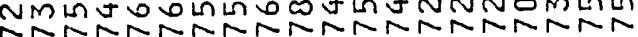

-

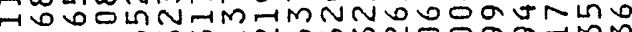
DoOOMMMNNORMNORGGTMM

M⿻

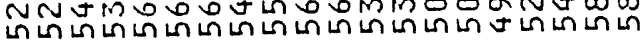

$\underset{w}{\infty}$

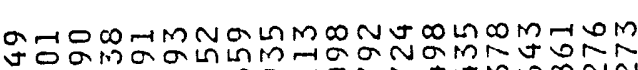

$\underset{5}{z}$ ช

Lก

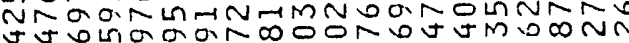

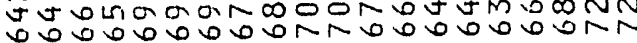

㟔

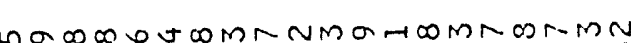
Lnampunm

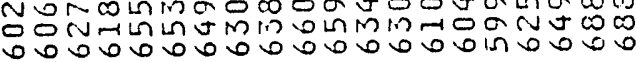

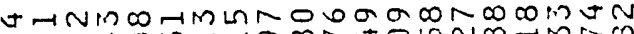

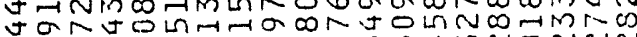
NN

๖ั

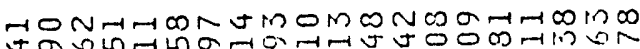
ง

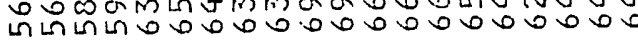

号冓

aक

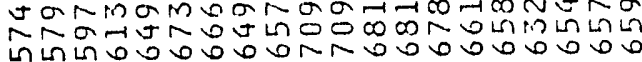

MNOLOLLMMULIN

$\bigcup_{1}$

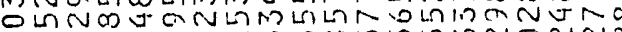

Lnthing

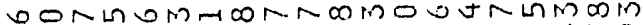

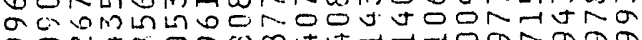

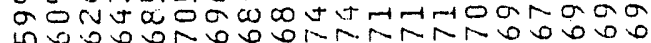

mULRONDOOHNIOULUONDOOHN

a a a a a a 000000000711

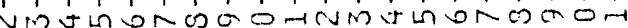

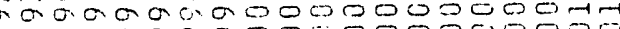

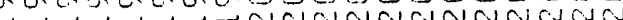

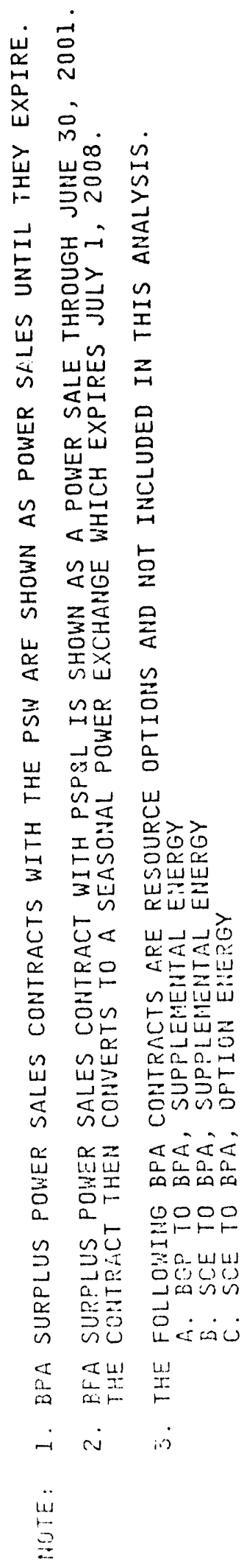


SECTION VII

REGIONAL SYSTEM EXHIBITS 


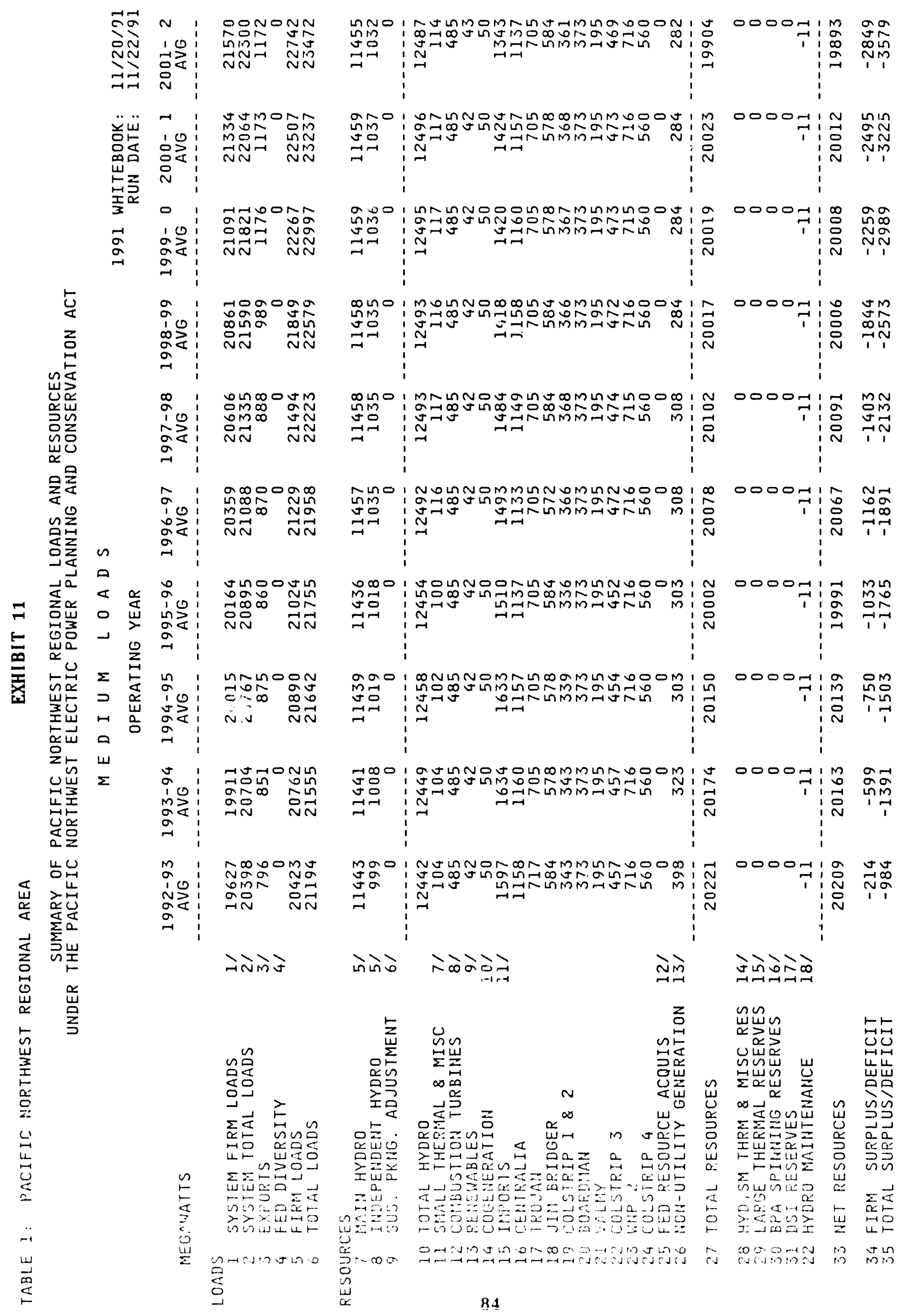




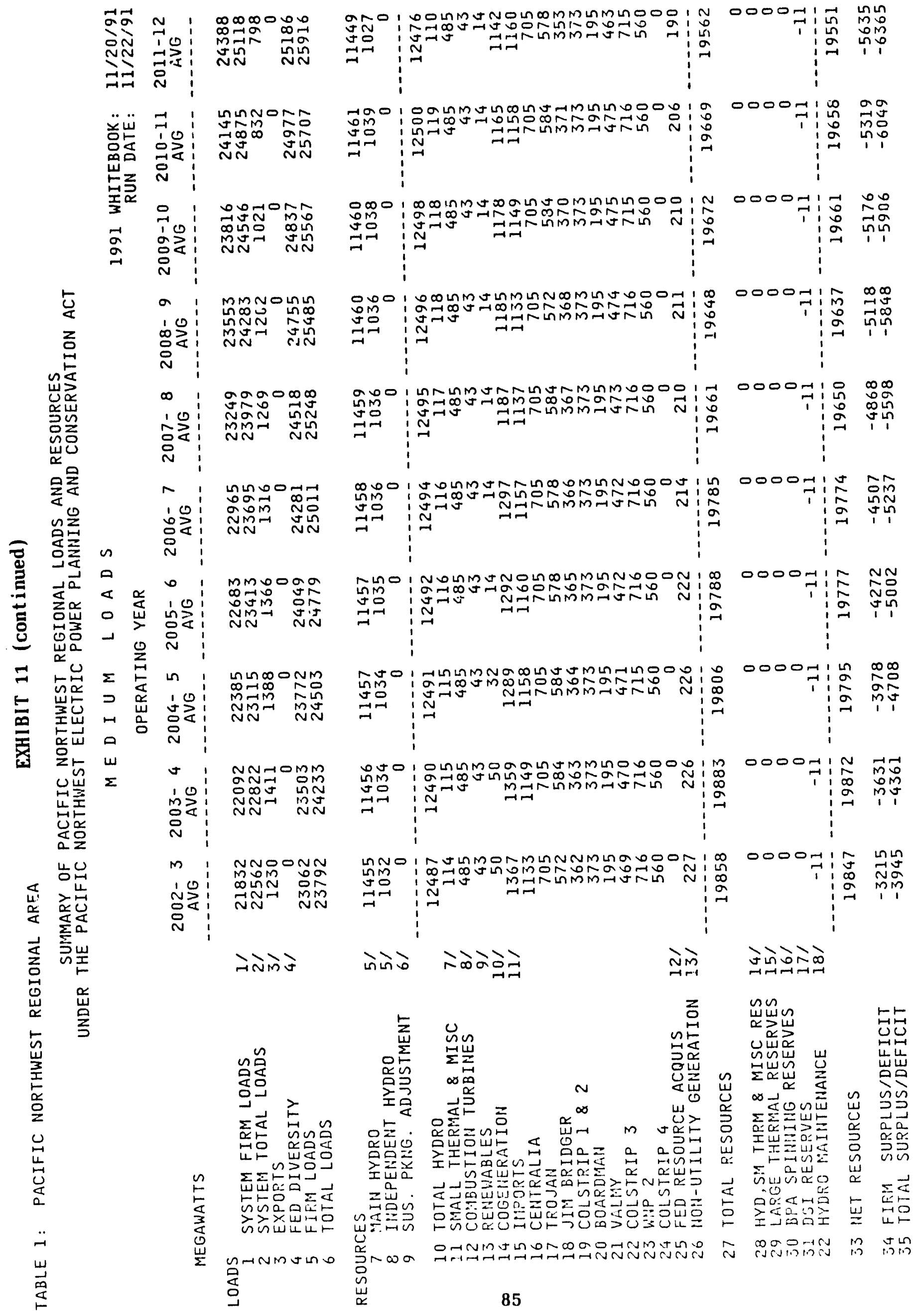




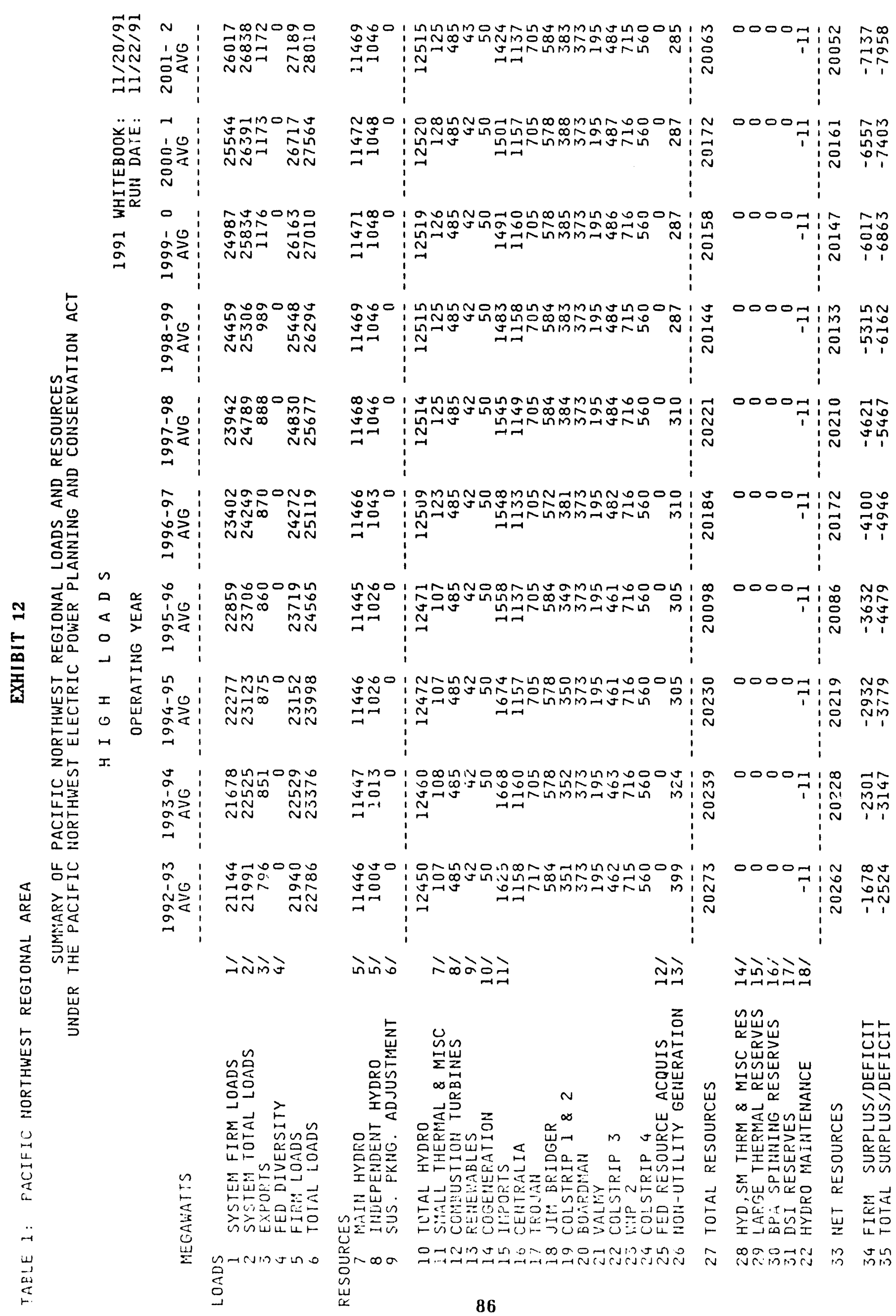




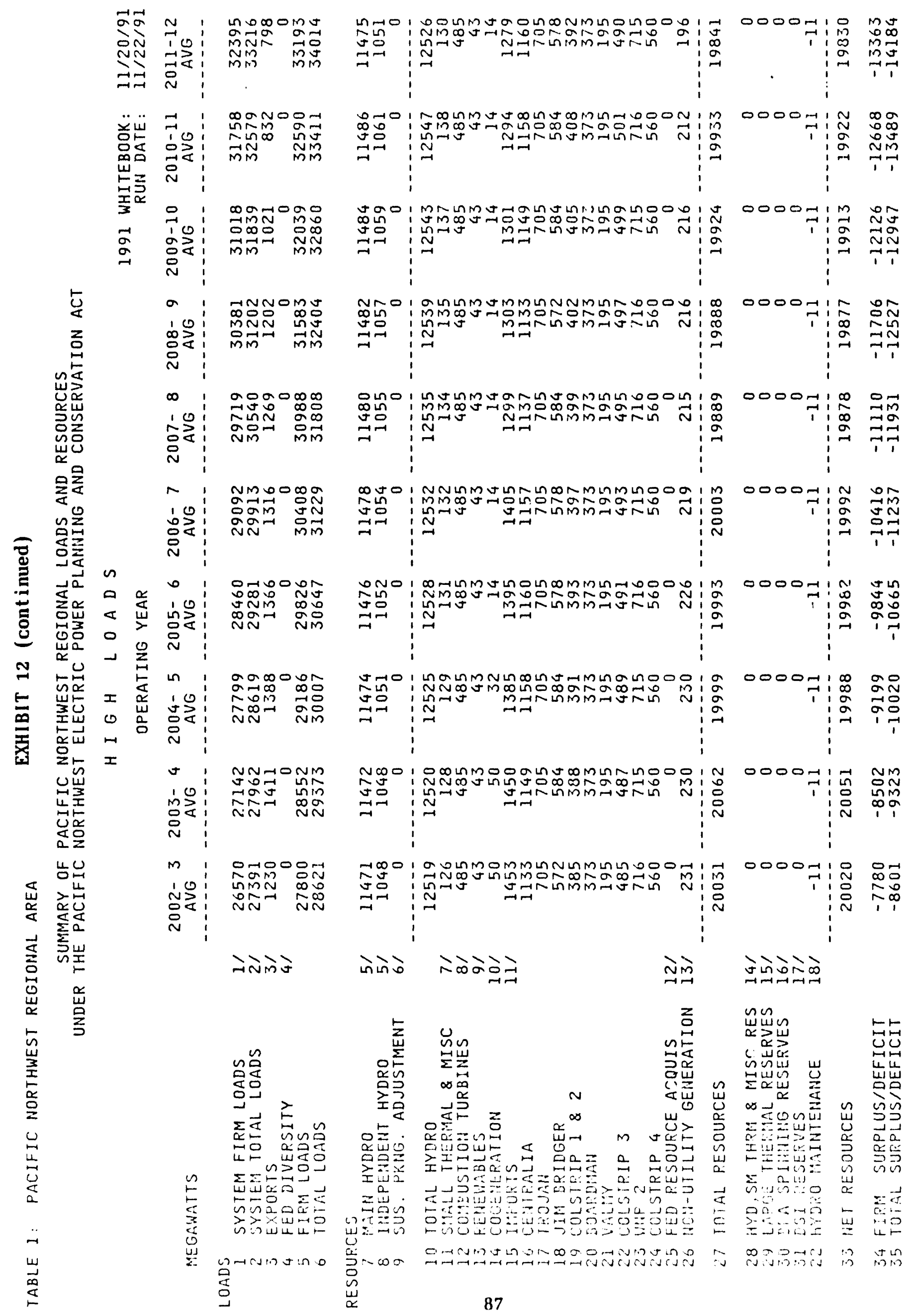




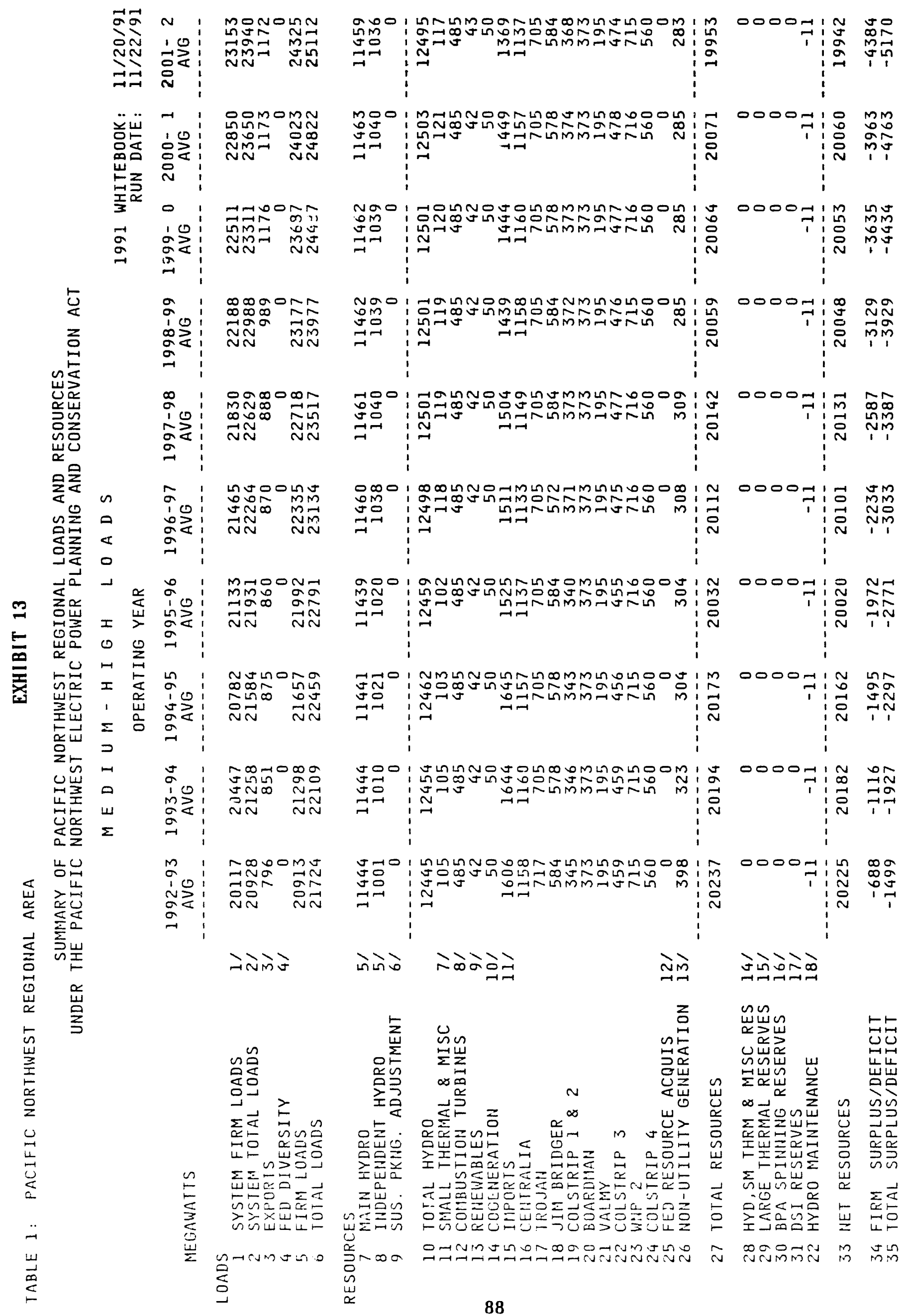




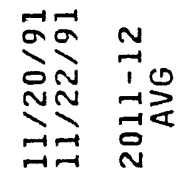

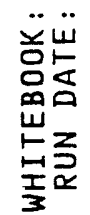

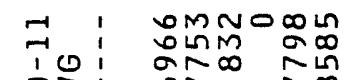

จํ̃त

N

बू

过

要

을

赵

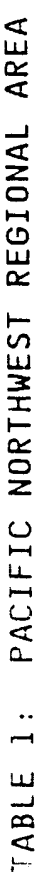

กิษั์

Mี

సึ $\quad \stackrel{\infty}{\infty}$

NN NN

ำก음

ปัก

10:

a I NONOUT

iी:

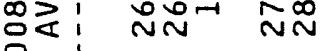

$\infty$ I mogona

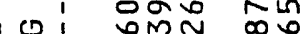

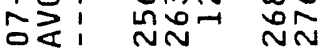

ก

$n$

n

$\rightarrow \infty 00 \mathrm{~N}$

0

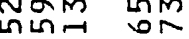

กิก Nก

品

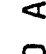

政

帘

战

峲㫐

동 虫

战

嵌

崖

종유

늠

$>0$

造造

$\sum_{i}$

剀

- InNDe- $\rightarrow$

นกำ

जิ녀ำ

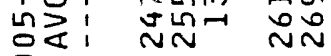

1

in $\quad$ Ompovi

प:

$\Sigma$ :

$\supset$

$\mapsto$

w

$\Sigma$

N

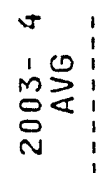

$\operatorname{LnTHODN}$

नूำ กีन

NNN

$m$ 1 omooom

ำ

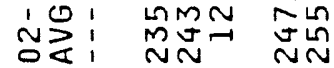

穴

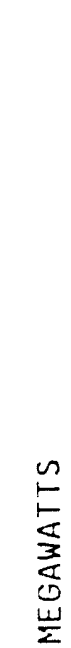

\section{नेतेले}

กต

옹ㅇ

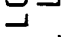

度点

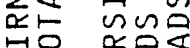

让品路

$-n>0$

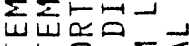

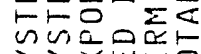

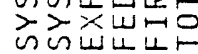

它

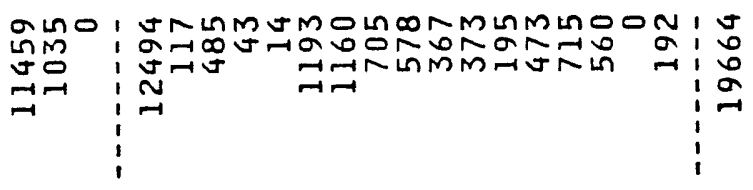

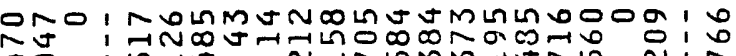

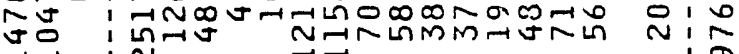

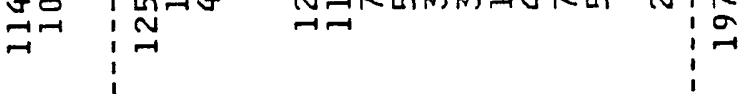

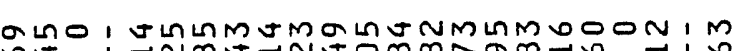

讨

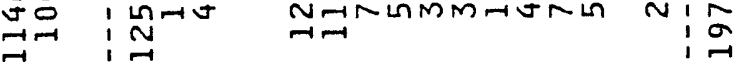

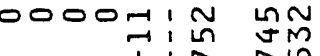

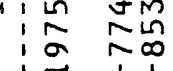

$0000-1 \ln m o$ $\rightarrow 1:$ 政 $10 \begin{gathered}\infty \\ 1\end{gathered}$

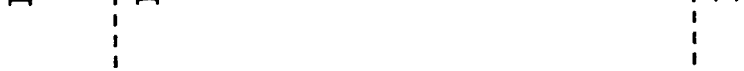

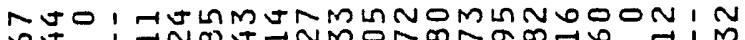

守品

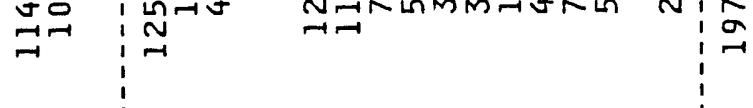

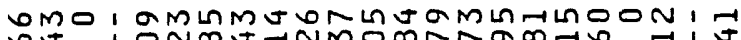

OU

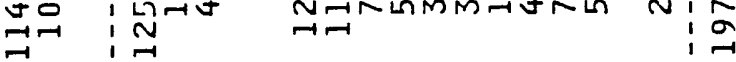
i

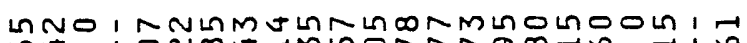

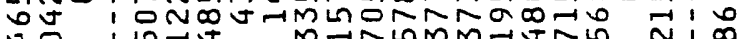

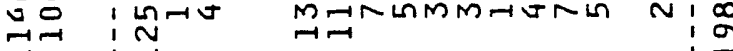<smiles>C1C[Al]1</smiles>

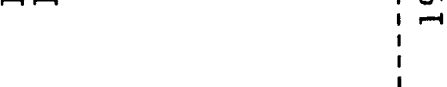

J70 ! L -

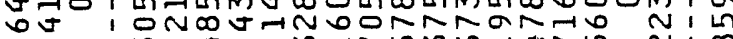

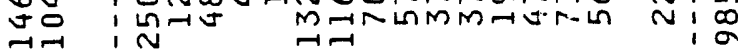

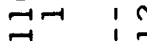
$\underset{1}{1}$

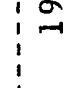

MaO, NOLMNHOLUMMLNOOON I

OM

जo :

$\begin{array}{l:l:l}\exists-1 & \sim & 0\end{array}$

-

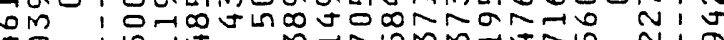

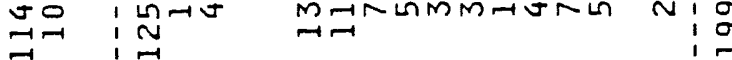

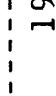

ONO N NOLMOLIMLNOMLINDOODI T

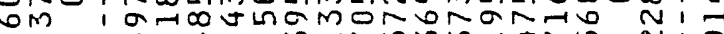

जo

$\rightarrow$

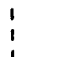

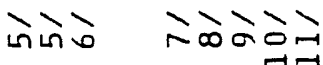

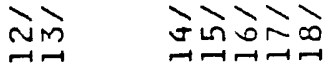

$0000-4 i i_{10}^{2}$ in a

$0000-1, \infty$ mo $\rightarrow 1 \stackrel{0}{0} 0$ a 1 î

$0-11000$

$\neg: \infty \infty ⿻ 上$ 10111

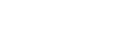

$0000 \pi 17 \min$ $1 ; 0$ a

DOFI: M MO a

(a)

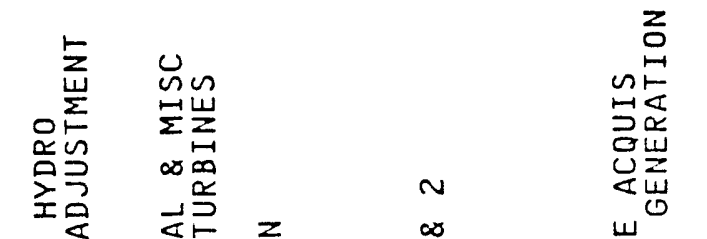

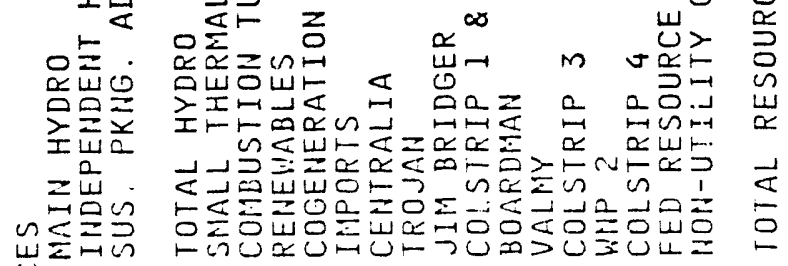

岁N

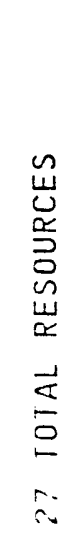

แึ山

崩出

ט $\frac{0}{2} \vec{x}$

我岕

턴

$\infty-\infty$

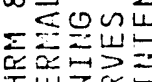

王些三品

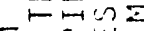

它的岕。

c

Q0心

넌기

늠 


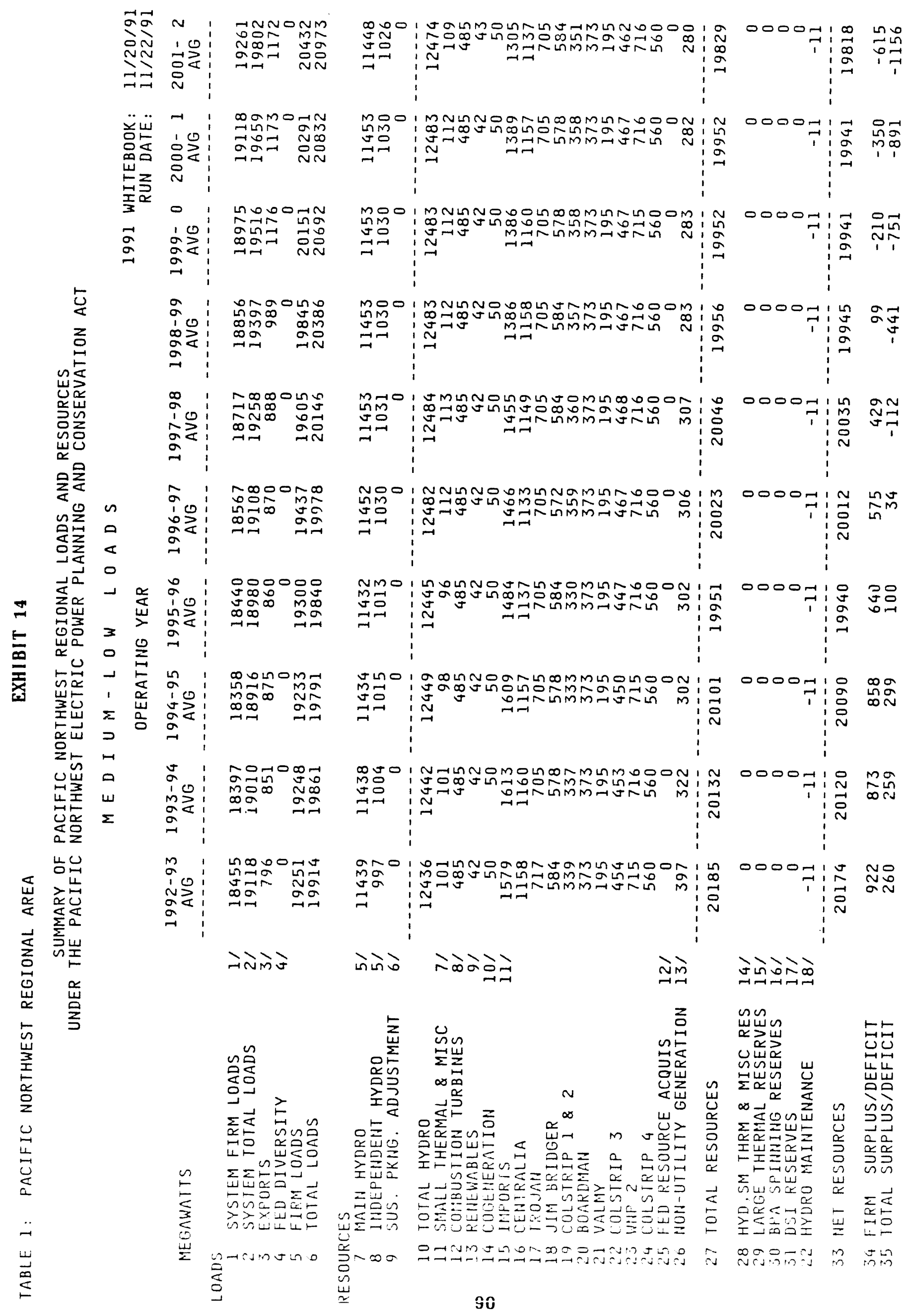




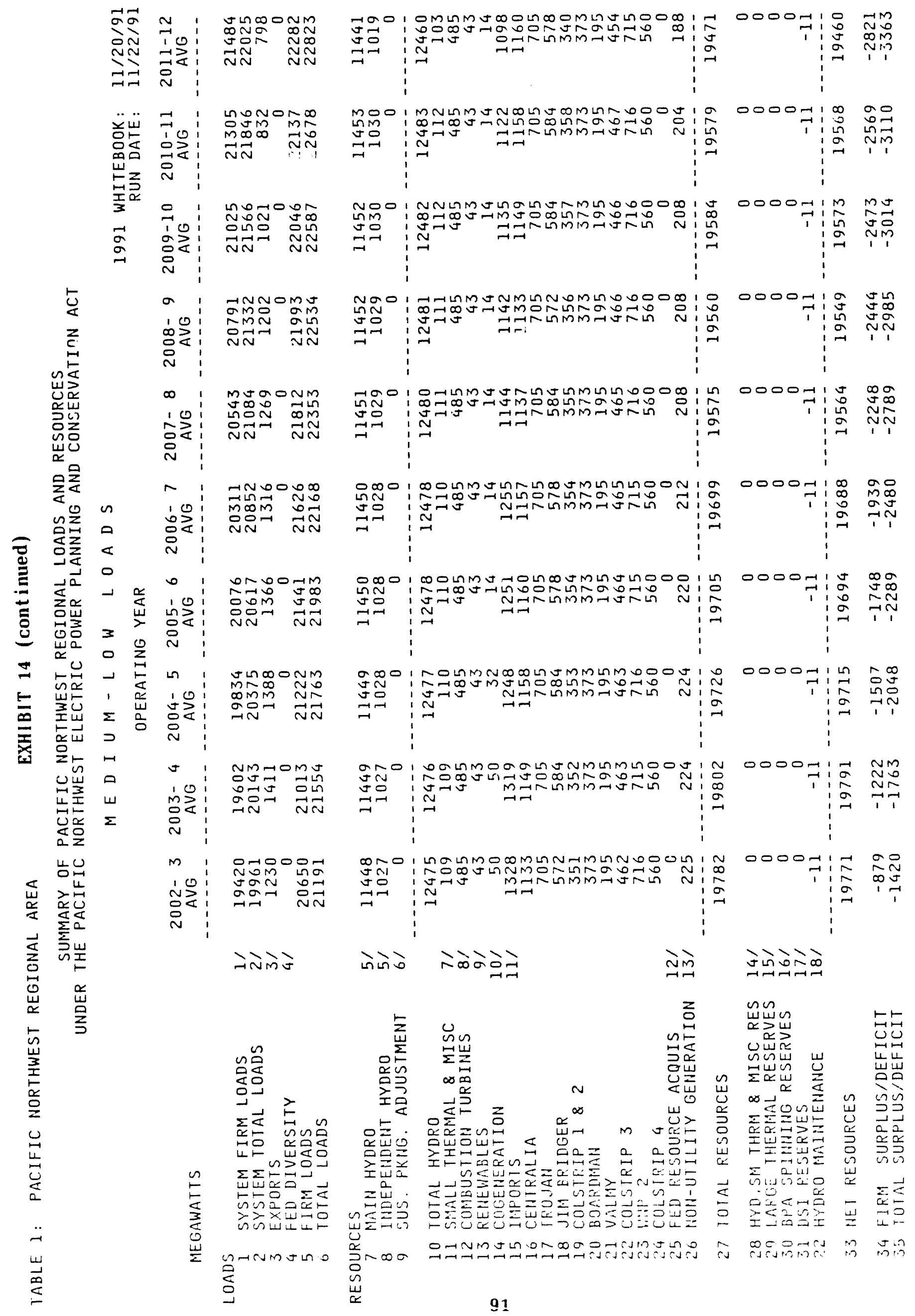




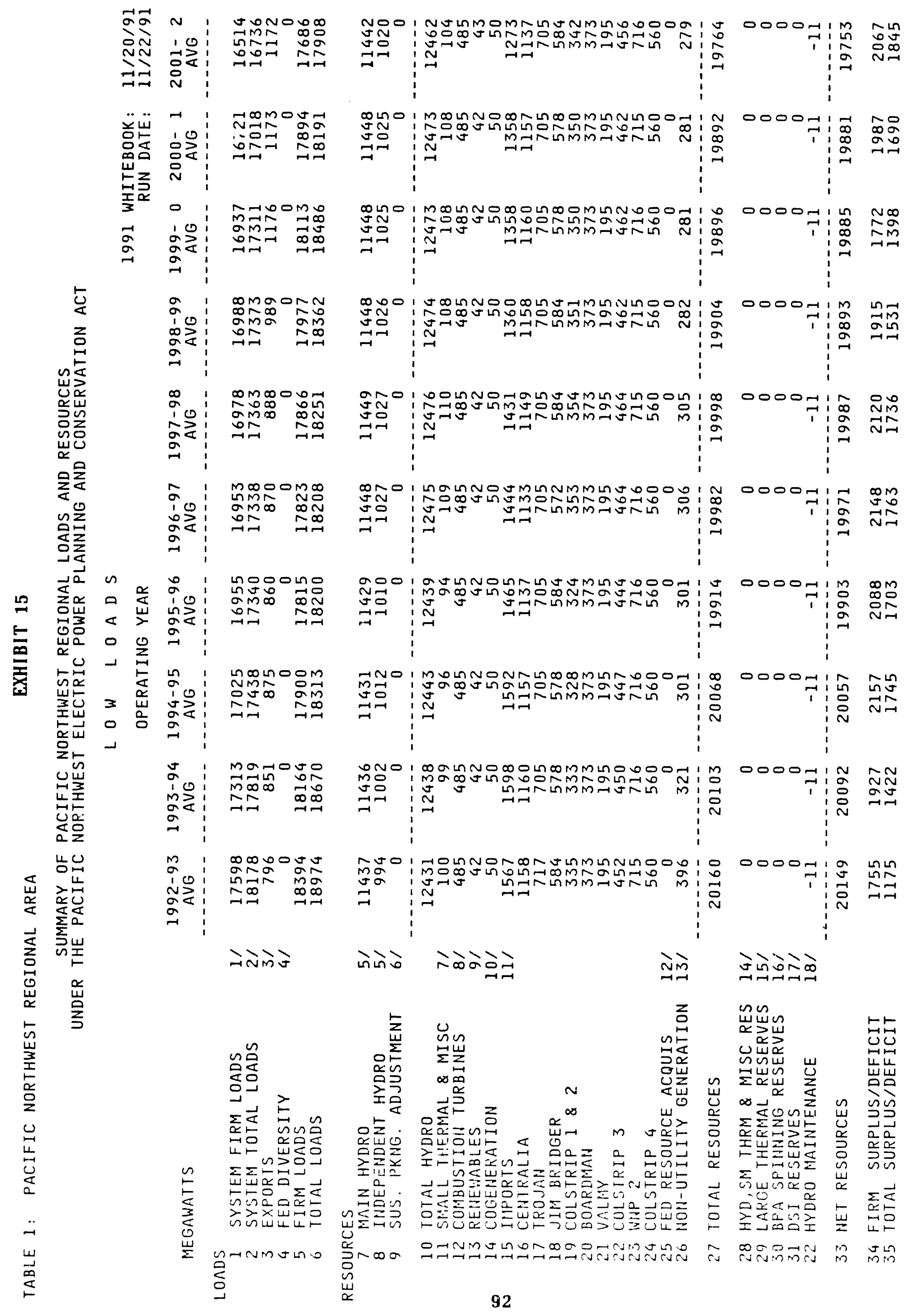




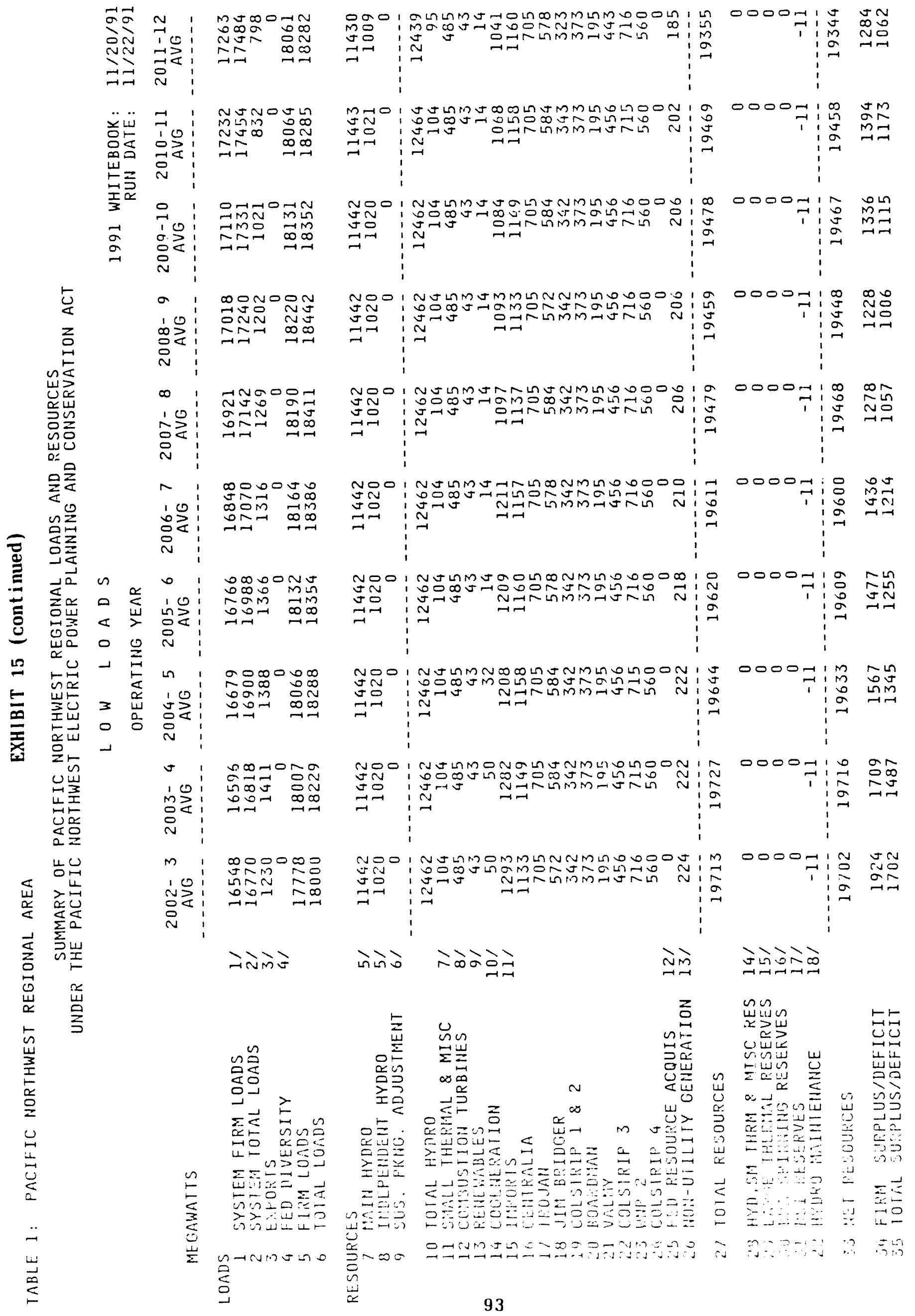




\section{REGIONAL FOOTNOTES}

\section{For Exhibits 11 through 15}

1/ Firm loads for the region include the sum of the estimated firm loads of Federal agencies, public agencies, Direct Service Industries (DSIs), Investor-Owned-Utilities (IOUs), and associated transmission losses. Peak loads represent non-coincidental capacity demands adjusted to account for Federal system diversity.

2/ Total loads for the region include system firm loads, plus BPA's nonfirm loads, which include industrial top-quartile loads, associated transmission losses, and Utah Power Company's interruptible load.

3/ Exports from the region by Northwest utilities include BPA's contracts for BPA's surplus firm power sales to the cities of Burbank, Glendale and Pasadena, and to Southern California Edison; BPA's surplus firm power sale to M-S-R Power agency which converts to capacity sale on November 1 , 2009; BPA's capacity sales to the cities of Anaheim and Riverside; BPA's contract with BC Hydro for Canadian Entitlement beginning Apri1 1, 1998; BPA's Northwest-Southwest intertie losses; Montana Power's power sale to the Los Angeles Deppartment of Water and Power; Pacific Power and Light's transfer to its Northern California load and its contracts with Pacific Gas and Electric, Southern California Edison, Sacramento Municipal Utility District, and Utah Power Company; Portland General Electric's contracts with City of Burbank, City of Glendale, Southern California Edison, and Western Area Power Administration (WAPA); Puget Sound Power and Light's contract purchased Pacific Gas and Electric; Seattle City Light's contract with Pacific Gas and Electric; Tacoma City Light's contract with WAPA; and Washington Water Power's contract with Pacific Gas and Electric.

Also included in exports are resources purchased by utilities outside the region. These include the WAPA's purchase of Longview Fibre and of San Diego Gas and Electric's purchase of 14.2 percent of Boardman.

4/ Federal diversity is a percentage reduction applied to the Federal system non-coincidental peak utility allocation requirements. This is due to the fact that all peaking electrical loads do not occur simultaneously throughout the region.

5/ Hydro resources are the sum of all utilities' regulated and independent hydro projects for Pacific Northwest regional utilities, except for Utah Power Company.

6/ Sustained peaking adjustment is a percentage reduction applied to the Federal hydro system to meet a capacity load of 50 hours per week. This adjustment also includes reductions for Federal hydro maintenance, spinning reserves, and forced outage reserves. 
I/ Small thermal and miscellaneous resources include Bonners Ferry's Diese1 No. 1, Diesel No. 2, and No Name; City of Idaho Falls' Diese1; Tacoma Public Utilities Steam Plant 2; Idaho Power's Energy Management System; Portland General Electric's Summit plants; Puget Sound Power and Light's Crystal Mountain and Shuffleton; Montana Power Company's portion of Corette and Bird in the region; and Seattle City Light's Boundary.

8/ Combustion turbines include Idaho's Wood River; Portland General Electric's Bethel and Beaver; Puget Sound Power and Light's Whidbey Island, Whitehorn, Fredrickson, and Fredonia units; and Washington Water Power's Northeast units.

9/ Keriswables include Emerald County PUD's Short Mountain; and Washington Water Power's Kettle Falls.

10/ Cogeneration includes Eugene Water and Electric Board's WEYCO Energy Center and Willamette Steam Plant.

Longview Fibre is sold outside the region to WAPA.

11/ Imports include exchange energy to BPA from M-S-R Public Power Agency after the surplus firm sale conrerts to a capacity/energy exchange beginning November 1, 2009; Anaheim and Riverside exchange energy to BPA; the cities of Burbank and Glendate contracts with Portland General Electric; Southern California Edison's contracts with Pacific Power and Light, Portland General Electric; Pacific Power and Light's transfers from Pacific Power and Light's Wyoming Division; BC Hydro and Pacific Gas and Electric's contracts with Puget Sound Power and Light; BC Hydro and Pacific Gas and Electric's contracts with Seattle City Light; Utah Power Company's intra-company transfer; and Pacific Gas and Electric's contract with Washington Water Power.

12/ Resource acquisitions are resources which BPA identified for future purchase. When these resources are not yet contracted for or on-line, they are not in this loads and resources balance.

13/ Non-Utility Generation are resources provided to utilities by independent power producers and bay be included under the Public Utility Regulatory Policies Act (PURPA).

14/ Hydro, small thermal and miscellaneous resources, and combustion turbine reserve requirements are estimated at 5 percent of the capacity of these resources for all utilities in the region.

15/ Large thermal reserves requirements are estimated at 15 percent of the total capacity of the Pacific Power and Light thermal import into the region plus the large thermal resources owned by utilities in the region.

16/ Federal spinning reserves equal the reserve generating capacity maintained to provide a regulating margin for the automatic generation and frequency control of power generation. 
17/ Direct service industry reserve requirements are estimated at two-thirds of the industrial firm load, or the sum of the reserve requirements for Federal hydro, small thermal and miscellaneous resources, combustion turbines and large thermal, whichever is smaller.

18/ Hydro maintenance is the sum of individual Federal system, public agencies, and IOUs hydro maintenance, based on the average of the 1983-84 through 1988-89 schedules submitted to the Northwest Power Pool. 


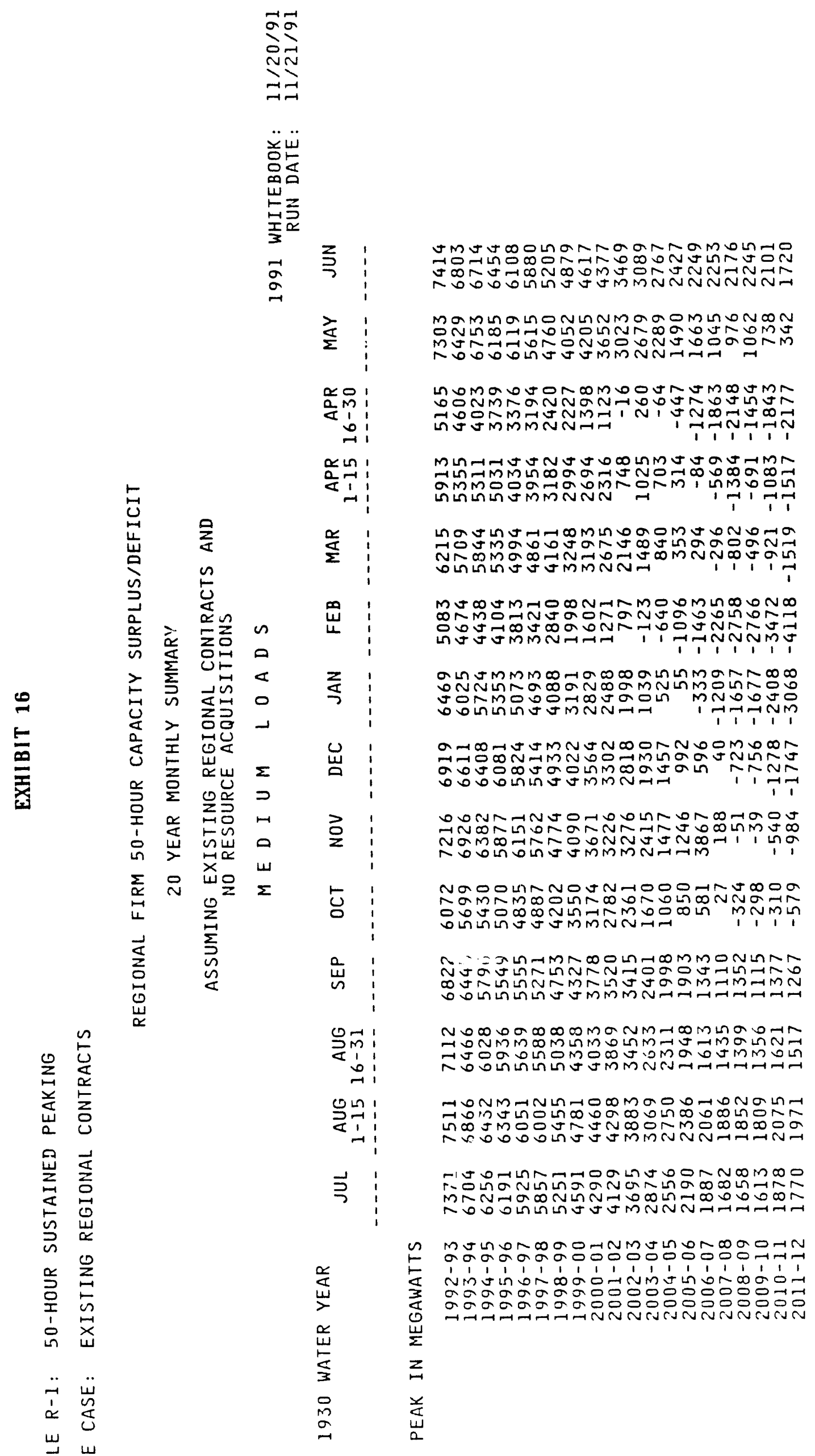




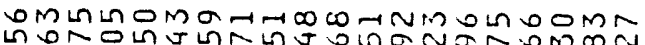
O०㇒o⿱

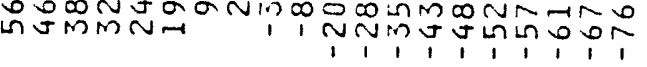

$\frac{2}{\Sigma}$

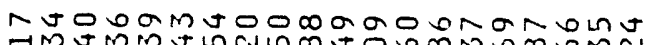
GMU

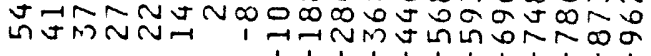

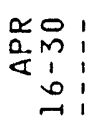

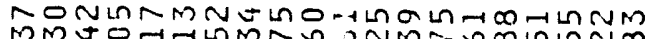
MMUOFتILMNODNM- OOLLIND

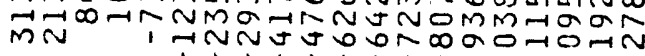
$11111,1,1,0=1$

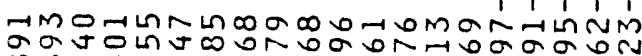

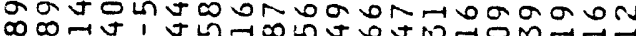
MNNU士 1 $111,1,1,1, \pi=1$ แn

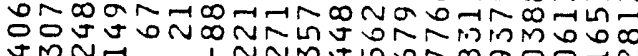
$1,1,1,1,1,1,-17$

w

崖

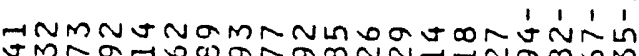

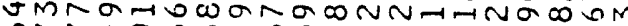

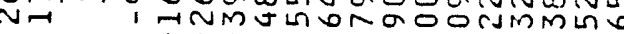
$\begin{array}{lllllllll}1 & 1 & 1 & 1 & 1 & 1 & 1 & 1 & 1\end{array}$ $\sum$

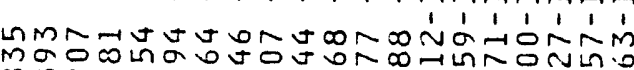
法 $\infty \infty a$

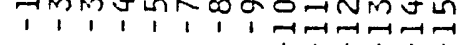
㟔

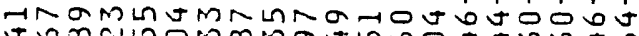

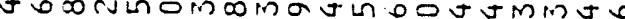
D

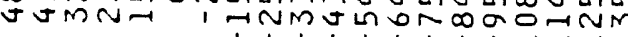
$1,1,1,1,1, \exists=1$

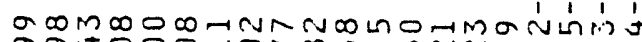
Nov กำNNA $11,1,1,1,1,0$

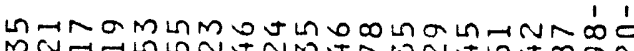

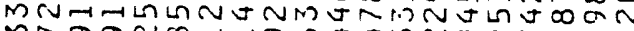

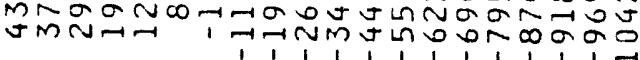

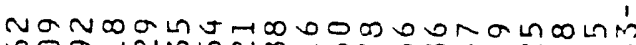

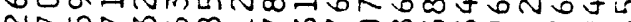
ผึ์

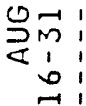

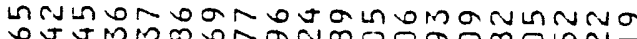
LNminconando

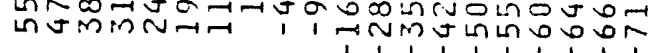

는

1

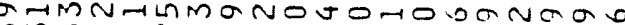

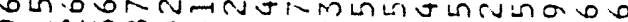

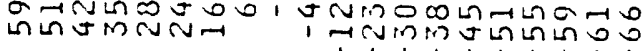

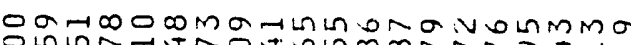

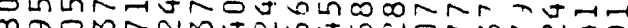

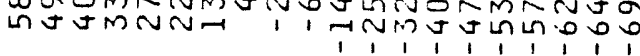

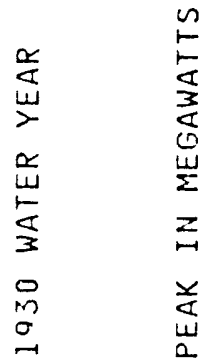

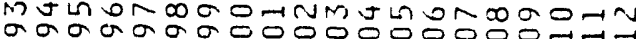

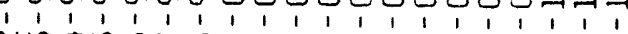

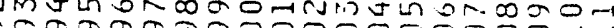

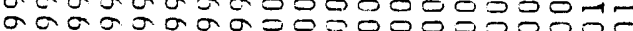

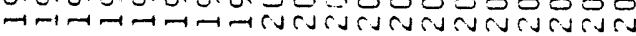




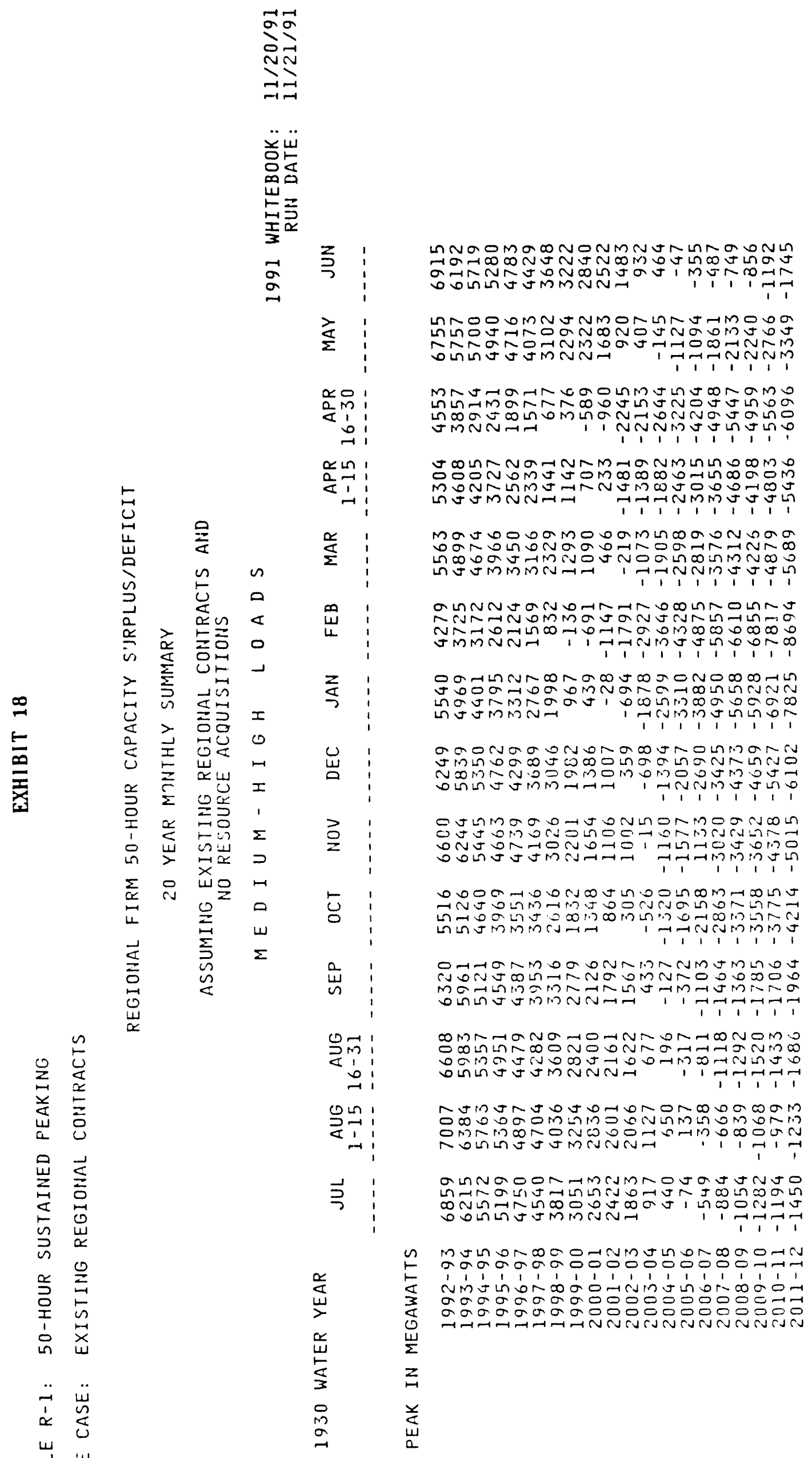




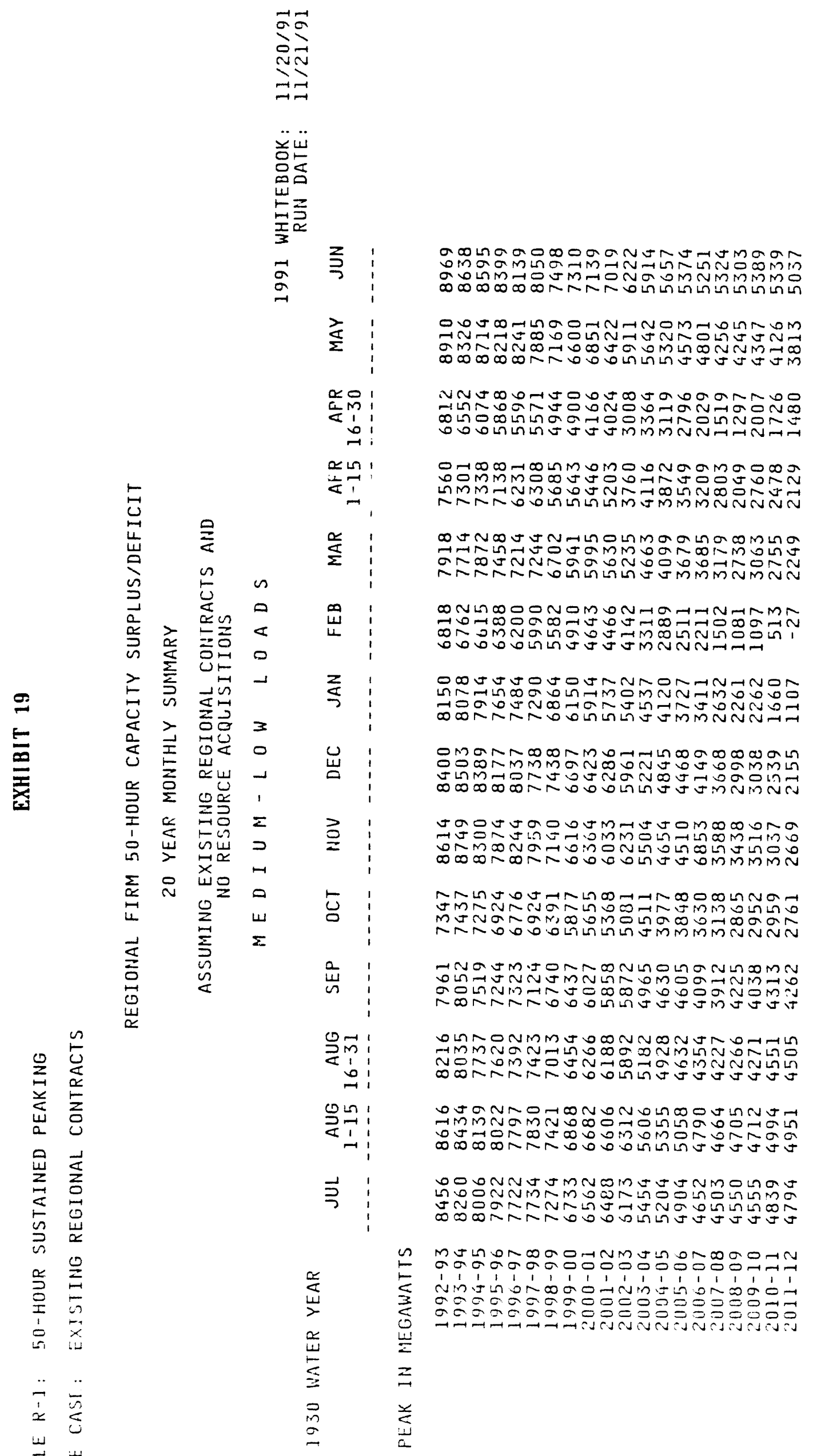


ONNNODG

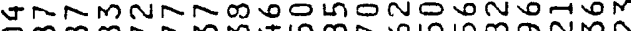

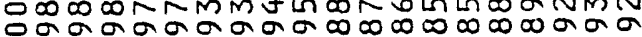

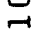

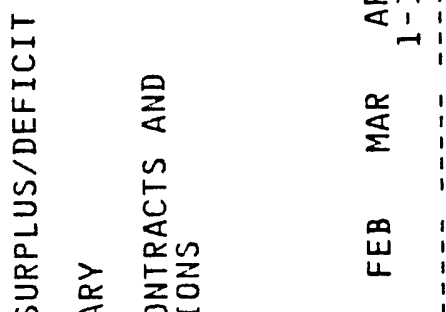

Mு M-10

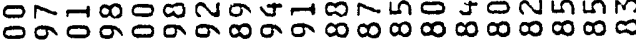
$\rightarrow \Rightarrow$

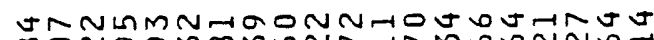

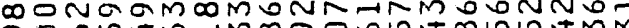

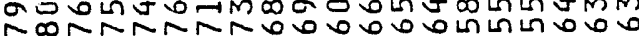

$\propto$ ㄴํ 1

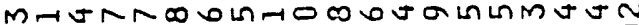

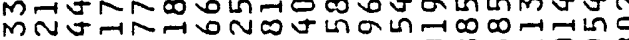
क⿻心㇒木

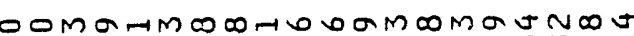

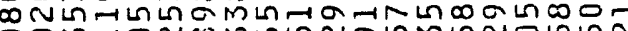
OON-10

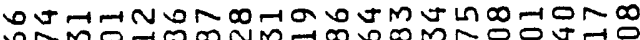
서메 D

OLOLOONOMMOUONNDNOUNO

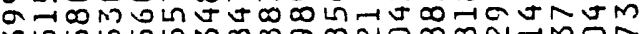

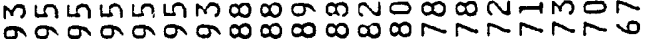

MLก Dm.

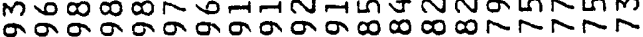

₹ษำm

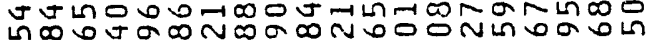

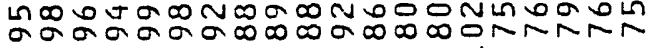

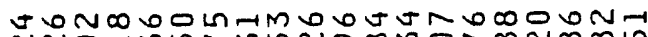
NNOHIRLNLNNODMONDNDEL

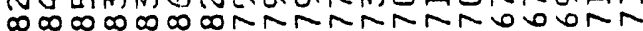

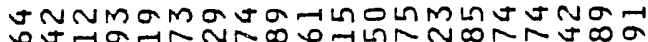
OU

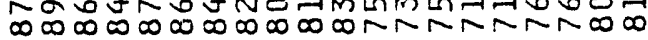

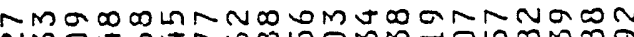
NMOUG $0 \infty \infty \infty \infty \infty \infty \infty \infty \infty \infty \infty \pi)$

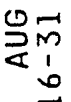

过艺:

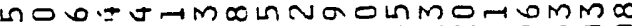

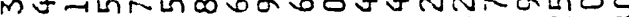

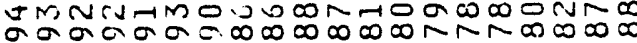

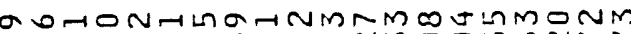
NADOATLLIONONMOOMUNN

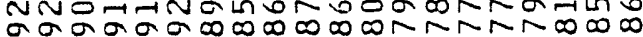

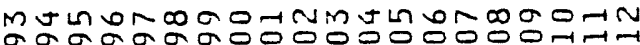

1

NmuLnowas

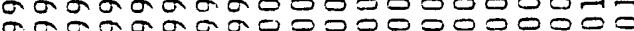

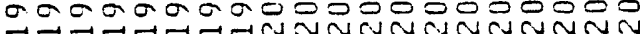


SECTION VIII

\section{GLOSSARY}




\section{$\underline{\text { GLOSSARY }}$}

Average Megawatts - A unit of electrical consumption or production over a year. It is equivalent to the energy produced by the continuous use of one megawatt of capacity served over a period of one year. (Equivalent to 8.76 gigawatt hours, 8,760 megawatt hours, or 8,760,000 kilowatt hours.)

Biomass - Any organic matter which is available on a renewable basis including forest residues, agricultural crops and waste, wood and wood wastes, animal wastes, livestock operation residue, aquatic plants, and municipal wastes.

Boiling Water Reactor (BWR) - A nuclear power plant in which steam from the reactor is fed directly into the steam turbine.

Bonneville Power Administration (BPA) - BPA is a power marketing agency, responsible for acquiring and delivering sufficient power to meet its contractual obligations to serve the electrical needs of its customers. BPA does not own generating resources.

Calendar Year - Calendar year (CY) is the 12-month period January 1 through December 31. For example, CY 1993 is January 1, 1993 through December 31, 1993.

Capacity - The maximum power that an electrical system or machine such as a hydro powered or thermal powered generating plant can produce under specified conditions.

Capacity factor - The ratio of the average load on a machine or piece of equipment over a given period to the maximum power rating of the machine or equipment.

Cugeneration - The simultaneous production of electricity and useful heat energy from a fuel source. Often this is accomplished by the recovery of waste energy caused by various industrial and commercial operations. This is typically used for industrial processes or space heating applications.

Conservation - Any reduction in electrical power consumption as a result of increases in the efficiency of energy use, production, or distribution.

Critical Period - That portion of the historical streamflow record during which the recorded streamflows, combined with all available reservoir storage, produced the least amount of energy.

Dedicated Resources - Generating resources owned by a utility and used to serve its firm loads. These resources are declared for a rolling 7-year period in Exhibit I of the utilities' power sales contracts with BPA. 
Direct Service Industries (DSI) - A group of industrial customers that purchase electric power directly from BPA. Most DSI's are aluminum and other primary metal smelting plants.

Diversity - An adjustment applied to peak loads to reflect the fact that all peaking electrical demands do not occur simultaneously across the region.

Energy Load - The demand for power averaged over a specified period of time.

Federal Columbia River Power System (FCRPS) - The FCRPS consists of 30 Federal hydroelectric projects constructed and operated by the U.S. Army Corps of Engineers (COE), U.S. Bureau of Reclamation (USBR), plus BPA's transmission facilities.

Federal system - The Federal system is a combination of BPA's customer loads and contractual obligations, and resources from which BPA acquires the power it sells. The resources include plants operated by the U.S Army Corps of Engineers (COE), U.S. Bureau of Reclamation (USBR), and hydroelectic projects owned by the city of Idaho Falls and WPPSS. BPA markets the thermal generation from WNP-2, operated by WPPSS and 30 percent of the output of Portland General Electric's Trojan nuclear power plant.

50-Hour Peak Capacity - The amount of capacity that can be sustained for 10 hours a day during peak-load hours for a five-day week.

Firm Capacity - Maximum on-peak electrical energy which is considered assurable to the customer to meet all contractual peak load requirements over a defined period.

Firm Energy - Electric power which is considered assurable to the customer to meet all contractual energy load requirements over a defined period.

Firm Energy Load Carrying Capability (FELCC) - The amount of electrical energy load that a hydro system could serve on a firm basis under critical-period streamflows.

Fiscal Year - In this study, fiscal year ( $F Y$ ) is the 12 month period October 1 to September 30. For example FY 1992-93 is October 1, 1992 to September 30, 1993.

Forced Outage Reserve - Capacity that is held in reserve, for use in case a generating unit malfunctions.

Forced Energy Sale (Spill) - Electrical energy that cannot be accepted into the system and must either be sold or spilled due to constraints and limitations of hydro projects.

Historical Streamflow Record - The unregulated streamflow database of the 50-years from July 1928 to June 1978. 
Hydroregulation - A study simulating operation of the Pacific Northwest electric power system that incorporates the historical streamflow record, monthly loads, thermal and other non-hydro resources, hydroelectric plant data for each project, and the constraints limiting each project's operation.

Interruptible Loads - Loads that can be interrupted in the event of a power deficiency on the supplying system.

Megawatts - A unit of electrical power equal to one million watts or one thousand kilowatts.

Model Conservation Standards (MCS) - A set of energy efficient building standards for new electrically heated residential and commercial and residential buildings. It also includes standards for residential and commercial buildings that have been changed to electric space heating.

Nondedicated Resources - Resources brought into service after June 1980 by BPA customers who choose not to use them to serve their own firm loads.

Nonfirm Energy - Electrical power produced by the hydro system that is availabie with water conditions better than those of the critical period without appreciably jeopardizing reservoir refill. It is available in varying amounts depending upon season and weather conditions.

Nonfirm Energy Loads - Loads that are seved with nonfirm energy whenever it is available.

Obligation - Capacity and energy the Federal system is required to provide to public agencies and IOU's under their power sales contracts with BPA.

Operating Year - For this study, operating year (OY) is the 12 -month period July 1 to June 30. For example, or 1992-93 is July 1, 1992 to June 30, 1993.

Peak Load - The maximum demand for power during a specified period of time.

PURPA Resources - Rescurces declared by utilities according to the Public Utility Regulatory Policies Act of 1978 (Public Law 95-617).

Region - The geographic area defined by the Pacific Northwest Electric Power Planning and Conservation Act. It includes Oregon, Washington, Idaho, Montana west of the Continental Divide, portions of Nevada, Utah, and Wyoming that lie within the Columbia River drainage basin; and any rural electric cooperative customer not in the geographic area described above but served by BPA on the effective date of the Northwest Power Planning Act.

Resource Acquisitions - Conservation or generating resources acquired in order to meet projected firm energy deficits.

Spinning Reserves - Reserve generating capacity which is maintained for immediate response to load variations. This provides a regulating margin for controlling the automatic generation and frequency of power in the Federal system. 
Surplus firm Capacity - The maximum amount of assured electrical power above the firm peak loads served by the power system.

Surplus firm Energy - The amount of assured electrical energy above the firm energy loads served by the power system.

Sustained Peak - The peaking capacity necessary to sustain a load for a given period of time.

Water Budget - A part of the Pacific Northwest Power Planning Council's Fish and Wildlife Program which calls for a quantity of water to be released in order to assist in the downstream migration of juvenile salmon and steelhead.

$(6582 f)$ 

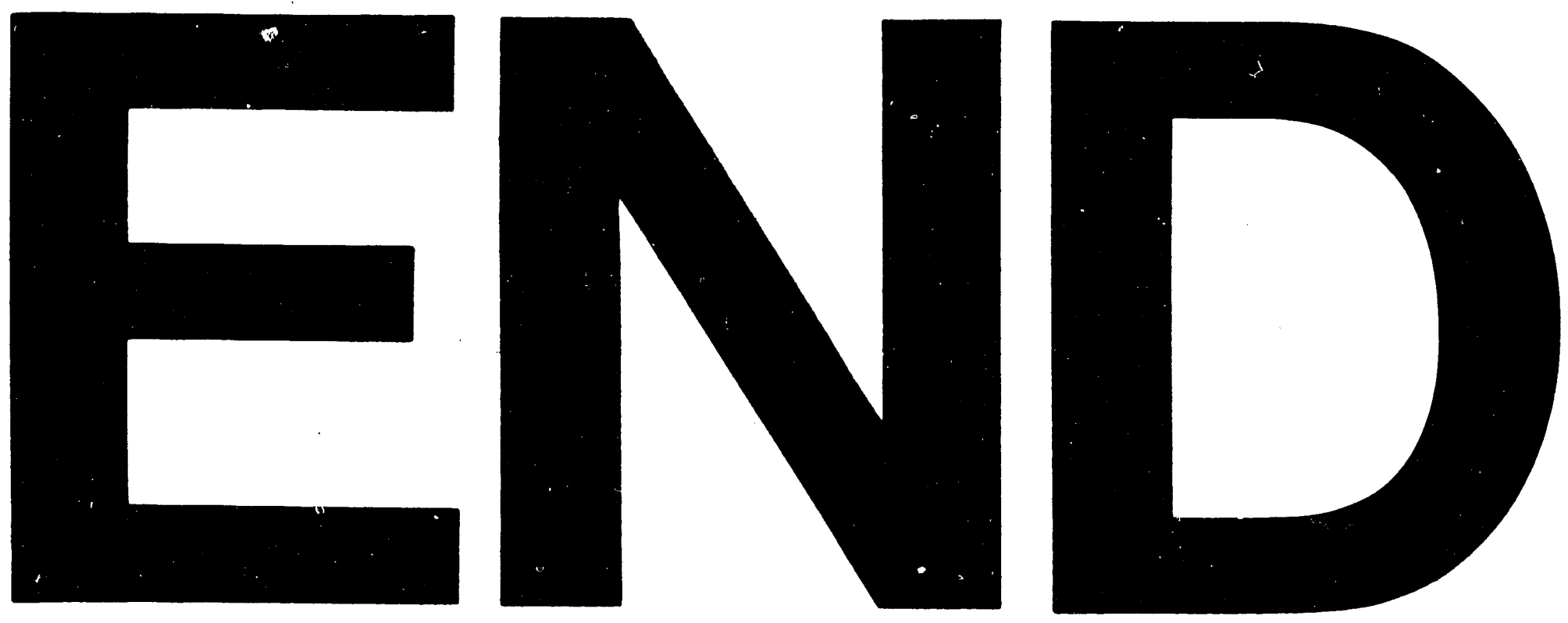

$\dagger$
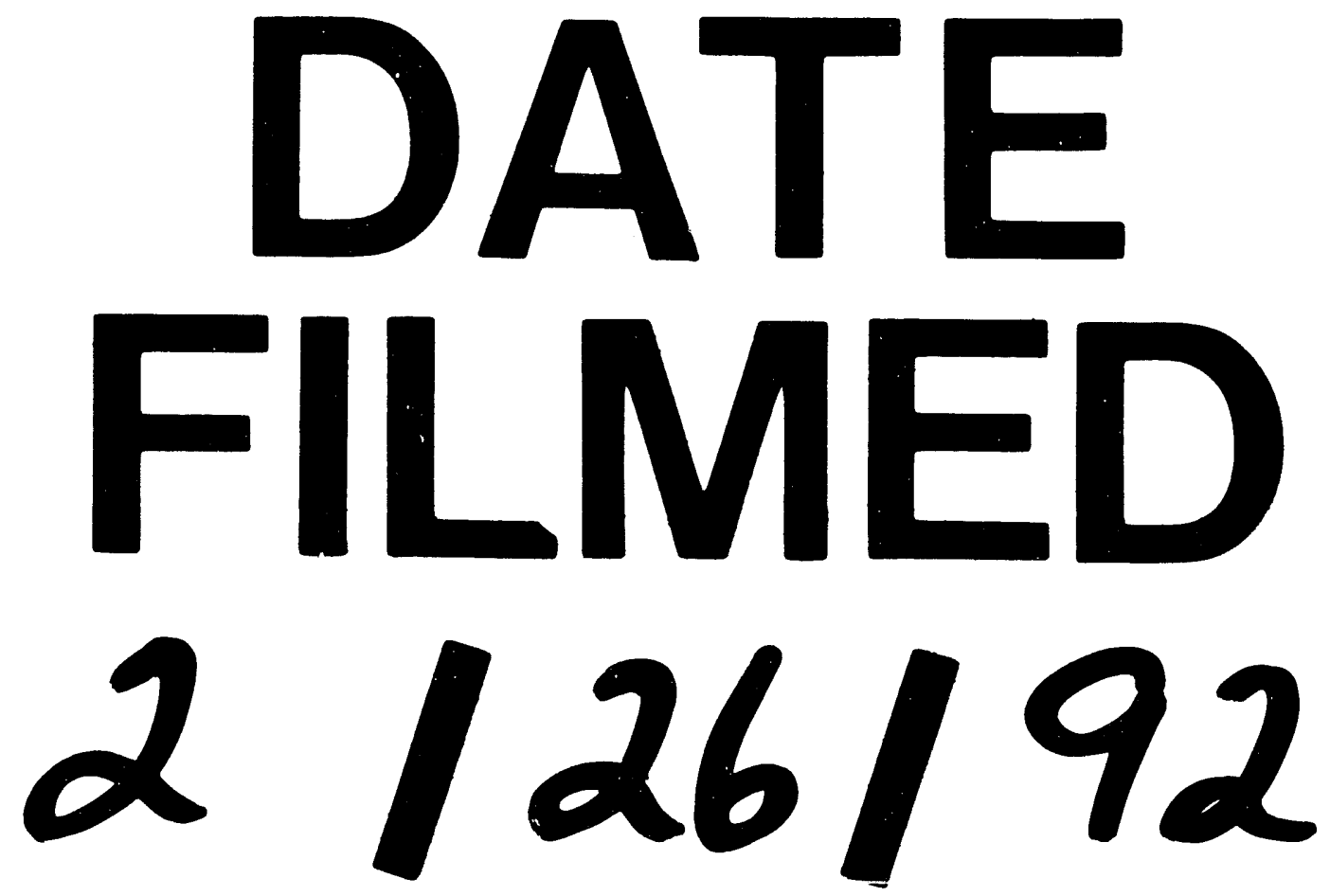
